\title{
Zum historischen Hintergrund
}

Die frühesten belegbaren Dokumente von der hier untersuchten Art stammen aus dem 14. Jh. Ältere Belegstücke sind nicht erhalten. Es ist allerdings unwahrscheinlich, dass nach 1300 wie aus dem Nichts heraus Rollen von jenem hohen kunsthistorischen Wert angefertigt werden, wie sie hier vorgestellt werden. Diese Tradition ist bis in die jüngere Vergangenheit in unterschiedlichen Kontexten in modifizierter Form weitergepflegt worden. Die Staatsbibliothek Berlin besitzt eine Rolle, die angeblich um 1970 in Syrien hergestellt worden ist. ${ }^{1}$

Die Ausführungen in diesem Abschnitt beleuchten im Sinn eines Abrisses die machtpolitischen Entwicklungen in der islamischen Welt zwischen ca. 1200 und 1800 , insofern sie für die Kontextualisierung der untersuchten Dokumente relevant sind. Die soziopolitischen Konstellationen werden in einem nächsten Schritt angesprochen (vgl. Kapitel 3).

Für die Einordnung der frühen Belegstücke sind die Verhältnisse im Osten der islamischen Welt zwischen ca. 1250 und 1500 von Bedeutung. Im Vordergrund stehen die Entwicklungen in einem Städtedreieck mit den Eckpunkten Konya, Tabriz und Bagdad. Frühe Dokumente in Rollenform dürften in dieser Region und ihrem weiteren Umfeld entstanden sein.

Am Anfang dieser Periode stehen der Einfall der Mongolen und der Sturz des Abbasiden-Kalifats (Fall Bagdads: 1258). Nach der Entdeckung des direkten Seewegs nach Indien durch Vasco da Gama (1497-1498) büsst die Region um 150o ihre geostrategische Bedeutung ein. ${ }^{2}$ Diese Gegend, insbesondere Iran und Zentralasien, wird dadurch vom internationalen Handel abgeschnitten. Die

1 Vgl. Kapitel 7.2, Anm. 43.

2 Vgl. zur Frage auch Mazzaoui, Origins of the Safawids 15. M. Mazzaoui datiert die Entdeckung dieses Seewegs ins Jahr 1496.
Konsequenzen waren in den beiden an der Seidenstrasse gelegenen Städten Tabriz und Samarkand deutlich spürbar. Die veränderten Gegebenheiten dürften indirekt dazu beigetragen haben, dass es den Safawiden 1501 gelang, die Macht in Iran zu übernehmen. ${ }^{3}$ Kurz nach 15 oo erlischt ausserdem die Dynastie der Mamluken, die die Verhältnisse im Nahen Osten zwischen 1250 und 1500 massgeblich geprägt hatte. ${ }^{4}$ Die Osmanen gliedern das zuvor mamlukische Syrien 1516 und Ägypten, das mamlukische Kernland, 1517 in ihr Reich ein. Überdies etablieren die Mogulen nach 1500 ihre Macht auf dem Indischen Subkontinent. ${ }^{5}$

Im hier interessierenden Städtedreieck sind die Nachwirkungen des Mongolensturms um 1300 noch deutlich zu spüren. Dies machte sich in einer grossen politischen Instabilität und sozialen Unrast bemerkbar. ${ }^{6}$ Im Süden dieses Dreiecks machten die in Ägypten und Syrien etablierten Mamluken ihre Machtansprüche geltend. Es gelang ihnen, den Vormarsch der Mongolen 126o bei 'Ayn Ǧālūt zu stoppen. Die Mongolen zogen sich darauf aus Syrien zurück. Die beiden grossen Ayyubiden-Prinzipate Aleppo und Damaskus gerieten zu jener Zeit unter mamlukische Kontrolle. Die drei kleineren Herrschaftsgebiete Homs, Hama und Karak in Syrien konnten ihre Unabhängigkeit vorerst bewahren. ${ }^{7}$

Im Westen dieser zwischen Konya, Tabriz und Bagdad gelegenen Grossregion stellte das christliche Byzanz um 1300 weiterhin einen bedeutenden Einflussfaktor dar. Zwar waren die Türkisierung und Islamisierung Anatoliens bereits 1071 in

3 Die Dynastie der Safawiden ist in Iran von 1501-1722 an der Macht.

4 Die Mamluken kontrollierten Ägypten von 1250-1517.

5 Die Mogulen waren von 1526-1858 an der Macht.

6 Mazzaoui, Origins 13.

Vgl. Holt, Mamlūks: I. Political history, in $E I^{2}$.

(C) TOBIAS NÜNLIST, 2020 | DOI:10.1163/9789004429154_003

This is an open access chapter distributed under the terms of the CC BY-NC-ND 4.o license. 
Gang gekommen, als die Seldschuken unter Alp Arslan $^{8}$ dem byzantinischen Kaiser Romanos IV. Diogenes in Manzikert eine Niederlage zugefügt hatten. Byzanz verlor danach die Kontrolle über das innere Kleinasien. Die Christen konnten sich jedoch in Trapezunt (Komnenen) noch längere Zeit und in Armenien bis heute halten. Sie herrschten ausserdem weiterhin über Konstantinopel, das ihre Hauptstadt war und erst 1453 unter Mehmed II. (reg. 1444-1446 und 1451-1481) in die Hände der Osmanen fiel. ${ }^{9}$

Die Niederlage der Byzantiner in Manzikert leitete die Einwanderung der Turkmenen nach Anatolien ein. Dies führte $\mathrm{zu}$ einer deutlichen Veränderung der ethnischen Zusammensetzung der ortsansässigen Bevölkerung. ${ }^{10}$ Die Seldschuken waren ursprünglich am Aralsee in Zentralasien beheimatet. Sie herrschten nach ihrem Einfall über bedeutende Teile Irans. Die oghusischtürkischen Rūm-Seldschuken machten sich 1077 von den Gross-Seldschuken unabhängig und kontrollierten fortan weite Teile Anatoliens (Rūm). Das Zentrum ihres Reichs befand sich in Konya." Die Rūm-Seldschuken gerieten allerdings nach der Schlacht am Köse Dağ $(1243)^{12}$ ihrerseits in die Abhängigkeit der mongolischen Īlhāniden. Das Reich der Rūm-Seldschuken löste sich 1307 endgültig auf. ${ }^{13}$

Auf der Ostseite dieses Städtedreiecks wiederum regierten um 1300 die soeben kurz erwähnten Îlhāniden. Sie waren im Nachgang zum Mongolensturm an die Macht gekommen und aus den mongolischen Eroberern selbst hervorgegangen.

8 Alp Arslan war von 1063-1072 Sultan der Gross-Seldschuken. Siehe zu ihm Mallett, Alp Arslan, in $E I^{3}$.

9 Kreiser und Neumann, Kleine Geschichte der Türkei $93 \mathrm{f}$. Vgl. zu den Entwicklungen am ausführlichsten Vryonis, Decline.

Vgl. zur Frage auch eingehender unten Anm. 63. Manzikert ist nördlich des Vansees gelegen.

11 Vgl. Bosworth, Saldjukids - The Saldjuks of Rum, in $E I^{2}$; ders., New Islamic dynasties 213f. (Nr. 107).

12 Der Köse Dağ liegt bei Sivas.

13 Kreiser und Neumann, Kleine Geschichte der Türkei 47; Bosworth, New Islamic dynasties 214.
Ihre Hauptstadt befand sich zuerst in Marāga. ${ }^{14}$ Später richteten sie sich in Tabriz und danach in Sultāaniyya ein, das etwa $100 \mathrm{~km}$ westlich von Qazwin liegt. Die Îlhāniden spielten eine massgebliche Rolle in den weiteren Entwicklungen in der Region. Es zeigt sich überdies, dass die in dieser Gegend zwischen 1250 und 1500 festzustellenden Veränderungen später ein Echo in den Reichen der Safawiden und der Osmanen finden und die dortigen Verhältnisse prägten. Diesen Nachwirkungen wird im Rahmen der Untersuchungen der sozio-politischen Implikationen besondere Aufmerksamkeit geschenkt (Kapitel 3).

Die vorangehenden Ausführungen hielten die Eckpunkte der Veränderungen in dieser Gegend fest. Die weitere Darstellung hebt einzelne Aspekte eingehender hervor.

\subsection{Vom Einfall der Mongolen bis zum Auftreten Timurs in Iran (1381)}

Der Einfall der Mongolen hatte den Osten der islamischen Welt in seinen Grundfesten erschüttert und war mit grossen Verheerungen verbunden. Die Forschung thematisierte die Zerstörungswut immer wieder, mit der die Mongolen unter Čingiz-Hāan (reg. 1206-1227) in die islamische Welt einfielen. Diese Eindringlinge hatten sich in Khorasan (NW-Iran) schon kurz nach 1200 bemerkbar gemacht und Angst und Schrecken verbreitet. ${ }^{15}$ Das einst blühende Nayšāpūr wurde bei ihrem Einfall arg in Mitleidenschaft gezogen. ${ }^{16}$

Die mongolischen Eroberer traten auch in Westiran schon deutlich vor dem Fall der Festung Alamut (1256) in Erscheinung. Sie waren im Win-

14 Marāğa liegt etwa 8o km südlich von Tabriz.

15 Gronke, Geschichte Irans 49-59. Ausführlich behandelt diese Zusammenhänge Spuler, Geschichte der Mongolen; ders., Die Mongolenzeit.

16 Vgl. Honigmann und Bosworth, Nīshāpūr, in $E I^{2}$ : „In 618/1221 the Mongols under Činghiz Khān sacked the city completely (see Djuwaynī-Boyle, i, $169-178$ ). Although Nīshāpūr's palmiest days were ended by the Mongol devastations, it soon revived from the effects of these." 
ter 617/1220-1221 zum ersten Mal vor den Mauern von Tabriz aufgekreuzt und erst nach der Bezahlung eines Lösegelds wieder abgezogen. Die Eindringlinge kehrten im folgenden Winter und 621/1224 vor die Stadt zurück. Zwischen 1225 und 1231 konnte der Huwārazm Šāh Ğalāl ad-Dīn Tabriz vor weiteren Angriffen bewahren. Als sich aber Ğalāl ad-Dīn 628/1231 aus Aserbaidschan zurückzog, eroberten die Mongolen die gesamte Provinz mit ihrer Hauptstadt. Ğurmaġun Noyin, der Anführer (malik) der Mongolen, auferlegte der Stadt Tabriz bedeutende Tributleistungen an den mongolischen Grosskönig Ögedey. Unter Güyük lag die Herrschaft über Arrān und Aserbaidschan in den Händen von Malik Șadr ad-Dīn, einem persischen Verbündeten der Mongolen. ${ }^{17}$

Bei ihrem Marsch gegen Westen eroberten die Mongolen ausserdem die Festung Alamut in der Nähe von Qazwin (1256). Die Burg hatte zuvor als uneinnehmbar gegolten. Alamut war der Hauptsitz der schiitisch orientierten Ismaeliten. ${ }^{18}$ Zwei Jahre danach nahmen die Mongolen unter Hülegü Bagdad ein (1258) und versetzten den seit längerem dahinserbelnden Abbasiden den Todesstoss. Der Einfall der Mongolen stellte für die islamische Welt einen Schock dar. Er führte zur Bildung eines Reichs, das sich vorübergehend von China bis ans Mittelmeer erstreckte. Die mongolischen Truppen hatten mutmasslich eine Stärke von 70o'оoo-80o'ooo Mann. ${ }^{19}$ Die Eroberer setzten sich durch, indem sie systematischen Terror ausübten. Sie zerstörten jene Orte, die sich ihnen nicht freiwillig ergaben.

Der Fall Bagdads hinterliess physische und psychische Wunden, die sich noch im ganzen 14. und 15. Jh. bemerkbar machten. Erst die Mamluken können dem Vormarsch der Mongolen

17 Vgl. Minorsky und Bosworth, Tabriz, 1. Geography and history, in $E I^{2}$.

18 Siehe Mazzaoui, Origins 5 und 7. Zur Ismāāliyya (SiebnerSchia) siehe ebenda 23 und 24-27 (zu Nāṣir ad-Dīn Ṭūsī); beachte überdies Daftary, A short history of the Ismailis, und die Artikel zur Ismā̄iliyya in $E I^{2}$ und $E I r$.

19 Lentz und Lowry, Timur and the princely vision 21 (mit Anm. 5, S. 64). bei 'Ayn Ğālūt Einhalt gebieten (Nordpalästina; 658/126o). ${ }^{20}$ Sie verhindern damit, dass die Eroberer in ihr Kernland Ägypten und weiter in Richtung Afrika vordringen. Die mit dem Mongoleneinfall verbundenen Erschütterungen und Umwälzungen waren aber auch in Ägypten spürbar. In Iran, Ostanatolien und Nordmesopotamien war die Destabilisierung einfach viel deutlicher wahrnehmbar. Der Sieg der Mamluken in 'Ayn Ğālūt hatte auch zur Folge, dass Ägypten, Syrien und die Gegend am Roten Meer unter mamlukischer Kontrolle und damit sunnitischem Einfluss blieben. ${ }^{21}$

Die Mongolen hatten sich zur Zeit ihres Einfalls in die islamische Welt noch nicht zum Islam bekehrt. Sie pflegten vielmehr weiterhin einen schamanistisch ausgerichteten Buddhismus, wie er ihnen aus ihrer zentralasiatischen Heimat vertraut war. Für die Îlhāniden selbst gelten ähnliche Feststellungen. ${ }^{22} \mathrm{Ab} 128 \mathrm{o}$ wandten sie sich aber zunehmend dem Islam zu, der in den von ihnen eroberten Gebieten dominierte. Die Īlhāniden waren in religiösen Fragen Opportunisten. Von Ülğäytü (Ulğaytū, reg. 1305-1316) ist bekannt, dass er zuerst schamanistischen und buddhistischen Praktiken anhing. Er bekehrte sich jedoch später zum Christentum und danach zum Islam. Am Ende seines Lebens lavierte er zwischen Sunnismus und Schiismus. ${ }^{23}$ Diese mehrfachen Abhängigkeiten in Glaubensfragen sind indirekt auch bei der Auseinandersetzung mit den Dokumenten in Rollenform von Bedeutung.

Die Mongolen zogen nach der Einnahme Bagdads unter Hülegü nach Aserbaidschan und liessen sich in Marāga nieder (ca. $80 \mathrm{~km}$ südlich von Tabriz). ${ }^{24}$ Sie kämpften darauf gegen Berkes Truppen, die ihnen 661/1263 im Nordkaukasus eine Niederlage zufügten. Hülegü kehrte danach nach Tabriz zurück und richtete unter den Händlern aus

20 Vgl. Amitai, 'Ayn Jālūt, in $E I^{3}$.

21 Mazzaoui, Origins 7.

22 Op. cit. 22; vgl. zur Frage auch Gronke, Derwische 2.

23 Lentz und Lowry, Timur and the princely vision 21 (mit Anm. 6, S. 64), wo Verweis auf Morgan, Mongols 73-83.

24 Vgl. Minorsky, Marāgha, in $E I^{2}$. 
dem Stamm der Kiptschaken ${ }^{25}$ ein Massaker an. Im Jahr 662/1264 bestätigte Hülegü Malik Ṣadr adDīn als Gouverneur über Tabriz und seine Provinz.

Die Īlhāniden regierten zuerst von Marāga und später von Tabriz bzw. Sulțāniyya ${ }^{26}$ aus mit wechselnder Autorität über Iran und Iraq. ${ }^{27}$ Ihre Dynastie begann mit dem Eroberer Hülegü (Hulagu Huān, gest. 663/1265) selbst und endete mit Sulțān Abū Sacīd (gest. 736/1335). Zwei weitere bedeutende Vertreter der Dynastie sind Ġāzān Huān (reg. 694-703/1295-1304) und Ulğaytū Hudābanda (reg. 703-716/1305-1316). Nachdem die Macht der RūmSeldschuken in Anatolien im Jahr 1307 sang- und klanglos geendet hatte, geriet auch ihr Reich unter den Einfluss der Îlhāniden. Die Mongolen ernannten jeweils Gouverneure, die die einzelnen Städte und ihre Umgebung kontrollierten. ${ }^{28}$ Diese Gouverneure genossen hohe Unabhängigkeit, die mit der Entfernung von der Hauptstadt Tabriz bzw. Sulțāniyya zunahm. Dies trifft gerade auf die in Anatolien gelegenen Gebiete zu. Die Īlhāniden hielten sich mit wechselndem Glück während etwa 75 Jahren an der Macht.

In der späteren İlhāniden-Zeit setzte in Anatolien der Aufstieg der Osmanen ein. Die Kleinstaaten (beylik) in Anatolien lagen weit weg von der Hauptstadt der İlhāniden. ${ }^{29}$ Sie pochten auf ihre Unabhängigkeit und verwalteten ihre inneren Angelegenheiten weitgehend selbständig. Die Osmanen setzten sich aber in Anatolien nur nach und nach durch. ${ }^{30}$ Erst in der zweiten Hälfte des 15. Jh. wurde Anatolien unter Mehmed II. (reg. 1444-1446 und 1451-1481) Teil des Osmanischen Reichs. Die Instabilität in dieser Region war gerade

25 Vgl. Hazai, Kipčak, in $E I^{2}$.

26 Vgl. Blair, Minorsky und Bosworth, Sulțāniyya, in $E I^{2}$.

27 Die weitere Übersicht stützt sich auf Mazzaoui, op. cit. 8 .

28 Dies geschah nach dem Tod von 'Alā' ad-Dīn Kayqubād III. im Jahr 707/1307. Die mongolischen Gouverneure waren danach in Sivas in Ostanatolien stationiert. Vgl. Mazzaoui, Origins 8 (Anm. 2).

29 Über die türkischen Emirate in Anatolien vgl. Gökbilgin et al., Beylik, in $E^{2}$; siehe auch Taeschner, Anadolu, v.a. III. Historical geography of Turkish Anatolia, in $E I^{2}$. in religiöser Hinsicht beträchtlich. Selbst unter Bāyazīd II. (reg. 1481-1512) waren die religiösen Machtverhältnisse in Anatolien noch weit von einer Klärung entfernt. ${ }^{31}$ Die Osmanen konnten ihre Macht über Anatolien erst nach Sulțān Selīms Sieg über den Safawiden Šāh Ismāōill in der Schlacht von Čāldirān (1514) durchsetzen.

Die Îlhāniden konnten sich nach Abū Saīìds Tod (1335) auch in Iran und Iraq nicht mehr länger an der Macht halten. Ihre Herrschaft ging an die ihnen vordergründig hörigen Nachfolgedynastien der Čūpāniden und Ğalāyiriden über. ${ }^{32}$ Die Vertreter dieser beiden Dynastien konnten ihre Machtansprüche allerdings kaum über ihre jeweiligen Hauptstädte Bagdad (Čūpāniden) und Tabriz (Ğalāyiriden) hinaus geltend machen. Die Regierungszeit Sulțān Aḥmads, des letzten ĞalāyiridenHerrschers (gest. 1410), dauerte 27 Jahre (13821410) und war ausgesprochen turbulent. Er musste vor Timur flüchten, der 1381 in Iran einfiel, und fand Schutz sowohl am Hof der Osmanen als auch bei den Mamluken. ${ }^{33}$ Schliesslich wurde er von seinem Reisegefährten Qara Yūsuf aus dem Turkmenen-Stamm der Qara Quyunlu umgebracht (1410). ${ }^{34}$

Im halben Jahrhundert zwischen dem Tod Abū Saīds (gest. 1335) und dem Einfall Timurs (1381) machten noch weitere Dynastien und Interessengruppen ihre Machtansprüche in Iran geltend. In der Provinz Fārs (Südiran, Shiraz) übten die Dynastien der Īnğūs (ca. 1325-1353) (35 $^{35}$ und danach jene der Muzaffariden (1314-1393) ${ }^{36}$ lokale Herrschaft aus. Von Bedeutung ist überdies die SarbadārBewegung, die sich in Sabzawār zwischen 1337 und 1386 an der Macht halten konnte. ${ }^{37}$ Diese Aufzäh-

\footnotetext{
31 Loc. cit.

32 Mazzaoui, Origins 9.

33 Ibid.

34 Ibid.

35

Zu den Īnǧūs vgl. Bosworth, New Islamic dynasties 266; Boyle, İndjū, in $E I^{2}$; Spuler, Die Mongolen in Iran 121; ${ }^{4} 1985$.

$36 \mathrm{Zu}$ den Muzaffariden vgl. Bosworth, New Islamic dynasties 264; siehe auch Roemer, The Jalayrids, Muzaffarids and Sarbadārs, in $c H I$ VI, 11-16 und 59-64. 
lung ist nicht vollständig, muss im Rahmen dieser Übersicht aber genügen. ${ }^{38}$

Die Herrschaft der soeben angeführten Dynastien reichte kaum je über längere Zeit deutlich über ihre jeweilige Hauptstadt und deren unmittelbares Umland hinaus. In den einzelnen Städten regierten lokale Emire und Sultane, die sich gegenseitig bekämpften. Nach dem Niedergang der Îlhāāniden - schon sie hatten ihre Gouverneure nur bedingt kontrollieren können - fehlte eine effiziente Zentralmacht zwischen 1335 und 1381 gänzlich. ${ }^{39}$

Diese Verhältnisse ändern sich mit dem Auftreten Timurs zumindest vorübergehend gründlich. ${ }^{40}$ Timur marschierte 1381 auch in Iran ein und verbreitete bis zu seinem Tod im Jahr 1405 während nahezu eines Vierteljahrhunderts Angst und Schrecken. Sein Machtzentrum befand sich in Samarkand, von wo er einen bedeutenden Teil der muslimischen Welt zwischen dem Syr Daryā und der Ägäis kontrollierte. ${ }^{41}$ Timurs Eroberungen in Iran, Iraq und Anatolien hatten jedoch keine Konsequenzen, die sich deutlich über seinen Tod

auch ein Echo in weiteren Regionen Irans. Sie stützt sich auf die engen Beziehungen zwischen den weltlichen Machthabern und Häretikern, wie sie sich später auch in der Muša ša'c, unter den Qizilbāš oder im Umfeld von SufiBruderschaften und damit verwandten Gruppierungen (Futuwwa- und Ahi-Bünde), beobachten lassen. Jedenfalls wurden bereits unter den Sarbadār schiitische Vorstellungen zur Grundlage einer Protestbewegung. Vgl. dazu Bosworth, New Islamic dynasties 269, mit weiteren Literaturangaben. Siehe auch Roemer, The Jalayrids, Muzaffarids and Sarbadārs, in CHI VI, 16-39; Melville, Sarbadārids, in $E I^{2}$.

38 Für einige weitere Hinweise siehe Mazzaoui, Origins 9.

39 Ibid.

40 Vgl. Mazzaoui, op. cit. 9; Bosworth, New Islamic dynasties 270-272. Zu den Timuriden siehe ausserdem Manz, Power, politics and religion; Manz et al., Timurids, in $E I^{2}$; CHI VI, 42-97.

41 Zur Ausdehnung von Timurs Reich siehe Brice, An historical atlas of Islam, Karte Nr. 25; Hodgson, Venture of Islam II.431 („The conquests of Tīmūr, 1370-1405“); Manz, Power, politics and religion $18 \mathrm{f}$.: „The Timurid realm and neighboring powers in the fifteenth century" (Map 1); Lentz und Lowry, op. cit. $18 \mathrm{f}$. und $22 \mathrm{f}$. hinaus auswirkten. Nach seinem Ableben kam es zu heftigen Nachfolgekämpfen unter seinen vier Söhnen, die das ehemalige Grossreich schwächten. Šāh Ruh (reg. 8o7-85o/1405-1447) ging daraus als Sieger hervor. ${ }^{42}$ Die Timuriden waren zwar in der Lage, ihre Macht während nahezu eines halben Jahrhunderts auch in den westlichen Provinzen ihres Reichs geltend zu machen. Dennoch kam es nach Timurs Tod gerade im Westteil rasch zu einer Rückkehr zu kleinräumigen Machtstrukturen.

Timur war es wenige Jahre vor seinem Tod (1405) gelungen, Ankara einzunehmen (805/1402). Er hatte in Anatolien auch die Beylik-Staaten zu neuem Leben erweckt und bediente sich dieser Strukturen zur Ausübung seiner Macht.43 Diese Beylik-Staaten gerieten allerdings zunehmend unter die Kontrolle der Osmanen, die unter Mehmed II. entschlossen gegen Osten vordrangen. Nach dem Ableben Timurs machen in Iran und Iraq im 15. Jh. ausserdem die Turkmenen ihre Machtansprüche geltend. Auf den Einfluss der beiden turkmenischen Stammesbünde der Qara Quyunlu (Schwarze Horde) und Aq Quyunlu (Weisse Horde) ist noch zurückzukommen. ${ }^{44}$

Den bisherigen Ausführungen ist die Bemerkung hinzuzufügen, dass der Einfall der Mongolen abgesehen von den kriegerischen Auseinandersetzungen mit bedeutenden Migrationsbewegungen verbunden war. Sie haben zu grundlegenden Veränderungen in der ethnischen Zusammensetzung der Bevölkerung in der Region geführt. Der Mongolensturm stellte dabei bereits die zweite Welle von Einwanderungen grösserer Volksmassen aus Zentralasien nach Westiran, Ostanatolien und Nordmesopotamien dar. ${ }^{45}$ Im Anschluss an den Sieg der Seldschuken in Manzikert (1071) war bereits zuvor eine bedeutende Zahl von Turkmenen nach Westen vorgedrungen und hier sesshaft geworden. ${ }^{46}$ Zwischen Alp Arslans Sieg über den

42 Vgl. Manz et al., Timurids, 1. History, in $E I^{2}$.

43 Mazzaoui, Origins 9.

44 Vgl. dazu unten Kapitel 2.3.

45 Vgl. dazu auch Sohrweide, Safaviden 101.

46 Kreiser und Neumann, Kleine Geschichte der Türkei 44. 
byzantinischen Kaiser in Manzikert (1071) und der Schlacht am Köse Dağ (1243) wanderte etwa eine Million Türken nach Anatolien ein. Das Vordringen der Seldschuken nach Anatolien im 11. Jh. bildete aber nur den Höhepunkt von Wanderungsbewegungen, die bereits im 8 . Jh. eingesetzt hatten. ${ }^{47}$ Mit der Ankunft der Mongolen im Lauf des 13. Jh. verstärkte sich der zentralasiatische Einfluss in der Region. Das mongolische Element ging allerdings rasch in der bereits in der Gegend ansässigen Bevölkerung türkischer Abstammung auf. ${ }^{48}$

Es lohnt sich, einen genaueren Blick auf jene Schwierigkeiten $\mathrm{zu}$ werfen, mit denen sich die Bevölkerung in der Region in Anschluss an den Mongolensturm konfrontiert sah. Während R. Yil$\operatorname{dirim}^{49}$ und I. Lapidus ${ }^{50}$ auf einer theoretischen Ebene auf diese Herausforderungen aufmerksam machen, befassten sich weitere Forscher im Rahmen von Fallstudien mit den Verhältnissen, die den Alltag der Menschen im Dreieck zwischen Konya, Tabriz und Bagdad im 14. Jh. prägten:

Es kann hier einerseits auf M. Gronke aufmerksam gemacht werden, die sich mit den Lebensbedingungen der Bevölkerung in Ardabil am Anfang des 14. Jh. auseinandersetzte. ${ }^{51}$ E.S. Wolper wiederum befasste sich mit den baulichen Eingriffen ins Stadtbild von Sivas, Amasya und Tokat in Ostanatolien zu jener Zeit. Sie versteht die architektonischen Veränderungen auch als Folge der Umwälzungen, die die Region im Nachgang des Mongoleneinfalls erfasst hatten. Religiöse und para-religiöse Gruppierungen spielten bei diesen Veränderungen eine zentrale Rolle. ${ }^{52} \mathrm{Ch}$. Werner seinerseits setzt sich mit der Kuğūğ̄i-Stiftung in Tabriz auseinander, die in der Stadt auch einen Derwisch-Konvent (hānaqūh) unterhielt. ${ }^{53} \mathrm{~J}$. Pfeiffer wiederum geht einerseits den Auseinander-

Siehe auch unten Anm. 63.

Vgl. dazu auch Gronke, Derwische 1.

Yildirim, Turkomans between two empires $57 \mathrm{f}$. und allgemein 34-62.

Vgl. Lapidus, Perspectives 35 .

Gronke, Derwische.

Wolper, Cities and saints.

Werner et al., Die Kuğuğ̌́-Stiftungen in Tabrīz. setzungen zwischen unterschiedlichen Derwischgruppierungen in Konya nach, wo die Mawlawiyya eine massgebliche Rolle spielte. ${ }^{54}$ Sie befasst sich anderseits mit den Entwicklungen in Tabriz im 14. Jh. ${ }^{55}$ Hinzuweisen ist sodann auf F.B. Yavuz, die die Ausbildung des Sufiordens der BayramiyyaMalāmiyya beleuchtet. ${ }^{56}$ Die soeben angeführten Studien enthalten wertvolle Informationen zu den gesellschaftlichen Verhältnissen in der diskutierten Region im 14. und 15. Jh. Da sie hier aber nicht alle in extenso vorgestellt werden können, vermitteln die weiteren Ausführungen v.a. anhand von M. Gronkes Untersuchung einen präziseren Überblick über die damaligen Lebensbedingungen.

M. Gronke beleuchtet in erster Linie die Existenzbedingungen der Bevölkerung in Nordwestiran zwischen ca. 1250 und 1350. ${ }^{57}$ Sie konzentriert sich auf die Verhältnisse in Ardabil, wo am Anfang des 14. Jh. der vorerst sunnitisch geprägte Derwischorden der Șafawiyya entstand. Ihre Erkenntnisse dürften auch die Situation in weiteren Städten in der Region charakterisieren.

Gemäss M. Gronke lebte die Bevölkerung zur Zeit der Mongolenherrschaft in Westiran in allgemeiner Unsicherheit und sah ihre Existenz in vielfacher Hinsicht bedroht. Ihre Untersuchung stützt sich in erster Linie auf Ibn Bazzāz' Șafwat uṣ-Şafă. ${ }^{58}$ Das Werk ist $135^{8}$ entstanden und befasst sich mit Begebenheiten aus dem Leben von Șafĩ ud-Dīn (gest. 1334), dem Begründer des

54 Pfeiffer, Mevlevi-Bektashi rivalries.

55 Pfeiffer, Confessional ambiguity vs. confessional polarization.

56 Yavuz, Sufi order 14.

57 Die weiteren Ausführungen stützen sich auf Gronke, Derwische 61-79 (Kapitel: Die Existenzbedingungen in der Mongolenzeit).

58 Zu Ibn Bazzāz' Șafwat uș-Ṣafā, siehe Savory, Ebn Bazzāz, in EIr; Glassen, Ibn al-Bazzāz al-Ardabīlī, in $E I^{2}$. Bei Ibn Bazzāz' Schrift Șafwat uṣ-Șafā handelt es sich um eine hagiographisch ausgerichtete Biographie über Șafĩ udDīn (gest. 935/1334), den Begründer des Derwischordens der Safawiyya. Der Verfasser beendete dieses umfangreiche Werk 759/1358, nur 24 Jahre nach dem Tod des Begründers der Șafawiyya. Er hatte den Auftrag zu dessen Abfassung von Șadr ud-Dīn, Șafī ud-Dīns Sohn, erhalten. 
Derwischordens der Șafawiyya. Die Schrift hat hagiographischen Charakter, vermittelt aber dennoch ein realitätsnahes Bild von den sozialen und politischen Wirren jener Zeit. ${ }^{59} \mathrm{M}$. Gronke rundet das Bild anhand von zusätzlichen Quellen ab. Zwar sahen sich sämtliche Bevölkerungsschichten mit den Folgen dieser Umwälzungen konfrontiert. Allerdings hatten die breiten Massen darunter viel stärker zu leiden als die mächtigen und einflussreichen Kreise. Das einfache Volk sei nur zu oft Opfer von rücksichtsloser Ausbeutung und Schikanierung geworden.

Diese Entwicklungen lassen sich anhand eines Abschnitts aus Rašīd ud-Dīns Weltchronik Ğāmi at-tawārih verdeutlichen. ${ }^{60}$ Rašìd ud-Dīn, der bekannte Wesir, stellt darin die sozialen und wirtschaftlichen Reformen unter dem Īlhāniden-Herrscher Ġāzān (reg. 1295-1304) vor. Der Text rückt zwar Ġāzāns Massnahmen in ein sehr positives Licht. Dennoch zeigt die Darstellung, dass sich damals jeder einzelne in seiner Existenz bedroht sah. M. Gronke hält fest, dass Ġāzāns Reformen wohl gut gemeint waren, aber nur punktuell zu Verbesserungen führten. ${ }^{61}$ Jedenfalls würden die von Nahğuwānī im Werk Dastūr al-kātib zusammengestellten Erlasse ğalāyiridischer Herrscher aus der Mitte des 14. Jh. nach wie vor den Eindruck nicht ablassender Not unter der lokalen Bevölkerung erwecken.

Auch Ibn Bazzāz' Berichte unterstreichen, dass sich die Menschen in Nordwest-Iran inmitten einer feindlichen Natur ständig an Leib und Leben bedroht sahen. Sie litten unter der Unterdrückung und Willkür durch die Obrigkeit, wirtschaftlicher Erpressung und den Kriegswirren. Sie waren ausserdem mit Krankheiten, Hungersnöten und Armut konfrontiert. Angesichts dieser vielfachen Bedrohungen sanken die Städte zu Dörfern herab.

59 Vgl. Gronkes Überlegungen zur Verwendung hagiographischer Literatur bei der Analyse historischer Entwicklungen in ihrer Arbeit Derwische im Vorhof der Macht 7-9.

6o Zu Rašīd ud-Dīn (hingerichtet 1318) vgl. Morgan, Rashīd al-Dīn, in $E I^{2}$.

61 Gronke, Derwische 61 (mit Anm. 1), wo weitere Verweise.
Dies war mit der Entvölkerung und Verödung breiter Landstriche verbunden. Die Entwicklung akzentuierte sich durch mehrere Pestzüge, die Iran um die Mitte des 14. Jh. heimsuchten. Da eine effiziente staatliche Kontrolle fehlte, wuchs auch die Zahl der Bettler, Räuber und Wegelagerer an. Nach dem Einfall der Mongolen war es in Iran überdies zu einem Zerfall islamischer Sittlichkeit und dem Anstieg der Prostitution gekommen. Diese Veränderungen beeinflussten die Lebensbedingungen der lokalen Bevölkerung massgeblich. Sie riefen grosse Orientierungslosigkeit und ein weit verbreitetes Schutzbedürfnis hervor. Diese Verhältnisse begünstigten die Ausbildung einer speziellen Volksfrömmigkeit, die ihren Rückhalt in den Derwischbewegungen fand. ${ }^{62}$

M. Gronke identifiziert die Unterdrückung und finanzielle Ausbeutung durch die mongolischen und türkischen Emire und ihre Gefolgsleute als das weitaus schlimmste Übel. ${ }^{63}$ Ibn Bazzāz cha-

62 Gronke, op. cit. 62 (mit Anm. 2).

63 Gronke, op. cit. 35f. und 62 f., weist darauf hin, dass im Gefolge des Vordringens der bereits islamisierten Seldschuken (1038-1194) im 11. und 12. Jh. bedeutende Scharen von Türken nach Westiran einwanderten. Es handelt sich bei ihnen v.a. um Oghusen und Kiptschaken. Während die arabischen Eroberer gänzlich in der ansässigen Bevölkerung aufgegangen waren, präsentiert sich die Situation im Fall der Türken anders, behielten sie doch ihre sprachliche und ethnische Identität weitgehend bei. Die Türken bilden noch heute eine eigenständige Bevölkerungsgruppe in Iran. Sie lassen sich nicht nur im Nordwesten des Landes (Zentrum: Tabriz) nachweisen. Sie besiedeln vielmehr auch in Khorasan und in der Turkmenensteppe am Südostrand des Kaspischen Meers geschlossene Siedlungsgebiete.

Die bereits unter den Seldschuken aufgebrochenen Gegensätze zwischen Persern und Türken verschärften sich im Gefolge der mongolischen Einwanderungen im 13. Jh. Die Mongolen verfügten über türkische Kontingente in ihren eigenen Truppen und fühlten sich den Türken überhaupt verwandt. Nach Īlhān Gāāans Konversion zum Islam (1295) kamen sich die beiden Volksgruppen noch näher, waren die Türken doch bereits Muslime. Am Ende der Īlhāniden-Zeit war dieser Prozess weit fortgeschritten. Vieles spricht auch dafür, dass die Mongolen in Westasien nicht besonders bedeutend waren und sprachlich und ethnisch bald gänzlich in den Türken aufgingen. Die mongolische Eroberung war somit in 
rakterisiert die Machthaber in der Șafwat uș-Ṣafā wiederholt als Tyrannen und Unterdrücker $(z \bar{a} l i-$ $m a \bar{n})$. Die Verarmung und Entwurzelung zahlreicher Menschen als Folge dieser Missstände haben auch in Ardabil und seiner Umgebung ihre Spuren hinterlassen. ${ }^{64}$ Es ist belegt, dass nicht nur das einfache Volk, sondern zunehmend auch an und für sich wohlhabende Gebildete und Kaufleute in kurzer Zeit ins Elend stürzen konnten. Die wachsende Anzahl verlassener und verödeter Dörfer liess im 13. und 14. Jh. überdies die Zahl der Bettler und Vagabunden anschwellen. Diese Bettlerscharen, zu denen auch zahllose Derwische zu zählen sind, genossen in der Landbevölkerung einen zweifelhaften Ruf. Sie gaben sich aus Armut oft für unlautere Zwecke her. Šayh Șafĩ ud-Dīn und sein Lehrer Šayh Zāhid hielten ihre Anhänger immer wieder dazu an, ihren Lebensunterhalt aus eigener Kraft zu bestreiten (kasb-i hala $\bar{l}$ ) und nicht durch Bettelei andern zur Last zu fallen. Bettelei sei eine Schande $(r u s w a \bar{a} \bar{\imath}){ }^{65}$

M. Gronke vermutet, dass sich Teile der verarmten Bevölkerung den Banden von Dieben und Wegelagerern angeschlossen hatten, die die Gegend unsicher machten. Diese Banden bildeten ein Sammelbecken für heruntergekommene Existenzen und hatten sich am Ende des 13.Jh. zu einer Landplage entwickelt. Rašīd ud-Dīn hält fest, dass sich diese Banden aus den Angehörigen der unterschiedlichsten ethnischen Gruppierungen zusam-

Iran mit dem Eindringen weiterer türkischer Elemente verbunden und führte zu einer bedeutenden Ausdehnung der türkischen Siedlungsgebiete. Das Kernland der mongolischen Herrschaft, Aserbaidschan, wurde erst zur Zeit der Īlhāniden endgültig für das Türkentum gewonnen, obwohl die Türkisierung bereits mit der Ankunft der Seldschuken eingesetzt hatte. Die einzelnen Phasen des türkisch-mongolischen Verschmelzungsprozesses lassen sich nicht im Detail nachzeichnen. Am Ende des 13. Jh. dürfte er aber so weit fortgeschritten gewesen sein, dass die Bevölkerung Persiens Türken und Mongolen mehr oder weniger gleichsetzte. Gebildete Autoren allerdings unterschieden sehr wohl zwischen Mongolen und Türken.

64 Gronke, op. cit. 69-71.

65 Gronke, Derwische 70 (mit Anm. 89), wo Verweis auf Ibn Bazzāz, Șafwat uṣ-Ṣafā. mensetzten; er nennt Perser, Mongolen, Kurden und Luren namentlich. Ausserdem schlossen sich ihnen versprengte Soldaten, Desserteure (murtaddān), geflüchtete Dienstknechte ( $\dot{g} u l a ̄ m a ̄ n)$, Vagabunde $(r u n \bar{u} d)$ und der Pöbel in den Städten $(a w b \bar{a} s ̌-i ~ s ̌ a h r-h \bar{a})$ an. ${ }^{66}$ Dies wiederum erhöhte die allgemeine Unsicherheit. Überfälle auf Reisende, das Wegtreiben ganzerViehherden oder das Abernten fremder Felder waren an der Tagesordnung. Gewisse Bandenführer erreichten Berühmtheit und standen Gruppierungen von bedeutender Stärke vor. Sie machten gelegentlich auch mit den Dorfbewohnern gemeinsame Sache, die ihnen Schutz und Rückzugsmöglichkeiten boten. Zwar wurden gefasste Wegelagerer hingerichtet und ihre Köpfe an den Stadttoren oder im Basar zur Schau gestellt. Dennoch waren Ġāzāns Versuche gescheitert, das Bandenwesen einzudämmen. Sein Nachfolger Ölğäytü wiederum unterhielt eine ganze Truppe unter der Leitung von Šaraf ud-Dīn Muzaffar. ${ }^{67}$ Ihre einzige Aufgabe bestand darin, die in Iran allenthalben aktiven Räuberbanden in Schach zu halten.

M. Gronke konstatiert anhand ihrer Quellen ausserdem einen allgemeinen Sittenzerfall. ${ }^{68}$ Sie betont, dass der Sittenkodex der Türken und Mongolen gegenüber jenem der Muslime freizügiger sei. Jedenfalls seien Freudenhäuser und Weinschenken in der Mongolenzeit zu einem weit verbreiteten Übel geworden. Die neuen Machthaber hätten auf die religiösen und sittlichen Empfindlichkeiten ihrer Untertanen keinerlei Rücksicht genommen. Dies habe die Spannungen zwischen den einzelnen Bevölkerungssegmenten zusätzlich zur politischen und wirtschaftlichen Willkür angeheizt. Es bestehen Hinweise darauf, dass zahlreiche Frauen im 13. und 14. Jh. aus purer Not in die Prostitution getrieben wurden. Die Freudenmädchen hätten ihre Dienstleistungen auf den Strassen

66 Gronke, Derwische 7o (mit Anm. 9o).

67 Von ihm leitet die später in Süd- und Mitteliran herrschende Dynastie der Muzaffariden ihren Namen ab; vgl. Bosworth, New Islamic Dynasties 264; siehe auch bereits oben Anm. 36.

68 Gronke, Derwische 74-79. 
und direkt neben den Eingängen zu den Moscheen oder Konventen (hānaqāh) angeboten. Zwar hätten v.a. die fremden Machthaber im Übermass Wein genossen und sich unzüchtig verhalten. Ihr Lebenswandel habe allerdings auch in der muslimischen Bevölkerung deutliche Spuren hinterlassen.

M. Gronke verdeutlicht die damaligen Missstände anhand einer Darstellung in Pūr-i Bahā’s Kār-nāma-i awquăf. Im Mittelpunkt seines Berichts steht ein betrügerischer Stiftungsverwalter, der von zahllosen Nichtsnutzen umgeben ist. Es sind scheinheilige Frömmler, die sich neben sexuellen Ausschweifungen dem Haschisch- und Weingenuss hingeben. Anstatt ihren Lebensunterhalt redlich zu verdienen, halten sie sich am Stiftungsgut schadlos. Unter den Protagonisten der Geschichte befindet sich ein Schreiber (munš̌ ), den seine Gebrechlichkeit nicht daran hindert, sich auf homoerotische Abenteuer einzulassen. Ein lüsterner Muezzin treibt's sodann mit Eseln. Der Stiftungsverwalter selbst gibt sich zwar als Asket, lebt seine Knabenliebe aber einfach im Geheimen aus.

Fromme und viele Derwische bemühen sich, diesem Sittenzerfall Einhalt zu gebieten, erregen aber nur das Missfallen der neuen Herrscher. Kulāhdūz Ardabīlī, der Statthalter der Ǧalāyiriden in Ardabil, scheint sich derart über die Moralpredigten der Derwische enerviert zu haben, dass er direkt neben Safì ud-Dīns Konvent Freudenmädchen einquartieren und eine Weinschenke einrichten liess. Die Sufis könnten dann dort das Tamburin schlagen und ihre Tänze aufführen. ${ }^{69}$ Gāāāns Massnahmen zum Zurückdrängen der Prostitution schien zwar zumindest ein gewisser Erfolg beschieden gewesen zu sein. Allerdings

69 Gronke, Derwische 75 (Anm. 142), macht allerdings darauf aufmerksam, dass der Emir seinen Plan nicht umsetzen konnte. Dies wurde übrigens dem Zorn des damals bereits verstorbenen Šayh Șafĩ ud-Dīn zugeschrieben. Der Emir habe in den Auseinandersetzungen zwischen seinem Herrn Ḥasan Ğalāyirī und Ḥasan Čūpānī seine Stellung verloren und sei nicht wieder nach Ardabil zurückgekehrt. entspannte sich die Lage nur vorübergehend. Dieselben Klagen lassen sich unter den Ğalāyiriden bereits wenig später wieder belegen. So ist bekannt, dass die Šayhs und frommen Bewohner Ardabils 1361-1362 Klage führten, da die Freudenmädchen die Strassen der Stadt säumten und durch ihre Anwesenheit die Muslime verärgerten. ${ }^{70}$

M. Gronke meint, der Weingenuss und die Verbreitung von Tavernen (hammāra, hammār-ḩāna, harābāt) sei zu recht mit den Mongolen in Verbindung gebracht worden. ${ }^{71}$ Der europäische Reisende Johann de Plano Carpini (Mitte 13. Jh.) weiss zu berichten, dass Trunkenheit bei den Mongolen als ehrenvoll galt. ${ }^{72}$ Auch bei Rašīd ud-Dīn finden sich Hinweise, wonach die meisten Leute im Land Wein und Schnaps konsumierten. Der ĪlhānidenHerrscher Gāāān sei zur Erkenntnis gelangt, dass nur strenge Strafen die Leute vom Alkoholgenuss abhalten können, da das Koranwort selbst offensichtlich nicht genüge. ${ }^{73}$

Das von M. Gronke zusammengetragene Material lässt das Bild entstehen, dass Iran im 13. und 14. Jh. ein zunehmend verödetes Land war. Das Volk lebte im Elend, und um die islamische Sittlichkeit war es übel bestellt. 'Alā’ ad-Dawla as-Simnānī fasst die damalige Situation wie folgt zusammen:

Der ganze Ruin unserer Zeit rührt daher, dass alle [...] Personen auf Abwege geraten sind. Der Beter geht nach Speisen aus, der Bauer überlässt sich dem Gottvertrauen [tawakkul], was Sache des frommen Beters ist, und wird zwangsläufig Bettler. Wenn sich der Herrscher nur dem Amüsement zuwendet, der Wesir nur dem Häuserbau [...] und [dem] Zusammenraffen unerlaubter Güter, die Offiziere nur ihrem Wohlleben, dann verlegen sich die Offiziere auf Wege-

\footnotetext{
70 Gronke, Derwische 75 (mit Anm. 144).

71 Gronke, Derwische 76 (mit Anm. 149ff.).

72 Vgl. ausführlicher bei Gronke, Derwische $76 \mathrm{f}$. (mit Anm. 157).

73 Gronke, Derwische 77 (mit Belegen in ihren Anmerkungen).
} 
lagerei. Wenn der Wesir seiner Raffgier nachgibt, senden die Bevollmächtigten in eine Stadt Obersten und Krieger. Dort setzen die Honoratioren Steuereintreiber ans Werk, die wie gierige Hunde über die Dörfer herfallen. Da zogen die Frommen aus der Heimat, wurden die Schwachen ein Opfer der Brutalen, die Handwerker Fronarbeiter und die Bauern Bettler. ${ }^{74}$

Bei Ḥamdallāh Qazwīnī lassen sich ähnliche Aussagen $\mathrm{zu}$ den verheerenden Auswirkungen der Mongolenherrschaft nachweisen. ${ }^{75}$ Er meint jedenfalls, dass die Folgen des allgemeinen Massakers jener Zeit noch während tausend Jahren spürbar sein werden, selbst wenn es zu keinem neuen Unglück komme. Ġāzān hatte sich zwar als erster Mongolenherrscher zum Islam bekehrt (1295). Allerdings konnten die von ihm in die Wege geleiteten Reformmassnahmen die Missstände nur bedingt beheben. Wenn auch Ölğäytü ernsthafte Anstrengungen unternahm, Ġāzāns Bemühungen fortzusetzen, kam es doch bald zu Rückfällen. Dennoch erlebten viele Menschen im 14. Jh. die späte Īlhāniden-Zeit unter den zum Islam übergetretenen Herrschern Ġāzān, Ölğäytü und Abū Sa ${ }^{\text {ìd }}$ als eine Periode von Stabilität und Sicherheit. ${ }^{76}$ Das Jahr 736/1335-1336 jedoch galt verschiedenen persischen Autoren des 15. Jh. als Jahr der Zuflucht (lawd) zu Gott. ${ }^{77}$ In diesem Jahr hätten zwei derart verheerende Ereignisse stattgefunden, dass die Muslime nur noch bei Gott Zuflucht nehmen konnten. Es handelt sich einerseits um das Todesjahr Abū Sa'īds, anderseits um das Geburtsjahr Timurs. ${ }^{78}$

74 Übersetzt bei Gronke, Derwische 77 (mit Anm. 164, wo Verweis auf Sīstānī bei Cordt, Simnānī 86).

75 Gronke, Derwische 77 (mit Anm. 165), wo Verweis auf Hamdallāh Mustawfì Qazwīnī, Nuzhat al-qulūb; übersetzt von G. LeStrange, Nuzhat al-Qulūb 34.

76 Vgl. Gronke, Derwische 78.

77 Gemäss der Abğad-Lesart entspricht der Zahlenwert des Wortes lawd 736 (christlich: 1335-1336); vgl. Gronke, Derwische 78 (Anm. 172).

78 Gronke, Derwische 78 (mit Anm. 173), wo Verweis auf Browne, Literary History II I, 58.
M. Gronke sieht in diesen Berichten zwar eine rückblickende Verklärung der Verhältnisse zur Îlhāniden-Zeit. Sie erklärt dies mit den Entwicklungen, die nach 1335 einsetzten und zu einer erneuten Verschlechterung führten. Die folgenden Jahrzehnte waren durch nicht enden wollende Thronkämpfe geprägt. Diese Auseinandersetzungen waren mit weiteren Hungersnöten, Pestzügen und allgegenwärtiger Unterdrückung verbunden. Angesichts dieser düsteren Existenzbedingungen lässt sich im 14. Jh. in breiten Kreisen der Bevölkerung ein allgemeines Bedürfnis nach Schutz und Hilfe feststellen. ${ }^{79}$ Es sind die Šayhs, die Vorsteher einer Gruppe sufisch orientierter Derwische oder eines Konvents, die der Bevölkerung angesichts der vielfältigen Wirren jener Zeit Halt vermitteln. Jedenfalls tritt im 13. und 14. Jh. in dieser Region eine grosse Zahl von Sufi-Šayhs in Erscheinung. Sie dienen der einfachen Bevölkerung als Orientierungspunkt und Lebensmitte. Diese sufischen Bewegungen hatten sich bereits unter den Seldschuken zunehmend der breiten Bevölkerung geöffnet und sich ihrer Sorgen und Anliegen angenommen. ${ }^{80}$

Nachdem sich die Verhältnisse als Folge des Mongoleneinfalls massgeblich verschlechtert hatten, erhielten die Sufi-Bewegungen gerade aus dem einfachen Volk breiten Zulauf. Die Sufis machten ihren Einfluss bereits nach kurzer Zeit in sämtlichen sozialen Schichten geltend und vermochten zahlreiche Anhänger zu gewinnen. M. Gronke erkennt in unsicheren, unablässig bedrohten Lebensverhältnissen einen wichtigen Nährboden für das Entstehen derartiger religiöser Volksbewegungen.

79 Gronke, Derwische $78 \mathrm{f}$.

8o Gronke, Derwische 79 (mit Anm. 173), wo Verweis auf Amoretti, $\mathrm{CHI}$ VI, 613 . 


\subsection{Timurs Auftreten in Iran (1381-1405)}

Die Herrschaft der Īlhāniden ging mit dem Tod Abū Saīids (gest. 1335) faktisch zu Ende. Bis zum Auftreten Timurs auf der iranischen Bühne (1381) machten verschiedene kleinere Dynastien während eines halben Jahrhunderts ihre Machtansprüche mit wechselndem Glück geltend. $\mathrm{Zu}$ ihnen zählen die Ğalāyiriden, die von ihrer Hauptstadt Tabriz aus ihren Einfluss in Westiran und Nordmesopotamien durchzusetzen versuchten. Die Čūpāniden wiederum agierten von Bagdad aus. Und in Shiraz (Fārs) waren vorübergehend die Muzaffariden an der Macht. ${ }^{81}$ Diese Dynastien waren vordergründig immer noch von den Îlhāāniden abhängig. Unter diesen Nachfolgedynastien kam es aber häufig zu kleineren und grösseren Auseinandersetzungen, sodass keine Konfliktpartei einen entscheidenden Vorteil erlangte. Diese andauernden Spannungen wirkten sich negativ auf die Lebensumstände der Bevölkerung aus. ${ }^{82}$

Erst mit dem Auftreten Timurs (1336-1405) stellte sich in der Region eine gewisse, allerdings bloss vorübergehende, machtpolitische Konsolidierung ein. ${ }^{83}$ Jedenfalls änderten sich die Verhältnisse in Iran mehr oder weniger über Nacht, als Timur 1381 in diese Region vordrang und seine Macht bis zu seinem Tod im Jahr 1405 geltend machte. ${ }^{84}$ Es gelang ihm, ein Reich aufzubauen, das sich am Ende seines Lebens von der Ägäis bis zum Syr Daryā in Zentralasien erstreckte. Das Zen-

81 Siehe dazu Roemer, The Jalayrids, Muzaffarids and Sarbadārs, in CHI VI, 1-39.

82 Mazzaoui, Origins 9.

83 Mazzaoui, Origins 9f.; Manz, Timur Lang, in $E I^{2}$, und Komaroff et. al., Timurids, in $E I^{2}$; Bosworth, New Islamic dynasties 270-272 (Nr. 144). Siehe ausführlicher Manz, Power, politics and religion; Roemer, $C H I$ VI, 2: „Timur in Iran“ (42-97), und VI, 3: „The Successors of Timur“ (98145); Lentz und Lowry, Timur and the princely vision 17-65 (Kapitel 1: Timur and the image of power).

84 Timur selbst war 1336 in Hwāḡū İlgāā in der Nähe von Šahr-i Sabz in Transoxanien geboren worden, das sich zwischen den beiden wichtigen Flüssen Amū Daryā und Syr Daryā (Oxus und Jaxartes) erstreckt; vgl. dazu Lentz und Lowry, op. cit. 2 oa. trum seines Reichs befand sich in Samarkand. ${ }^{85}$ Timurs Armeen folgten bei ihrem Vordringen nach Westen immer wieder denselben Pfaden, die im 13. Jh. bereits die Mongolen gewählt hatten. ${ }^{86}$

Timur legitimierte seine Machtansprüche, indem er sich auf die mongolische Tradition berief und wiederholt auf seine persönliche Abstammung aus dem Haus Čingiz Hāns verwies. Timur unterschied sich anfänglich nicht von zahllosen weiteren Stammesvorstehern, die sich in Zentralasien gegenseitig bekämpften. Seine beeindruckendste Leistung bestand darin, dass er sich eine bedeutende Anhängerschaft aufbauen konnte. Dies darf nicht als selbstverständlich angesehen werden, lebte er doch in einer Gesellschaft, in der jeder einzelne Stamm auf den Erhalt seiner Autonomie bedacht war. In einem derartigen Umfeld konnte sich nur durchsetzen, wer - wie Čingiz Hān oder eben Timur - dank seines politischen und persönlichen Charismas auf eine treu ergebene Gefolgschaft zählen konnte.

Nachdem Timur seine Macht in Transoxanien gefestigt hatte, wurde er 1370 in Balh gekrönt. ${ }^{87}$ Es war ihm kurz zuvor gelungen, dem mongolischen Herrscher Amīr Ḥusayn (gest. 1370), einem seiner bedeutendsten Rivalen und Grossohn des Amīr Qazagāan (gest. 1358), eine entscheidende Niederlage zuzufügen. Mit seinen verbliebenen Kontrahenten konnten er sich auf strategische Allianzen einigen. Dies gestattete es ihm, eine Reihe von militärischen Angriffen zu lancieren, die seiner Karriere eine neue Wendung gaben. Er plante seine Angriffe sorgfältig und ging mit äusserster Grausamkeit vor. Wenn sich eine Stadt dazu verstieg, seinen Truppen Widerstand zu leisten, richtete er dort ein Massaker an. Die Schädelpyramiden, die er nach der Einnahme widerspenstiger Nester errichten liess, waren ebenso berühmt wie berüch-

85 Zur Ausdehnung von Timurs Reich siehe Brice, An historical atlas of Islam, Karte Nr. 25. Für Hinweise auf weiteres Kartenmaterial siehe Anm. 41.

86 Lentz und Lowry, op. cit. 2ob; Čingiz Hुāns erster Einfall in die islamische Welt hatte im Jahr 1219 stattgefunden.

87 Lentz und Lowry, op. cit. $24 \mathrm{f}$. 
tigt. ${ }^{88}$ Timur schüchterte die Bevölkerung systematisch ein. Er verschonte, wenn überhaupt, nur die Alten, Handwerker, Künstler und Kinder unter fünf Jahren. In drei Angriffswellen, nämlich von 13861388, von 1392-1396 und im Jahr 1399, gelang es ihm, Iran zu unterwerfen. ${ }^{89}$

Am Ende des 14. Jh. waren Timurs Truppen in der gesamten östlichen islamischen Welt präsent. Sie zogen in grosser Geschwindigkeit von einem Ende ans andere seines sich rasch ausdehnenden Reichs. Ihre Ruchlosigkeit stand jener ihrer mongolischen Vorgänger in nichts nach. Nach einer Reihe von Schlachten gelang es Timur 1395, auch Toqtamī̌s endgültig zu unterwerfen. Toqtamīš, der Vorsteher der Goldenen Horde, war anfänglich mit Timur verbündet gewesen. ${ }^{90}$ Nur zwei Jahre später überquerten Timurs Truppen den Hindukusch und eroberten Delhi (1398). ${ }^{91}$ Danach kehrte Timur wieder nach Samarkand zurück. Im Herbst des Jahrs 1400 drang er nach Westen in die arabische Welt vor. Er griff die Mamluken in Syrien an, wo er Aleppo, Hama, Baalbek und nach langer Belagerung Damaskus einnahm. ${ }^{92}$

Timur wandte sich danach nach Anatolien, wo er Bāyazid I. (reg. 1389-1402) in der Schlacht von Ankara (1402) besiegte. ${ }^{93}$ Nach der Gefangennahme des osmanischen Herrschers hatte Timur den Widerstand all seiner Feinde gebrochen. Sämtliche wichtigen Machthaber zwischen Kairo und den Grenzen Chinas hatten sich ihm beugen müssen. In Iran selbst hatte er sich die Dynastien der Ğalāyiriden, der Kart, ${ }^{94}$ der Muẓaffariden und der Qara Quyunlu untertan gemacht. ${ }^{95}$

88 Vgl. dazu Aubin, Tamerlan; Lentz und Lowry, op. cit. 26 (mit Anm. 10), wo Verweis auf Roemer, Timur in Iran, in CHI VI, $55 \mathrm{f}$.

89 Lentz und Lowry, op. cit. 25.

90 Lentz und Lowry, op. cit. 25. Zu Toqtamī̌s vgl. Roemer, Tīmūr in Iran, in $C H I$ VI, $57-59$.

91 Lentz und Lowry, op. cit. 26.

92 Ibid.

93 Lentz und Lowry, op. cit., 26 (mit Anm. 9), wo Verweis auf Roemer, Tīmūr in Iran, in $c H I$ VI, 78.

94 Vgl. zu dieser Dynastie Spuler, Āl-e Kart, in EIr.

95 Lentz und Lowry, op. cit. 26a.
Zum Zeitpunkt seines Todes bereitete Timur gerade einen Feldzug gegen China vor. China war das letzte ehemalige mongolische Teilreich, das noch nicht unter seiner Kontrolle stand. Es war bis 1368 von der mongolischen Dynastie der Yuan beherrscht worden. Danach übernahm dort die Ming-Dynastie die Macht. Timur und der Ming-Herrscher nannten sich in Briefen gegenseitig Vasallen. Als 1403 ein neuer Ming-Herrscher an die Macht kam, verschärfte sich der Ton. Es steht jedenfalls fest, dass Timur Vorbereitungen zu einem Feldzug gegen seinen Herausforderer im Osten traf. Seine Truppen hatten das Lager bereits in Utrar, 25 o km nördlich von Samarkand, aufgeschlagen, als Timur 1405 unerwartet starb. ${ }^{96}$

Sein gewaltiges Reich sollte nicht lang über seinen Tod hinaus Bestand haben. Diese Feststellung trifft gerade auf Iran, Iraq und Anatolien zu. Zwar hatte bereits Timur sein Grossreich in vier Einflusszonen aufgeteilt und sie seinen Söhnen 'Umar Šayh, Ǧahāngīr, Mīrān Šāh und Šāh Ruh zugewiesen. Kurz nach seinem Ableben kam es unter seinen Söhnen aber dennoch zu verbissenen Nachfolgekämpfen.

Gewinner dieser Auseinandersetzungen war Šāh-Ruh, Timurs vierter Sohn (reg. 8o7-85o/14041447). Er konnte zumindest am Anfang noch über nahezu das gesamte Grossreich seines Vaters herrschen. Allerdings entglitt ihm die Kontrolle über die ehemaligen Beylik-Provinzen im Westen nach und nach. Timur hatte sie nach der Einnahme Ankaras (805/1402) reaktiviert, um seine Macht effizienter durchsetzen zu können. Die in Anatolien zu jener Zeit im Aufstieg begriffenen Osmanen waren jedoch nicht willens, fremde Einmischung widerspruchslos zu dulden. Jedenfalls war Mehmed II. (reg. 1444-1446 und 14511481) darum bemüht, seine Macht Richtung Osten auszudehnen. Ausserdem machten die beiden turkmenischen Stammesbünde der Qara Quyunlu (Schwarze Schafe) und der Aq Quyunlu (Weisse Schafe) im 15. Jh. den Timuriden in Westiran

96 Lentz und Lowry, op. cit. 26b; Roemer, Tīmūr in Iran, in CHI VI, 8o-83. 
und Nordmesopotamien die Macht strittig. Das 15. Jh. gilt in dieser Region als Jahrhundert der Turkmenenherrschaft. Die Unruhen, die aus den endlosen Kämpfen unter Timurs Erben resultierten schwächten diese Dynastie und höhlten ihre Macht aus. ${ }^{97}$ Am Ende des 15. Jh. regierten die Timuriden nur noch über Khorasan und Teile Transoxaniens. Sie kontrollierten die Überbleibsel des einst grossen Reichs bis zum Ende der Dynastie im Jahr 1507 von Herat aus. ${ }^{98}$

Die vorangehenden Ausführungen zeigten auf, dass Timurs Reich nach seinem Ableben rasch auseinanderbrach. Zu einer umfassenden Würdigung von Timurs Leistungen und Wirken gehört aber auch ein Blick auf seine religiöse Abhängigkeiten und Beiträge zur Weiterentwicklung der Kultur:

Mutmasslich haben ganz unterschiedliche religiöse Auffassungen Timur beeinflusst. Timur gehört dem Barlas-Stamm an, der im Qašqa DaryāTal in Transoxanien beheimatet war. Die dortige Kultur war im 14. Jh. von traditionellen turko-mongolischen Praktiken ${ }^{99}$ und vordergründig islamischen Vorstellungen geprägt. Auch lassen sich buddhistische Auffassungen nachweisen. In der von heterodoxen Auffassungen beeinflussten Grenzregion Transoxaniens waren die Unterschiede zwischen Sunna und Schia weitgehend irrelevant. Unter Timurs Gefolgsleuten und Anhängern war ein volkstümlich orientierter Islam weit verbreitet. Sufis und Angehörige anderer religiöser Gruppierungen entfalteten in dieser Region ihre Aktivitäten. Sie zeichneten auch für die Bekehrung grosser Teile der Bevölkerung Zentralasiens zum Islam verantwortlich. Sie vermischten dabei volkstümliche Überlieferungen gern mit magischen Vorstellungen und islamischen Auffas-

\footnotetext{
97 Lentz und Lowry, op. cit. 32 (mit Anm. 33), wo Verweis auf Manz, Politics and control under Tamerlane 15.

98 Lentz und Lowry, op. cit. 32 (mit Anm. 34), wo Verweis auf Fletcher, The Mongols: Ecological and social perspectives 25.

99 Dazu gehören auch schamanistische Praktiken; vgl. Lentz und Lowry, op. cit. 27.
}

sungen. ${ }^{100}$ Auch in dieser Gegend nahmen die Sufis Funktionen wahr, die mit jenen übereinstimmen, die M. Gronke in Ardabil beobachtet hatte.

Timurs Vater Amīr Taragiay, ein führendes Mitglied des Barlas-Stamms, hatte einen spirituellen Berater, bei dem es sich um den Șūfī-Šayh Šams adDīn Kulāl handelte. ${ }^{101}$ Auch Timur pflegte in seiner Kindheit engen Umgang mit diesem Amīr Kulāl. Er legte später überdies auch selbst grossen Wert auf persönlichen Kontakt zu derartigen heiligmässigen Männern. Timur liegt zu Füssen seines eigenen spirituellen Beraters, Mīr Sayyid Baraka, begraben. ${ }^{102}$ Diese engen Beziehungen zwischen weltlichen Machthabern und spirituellen Führergestalten sind bezeichnend für das religiöse Umfeld im Osten der islamischen Welt im Nachgang des Mongolensturms.

Timur ordnete auch den Bau von Moscheen, Madrasen und weiteren religiösen Einrichtungen an. Seine Faszination für heiligmässige Männer aus seiner Kindheit lässt ihn auch später nicht los. Als gestandener Herrscher lässt er jedenfalls einer Reihe von Derwischinstitutionen massgebliche Unterstützung zukommen. Er dürfte dies v.a. aus politischem Kalkül und nicht aus Frömmigkeit getan haben. Die Timuriden (13701507) sind überhaupt dafür bekannt, dass sie in ihrem gesamten Reich Moscheen und Schreinbauten unterstützten. ${ }^{103}$ Sie taten dies u.a. im Fall der Heiligtümer der Șafawiyya (Ardabil), ${ }^{104}$ der

\footnotetext{
100 Vgl. Lentz und Lowry, op. cit. 28b (mit Anm. 22), wo Verweis auf Hodgson, Venture of Islam II, 430.

101 Lentz und Lowry, op. cit. 28b (mit Anm. 23), wo Verweis auf Roemer, Timur in Iran, in $C H I$ VI, 44. Zu Šams udDīn Kulāls Mausoleum in Šahr-i Sabz siehe: https://de .wikipedia.org/wiki/Historisches_Zentrum_von_Shah risabz (Stand 28. August 2017).

V

(1)

Lentz und Lowry, op. cit. 29.

Rizvi, Dynastic shrine 3 (mit Anm. 3); Golombek und Wilber, Timurid architecture I, 362-364 (Nr. 136), und II, 325-329 und Plan 112.

Man weiss, dass Timur dem Schrein in Ardabil Unterstützung hatte zukommen lassen, als er dort auf dem Rückweg aus Anatolien mit Huwāğa 'Alī zusammengetroffen war; vgl. dazu bei Anm. 162.
} 
Yasawiyya (Yasi) ${ }^{105}$ und jenem des 'Abdullāh Anșārī (Gazurgāh).106

Timurs Verhältnis zum Islam ist als ambivalent einzustufen, war er doch widersprüchlichen Gesetzesordnungen verpflichtet. Er stand einerseits in der mongolischen Tradition, die durch das Stammesgesetz (yasa) geprägt war. Er orientierte sich anderseits an der islamischen šarīa. Dieselbe Beobachtung trifft auf die weiteren timuridischen Prinzen im 15. Jh. zu. Timur war jedoch nicht nur bereit, Schreine zu unterstützen. Er konnte durchaus auch die Zerstörung heiliger Stätten anordnen, falls dies aus machtpolitischem Kalkül angezeigt war. Wenn es ihm aber gelegen kam, stellte er sich als Schutzherr des Islams dar. Immer wieder unternahm er Feldzüge unter dem Vorwand, die religiöse Ordnung und die šarīa zu schützen. ${ }^{107}$ Timur unterstützte den Islam in erster Linie, um gesicherte Verhältnisse zu schaffen, was die Grundbedingung für einen blühenden Handel war.

In kultureller Hinsicht baute Timur auf jenen Voraussetzungen auf, die er in seinem Einflussbereich vorfand. Wenn seine Herrschaft selbst auch nur vier Jahrzehnte gedauert hatte, hinterliess er im Osten der islamischen Welt doch ein kulturelles Erbe, das ihn deutlich überdauerte. ${ }^{108} \mathrm{Er}$

105 Timur hatte im Winter 1397 eine Pilgerfahrt zum Grab Ahmad Yasawīs unternommen. Er hat dabei auch den Bau eines massiven neuen Heiligtums mit einem imposanten Zugang und einer hochragenden Hauptkuppel befohlen. Er gab damals ausserdem weitere Gegenstände für das Heiligtum in Auftrag. Dazu zählen ein gewaltiges Wasserbecken aus Bronze und sechs massive Leuchter. Vgl. die Abbildungen bei Lentz und Lowry, op. cit. 29 (Figur 4) und 30 f. (Abbildungen Nr. 4A-C und 5). Gemäss einer Datierung soll Timur die Anfertigung des Wasserbeckens am 20. Šawwāl 802/25. Juni 1399 befohlen haben (Komaroff, The Timurid phase in Iranian metalwork 187, zitiert bei Lentz und Lowry, op. cit. 29 mit Anm. 24). archnet.org/sites/6410 (Stand 17. Juni 2017). Siehe ausserdem Golombek, Timurid Shrine at Gazur Gah. Lentz und Lowry, op. cit. 30 (mit Anm. 27), wo Verweis auf Manz, Tamerlane and the symbolism of sovereignity 10.

Vgl. für die weiteren Ausführungen Lentz und Lowry,

begnügte sich nämlich nicht mit seinen militärischen Erfolgen, sondern krempelte die politische, soziale und kulturelle Landschaft in seinem Einflussbereich gründlich um. Da sich Elemente der Kunst der Timuriden wiederholt auf den in dieser Arbeit untersuchten Dokumenten in Rollenform nachweisen lassen, lohnt es sich, ihren wichtigsten Aspekten eingehender Aufmerksamkeit zu schenken:

Zwar waren die Verhältnisse nach dem Einfall der Mongolen in der Region schwierig. Bereits die Îlhāniden bemühten sich aber um die Förderung von Wissenschaft und Kultur. Sie unterstützen den berühmten Mathematiker Nāṣir ad-Dīn Ṭūsī (12O11274) ${ }^{109}$ oder den Geschichtsschreiber Rašīd adDīn (ca. 1247-1318). ${ }^{110}$ Sie entfalteten ausserdem eine rege Bautätigkeit. Die Forschung hat wiederholt auf die bedeutenden Beiträge der Îlhāniden zur Entwicklung der islamischen Kunst und Kultur hingewiesen. ${ }^{111}$

Timur setzte diese Bestrebungen fort. Er hatte mit der Unterstützung von Kunst und Kultur sogar nachhaltigeren Erfolg als in militärischer und politischer Hinsicht. Obwohl die Macht der Dynastie nach dem Tod ihres Gründers rasch nachliess, konnten die Timuriden ihr kulturelles Prestige im Lauf der Jahrzehnte stärken. Sie entwickelten eine visuelle Sprache, die die islamische Kunst ab dem 15. Jh. von der Türkei bis nach Indien beeinflusste. Die Kunst der Timuriden stellte kurz vor dem Untergang der Dynastie am Anfang des 16. Jh. die Leitkultur in der islamischen Welt dar.

Timurs Inszenierung seiner Dynastie war nicht nur durch seinen individuellen Geschmack geprägt. Er unterhielt in Samarkand mit grosser

op. cit. 17-65. Diese Darstellung macht im Gegensatz zu jener bei H.R. Roemer auch auf die kulturellen Implikationen von Timurs Herrschaftszeit aufmerksam.

M. Mazzaoui, Origins 23 und 24-27.

Vgl. Morgan, Rashīd al-Dīn, in $E I^{2}$ : „[Rashīd al-Dīn:] Persian statesman and the greatest historian of the Īlkhānid period (ca. 645-718/ca. 1247-1318).“

111 Vgl. dazu v.a. Sh. Blairs Studien, z. B. Shrine complex at Natanz; Blair und Bloom, Art and architecture of Islam 1of. (auch ihr Index s.v. „Natanz“, 346). 
Wahrscheinlichkeit ein Atelier (kitābhāna), das einen wichtigen Beitrag zur Ausbildung einer für seine Dynastie charakteristischen visuellen Sprache leistete. ${ }^{112}$ Diese Institution war in ähnlicher Form bereits unter den Îlhāniden in Tabriz bekannt gewesen. Die verfügbaren Informationen laufen darauf hinaus, dass Timur in seinem Kitābhāna ein Elitekorps unterhielt, dem Kunsthandwerker aus den unterschiedlichsten Gegenden seines Reichs angehörten. Arabische, persische und europäische Quellen aus dem 15. Jh. weisen übereinstimmend auf die grosse Zahl von Handwerkern und Künstlern hin, die Timur aus Iran, Syrien, Anatolien und Indien in seine Hauptstadt Samarkand geholt hatte. ${ }^{113}$ Ibn 'Arabšāh hält fest, dass Timur aus Damaskus zahllose Gelehrte und Handwerker deportiert habe. ${ }^{114}$ Auch aus Tabriz holte Timur zahllose Handwerker und Künstler; sie waren danach in seinem Atelier in Samarkand tätig. ${ }^{115}$

Das neue visuelle Vokabular der Timuriden wurde auch dadurch geprägt, dass sich Timur vielfach durch jene Orte, Bauten und Kunstgegen-

112 Es lässt sich zwar nicht beweisen, dass in Samarkand selbst ein Kitābhāna existiert hatte. Vieles deutet aber darauf hin, dass dies der Fall war. Auch ist bekannt, dass nach Timurs Tod an den Höfen seiner Nachfolger lokale Kitābhānas unterhalten wurden, die gerade in der östlichen islamischen Welt Massstäbe auf dem Gebiet der Kunst setzten. Vgl. Lentz und Lowry, op. cit. 5 .

113 Lentz und Lowry, op. cit. 45 (mit Anm. 64-65), wo Verweise auf a. Šaraf ad-Dīn 'Alī Yazdī, Zafarnāma, übersetzt von Pétis de la Croix; auch Niẓām ad-Dīn Šāmī, Zafarnama: Histoire de la conquête de Tamerlan, b. Clavijo, Embassy to Tamerlane 286-287.

114 "[From Damascus alone Timur took] learned men and craftsmen and all who excelled in any art, the most skilled weavers, tailors, gem-cutters, carpenters, makers of head-coverings, farriers, painters, bow-makers, falconers, in short craftsmen of every kind." Aus Lentz und Lowry, op. cit. 45 (mit Anm. 66); siehe auch Ibn 'Arabšāh, Tamerlane 161.

115 Lentz und Lowry, op. cit. 26 f. (mit Anm. 11), wo Verweis auf Roemer, Timur in Iran, in CHI VI, 55. Sohrweide, Safaviden $127 \mathrm{f}$., führt zusätzliche Beispiele dafür an, dass Timur Wissenschafter, Künstler und Handwerker nach Samarkand deportierte. stände beeindrucken liess, die er bei seinen Eroberungszügen gesehen hatte oder die als Beutestücke und durch Handel in seinen Besitz gelangt waren. Es wird vermutet, dass die Freitagsmoschee in Samarkand ein Echo von Ülğäytüs (Ulğaytūs) Mausoleum in Sulțāniyya in Nordwest-Iran ist. Timur hatte es bei der Eroberung Sulțāniyyas im Jahr 1385 gesehen. ${ }^{116}$

Die Timuriden verstanden sich gerade am Anfang ihrer Herrschaft weiterhin als Nomaden und legten grossen Wert auf ihre Mobilität. Es waren allerdings sie, die die nomadische Steppenkultur aus Zentralasien in direkten Kontakt mit Iran und dessen kulturellen Errungenschaften brachten. Diese doppelte Abhängigkeit von einem nomadischen Erbe und vom urbanen Kulturverständnis der sesshaften Bevölkerung beeinflusste die kulturellen Leistungen der Timuriden.

Timur inszenierte seine Machtfülle einerseits im Rahmen eines komplexen Hofrituals, das u.a. vom Spanier Gonzales de Clavijo beobachtet worden war. ${ }^{117}$ Seine Empfänge fanden zumeist in reich ausgeschmückten halbpermanenten Zelten statt, die in grossen Parkanlagen aufgestellt wurden. Ausserdem startete Timur in Samarkand und seiner Umgebung ein eindrucksvolles Bauprogramm und nahm dadurch an der Kultur der in den Städten sesshaften Bevölkerung teil. $\mathrm{Zu}$ seinen wichtigsten Bauwerken in Samarkand zählen die Masğid-i Ğāmi', im Volk als Bībī Hुānum-Moschee bekannt, ${ }^{118}$ der Gūr-i Amīr-

\footnotetext{
116 Lentz und Lowry, op. cit. 48 (mit Anm. 69), wo Verweis auf Blair, Sultaniyya, ,the Imperial'.

117 Lentz und Lowry, op. cit. 33 (mit Anm. 37), wo Verweis auf LeStrange [de Clavijo], Embassy to Tamerlane 218300 .

118 Die Grosse Freitagsmoschee (Masğid-i Ğāmic) ist heute teilweise zerstört. Timur hatte ihren Bau 1399 begonnen. Sie weist ein gewaltiges Portal und einen riesigen Innenhof auf. Der Bau wurde mit Backsteinen und Steinsäulen errichtet und ist mit vielfarbigen glasierten Backsteinen und Kacheln verziert. Vgl. dazu Lentz und Lowry, op. cit. 36 (mit Fig. 5-6); siehe auch Golombek und Wilber, Timurid architecture I, 255-26o (Nr. 28) und II, Abb. 66-78 und Tafel v (Farbe); archnet: https://archnet.org/sites/2464/media _contents/97633 (Stand 28. August 2017).
} 
Komplex, ${ }^{119}$ der heute nicht mehr existierende Bazar und der inzwischen zerstörte Palast namens Kök Sarāy („Blauer Palast“). ${ }^{120}$ Der Gūr-i AmīrBau zeichnet sich durch seine Majestät aus. Timur errichtete dieses Grab im Jahr 1404 an der Stelle der madrasa und des hānaqāh seines Grossohns Muhammad-Sulțān, den er zu seinem Erbprinzen ernannt hatte. Wenn auch Timur selbst später hier bestattet wurde, ist doch nicht klar, ob er diesen Bau als Gruft für Angehörige der Dynastie vorgesehen hatte. ${ }^{121}$ Es steht jedenfalls fest, dass er bereits zuvor für seinen ältesten Sohn Ǧahāngīr in Šahri Sabz (Kī̌s) ein Monumentalgrab hatte erstellen lassen. ${ }^{122}$ Der Gūr-i Amīr-Bau unterstreicht Samarkands Bedeutung als Hauptstadt des Reichs. ${ }^{123}$

Auch weitere Angehörige Timurs, v.a. seine Frauen, errichteten in Samarkand das Stadtbild prägende Bauten. Saray Malik Hānum liess direkt gegenüber der Freitagsmoschee eine madrasa bauen. Tümän Āgāa, eine weitere Frau Timurs, initiierte den Bau eines hānaqāh im Šāh ZindaGrabkomplex. $^{124}$ Weitere Gattinnen des Herrschers errichteten in diesem Komplex in der zweiten Hälfte des 14. Jh. mit farbigen Kacheln besetzte Gräber. $^{125}$

119 Vgl. dazu Lentz und Lowry, op. cit. 34 und 36; siehe auch Golombek und Wilber, Timurid architecture I, 261-263 (Nr. 29C), und II, Abb. 80-87 und Tafel VI (Farbe), mit Plan 27; archnet: https://archnet.org/sites/2127/media _contents/11959 (Stand 28. August 2017). Für Timurs Bauprogramm in Samarkand vgl. ausführlich Golombek und Wilber, Timurid architecture I, Appendix A (446).

121 Lentz und Lowry, op. cit. 36 (mit Fig. 7).

122 Golombek und Wilber, Timurid architecture I, 275-278 (Nr. 40), und II, Abb. 110-114; archnet: https://archnet .org/sites/2482/media_contents/1404 (Stand 29. Dezember 2017).

123 Lentz und Lowry, op. cit. 36; vgl. Golombek und Wilber, Timurid architecture I, 26o-263 (Nr. 29) Bd. II, Abb. 7987 , Tafel vi (Farbe), Plan 27.

124 Lentz und Lowry, op. cit. 41 (mit Anm. 53), wo Verweis auf O'Kane, Timurid architecture in Khurasan 82. Siehe ausserdem Abbildung bei Lentz und Lowry, op. cit. 40 (Fig. 8)

125 Zum Šāh Zinda-Grabkomplex siehe Golombek und Wilber, Timurid architecture I, 233-252 (Nr. 11-24) und II, Abb. 17-59 und Tafeln I-IV (Farbe).
Im Šāh Zinda-Komplex lässt sich auch beobachten, dass Timur nicht nur den traditionalistisch ausgerichteten Islam der Religionsgelehrten ('ulamā') förderte, sondern sich ebenso gegenüber der volkstümlichen Frömmigkeit aufgeschlossen zeigte. Im Zentrum der Anlage befand sich das angebliche Grab des Qutam b. al-Abbās, eines Cousin des Propheten Muhammad. Gemäss einer Legende soll der Prophet Hiḍr Qutam an dieser Stelle in einen Brunnen hinabgeführt haben, wo dieser noch lange über seinen angeblichen Tod hinaus in Wohlergehen lebte. Diese Legende erklärt auch den Namen der Anlage bedeutet šăh-i zinda doch „der lebende König“. In diesem Komplex lassen sich Bautechniken beobachten, die in der zweiten Hälfte des 14. Jh. in Zentralasien üblich waren und oft auf iranische Fertigkeiten zurückgingen.

Timur setzte seine architektonischen Vorstellungen auch ausserhalb Samarkands um. ${ }^{126} \mathrm{Er}$ errichtete in Šahr-i Sabz von 1379-1396 den Aq Sarāy-Palast, der heute zwar weitgehend zerstört ist. Beschreibungen dieses Baus lassen sich aber beim spanischen Gesandten Clavijo nachweisen. ${ }^{127}$ Die von der Fassade erhalten gebliebenen Teile mit den Inschriften und den glasierten Kacheln lassen erahnen, dass das Gebäude ursprünglich reich verziert war. Das von Timur errichtete Mausoleum Ahmad Yasawīs weist ebenso mehrfach Ähnlichkeiten mit den Bauten in Šahr-i Sabz auf. ${ }^{128}$ Gerade die am Yasawī-Schrein

126 Lentz und Lowry, op. cit. 42 (mit Fig. 10-12); siehe dazu ausserdem Golombek und Wilber, Timurid architecture I, 271-279 (Nr. 39-41); archnet: https://archnet.org/ sites/2481 (Stand 28. August 2017).

127 Lentz und Lowry, op. cit. 42 (mit Anm. 57), wo Verweis auf de Clavijo/Le Strange, Embassy to Tamerlane $207 \mathrm{f}$.

128 Lentz und Lowry, op. cit. 43 (mit Fig. 13-14); Golombek und Wilber, Timurid architecture I, 284-288; archnet (Schrein des Aḥmad Yasawī): https://archnet.org/sites/ 3057 (Stand 28. August 2017). Diese Absicht kommt allein in den Dimensionen des Wasserbeckens und der Leuchter zum Ausdruck, die Timur für das Mausoleum Ahmad Yasawīs hatte anfertigen lassen. $\mathrm{Zu}$ den Öllampen siehe auch Lentz und Lowry, op. cit. 45 (mit Anm. 6o), wo präzisierende Hinweise. Vgl. dazu bereits oben Anm. 105. 
angebrachten Verzierungen lassen sich in modifizierter Form auf einzelnen Dokumenten in Rollenform nachweisen.

Zu Lebzeiten Timurs befand sich das Zentrum seines Reichs in Transoxanien mit seiner Hauptstadt Samarkand. Bereits im Lauf des 15. Jhs. bildeten sich aber in den wichtigen Städten Irans, u. a. in Tabriz, Shiraz und Isfahan, Nebenzentren aus, wo in lokalen Ateliers ebenso ein Stil gepflegt wurde, der als timuridisch bezeichnet werden kann. Ausserdem spielte auch die Stadt Herat im späten 14. und im ganzen 15. Jh für die Timuriden eine bedeutende Rolle. Diese Städte hatten sich zu wichtigen Zentren der persischen Kultur und Gelehrsamkeit im Osten der islamischen Welt entwickelt.

\subsection{Die Vormachtstellung der Turkmenen in Iran und im Iraq im 15. Jh.}

Im Vordergrund der folgenden Ausführungen stehen weiterhin die Verhältnisse im Städte-Dreieck mit den Eckpunkten Konya, Tabriz und Bagdad. ${ }^{129}$ Die Turkmenen hatten sich im 15. Jh. in dieser Region vermehrt zusammengeschlossen. Die Mamluken, Osmanen und Timuriden, konnten ihren Einfluss in der Region gegenüber diesen neuen Kräften nur noch eingeschränkt durchsetzen. M. Mazzaoui bezeichnet diese Gegend in West-Iran, Nord-Iraq und Ost-Anatolien deshalb als Niemandsland. ${ }^{130}$ Dieses Machtvakuum begünstigte das Erstarken heterodoxer Gruppie-

129 Vgl. Mazzaoui, Origins 10-12. Für eine detailliertere Auseinandersetzung nach wie vor sehr hilfreich ist ausserdem Hinz, Irans Aufstieg. W. Hinz' Erkenntnisse sind allerdings in einem wesentlichen Punkt mit Vorsicht zu würdigen: Die Vereinigung der persisch-sprachigen Gebiete im Osten unter den Safawiden kann nicht wirklich als Anfang eines persischen Nationalbewusstseins bzw. Nationalstaates verstanden werden. W. Hinz, dessen Sympathien für den Nationalsozialismus bekannt sind, war in diesem Punkt einfach ein Kind seiner Zeit. Vgl. zu dieser Einschränkung Gronke, Geschichte Irans $68 \mathrm{f}$. rungen, wozu nicht allein die Șafawiyya zählte. ${ }^{131}$ I. Mélikoff jedenfalls nennt die weitere hier interessierende Region zu jener Zeit ein „centre d'hérésies". Indem sie von Häresien im Plural redet, hebt sie hervor, dass das politische Machtvakuum dem Aufblühen ganz unterschiedlicher heterodox orientierter Gruppierungen zuträglich war. ${ }^{132}$

Im 15. Jh. konnten in einem ersten Schritt die Qara Quyunlu (Schwarze Schafe) ihren Einfluss in der Region geltend machen. Ihr Machtzentrum lag anfänglich nördlich des Van-Sees. Das Zentrum des zweiten turkmenischen Stammesbundes, jenes der Aq Quyunlu, befand sich in Diyarbakr. ${ }^{133}$ W. Hinz macht auf die wechselnden Ausdehnungen ihrer jeweiligen Einflussbereiche im Lauf des 15.Jh. aufmerksam und illustriert diese anhand von Karten. ${ }^{134}$

Die erste für die politischen Entwicklungen bedeutende Figur unter den Qara Quyunlu war Qara Muhammad. ${ }^{135}$ Er war vordergründig als Vasall von Sulțān Aḥmad Ğalāyir abhängig, dessen Regierungszeit ausgesprochen turbulent verlaufen war. Nach Qara Muhammads Tod (792/139o) ging seine Stellung im Stamm der Qara Quyunlu an Qara Yūsuf über. Qara Yūsuf und Aḥmad Ğalāyir waren nicht in der Lage gewesen, sich wirksam gegen Timur zur Wehr zu setzen. Die beiden flohen beim Herannahen von dessen Armeen zuerst auf osmanisches Gebiet und danach nach Ägypten. Sie kehrten aber nach Timurs Tod und dem Ende der Vormachtstellung seiner Nachfolger über die westlichen Teile ihres Reichs in ihre frühere Heimat zurück. Es kam zwischen den beiden bald zu Spannungen, aus denen die Qara Quyunlu siegreich hervorgingen. Die Ğalāyiriden verloren 813/1409 eine Schlacht in der Nähe von Tabriz, bei der Sulțān Ahmad ums Leben kam. Die Qara Quyunlu dominierten die Region danach während mehr als eines halben Jahrhunderts.

131 Zum Aufstieg der Șafawiyya vgl. Kapitel 2.4.

132 Mélikoff, Hadji Bektach: Un mythe et ses avatars $35 \mathrm{f}$.

133 Mazzaoui, Origins 10.

134 Hinz, Irans Aufstieg, Karten 1-4 (am Schluss seiner Arbeit).

135 Mazzaoui, Origins 10. 
Der bedeutendste Vertreter dieser Dynastie war Qara Yūsufs Sohn Ğahān-Šāh. Er hatte die Macht nach dem Tod seines Vaters 823/1420 übernommen. Ǧahān-Šāh konnte sich mit den Timuriden arrangieren, die ihren Einfluss über die westlichen Provinzen weiterhin geltend zu machen versuchten. Diese Provinzen standen zumindest nominell noch unter ihrer Kontrolle. Der Timuride ŠāhRuh unterstützte Ǧahān-Šāh jedenfalls in der Hoffnung, in den Nachfolgekämpfen nach Timurs Tod seine eigene Macht festigen zu können. ${ }^{136}$

Nachdem Ğahān-Šāh allerdings seine Position im Iraq und in Aserbaidschan hatte absichern können, richtete er seinen Blick zunehmend gegen Osten auf das Kernland der Timuriden. ${ }^{137}$ Der aufkeimende Konflikt gipfelte 863/1458 in einer Schlacht zwischen Ğahān-Šāh und Tīmurs Urgrossohn Abū Sa'īd. Ğahān-Šāh besiegte Abū Sa'̄ìd und besetzte Herat, die Hauptstadt der Timuriden, während sechs Monaten.

Etwa zu derselben Zeit erstarkten die Aq Quyunlu (Weisse Schafe) in Diyarbakr. ${ }^{138}$ Auch diese Dynastie dehnte ihre Besitzungen nach Osten aus, was zu Konfrontationen mit den Qara Quyunlu führte. Es kam schliesslich zum Zusammenstoss zwischen den beiden turkmenischen Stammesbünden. Ğahān-Šāh wurde dabei von Uzūn Hasan, dem bedeutendsten Vertreter der Aq Quyunlu, besiegt und umgebracht (872/1467). Gemäss der allgemein vertretenen Auffassung endet die Dynastie der Qara Quyunlu mit ĞahānŠāhs Tod.

Der Aufstieg der Aq Quyunlu begann, als sich ihr Vorsteher Qara 'Uțān dazu entschloss, mit Timur auf seinen Eroberungszügen gegen Westen gemeinsame Sache zu machen. ${ }^{139}$ Qara 'Uțān kämpfte gegen Qara Yūsuf von den Schwarzen

136 Wie bereits aufgezeigt, brachen nach Timurs Tod unter seinen Angehörigen heftige Kämpfe um die Vormachtstellung aus; sie waren durchaus typisch in der Region. Vgl. dazu Lentz und Lowry, op. cit. 32 (mit Anm. 33); Manz et al., Timurids, 1. History, in $E I^{2}$.

137 Mazzaoui, Origins 10.

138 Mazzaoui, Origins 1o; Hinz, Aufstieg 33-37.

139 Mazzaoui, Origins 11.
Schafen (Qara Quyunlu). Darauf zog Qara 'Uțmān in Richtung Westen, wo er im Jahr 8oo/1398 Qāḍī Burhān ad-Dīn aus Sivas besiegte. Qara 'Uțmān schloss sich danach Timur selbst an, der 1402 in der Schlacht von Ankara Bāyazīd Yildirim eine Niederlage zufügte. Qara 'Uțmān zog darauf mit Timur nach Syrien weiter. Timur setzte Qara 'Uțān als Dank für seine Unterstützung als Gouverneur über Diyarbakr ein. Die Aq Quyunlu konten ihre Macht danach von Diyarbakr aus in unterschiedliche Richtungen ausdehnen. Sie taten dies in einem ersten Schritt auf Kosten der christlichen Komnenen in Trapezunt. Qara 'Uțmān starb 839/1435.

Die bedeutendste Figur aus der Dynastie der Aq Quyunlu war Qara 'Uțāns Grossohn Uzūn Hasan. ${ }^{140}$ Er war neben Mehmed II. wohl jener Machthaber, der die Entwicklungen in der Region im 15. Jh. am deutlichsten prägte. Er herrschte von $857-882 / 1453-1478$ über weite Teile des hier im Vordergrund stehenden Städtedreiecks. Uzūn Hasan unterhielt freundschaftliche Beziehungen mit der byzantinischen Dynastie in Trapezunt und heiratete Despina, die Tochter des Kalo Ioannes, des letzten Vertreters dieses Herrscherhauses.

Wegen seiner Unterstützung für die Komnenen in Trapezunt wurde Uzūn Hasan in einen bewaffneten Konflikt mit Mehmed II. verwickelt. Die Osmanen hatten unter Mehmed II. Konstantinopel erobert und damit dem Oströmischen Reich ein Ende gesetzt (1453). Sie waren daran, ihr Reich auch gegen Osten abzurunden. Da Uzūn Hasan bestrebt war, seine Macht gegen Norden auszudehnen, stand er unablässig in Konflikt mit den Armeniern und Georgiern in der Kaukasusregion. Er zog ausserdem fünf Mal gegen die Tscherkessen in den Krieg. Bereits bei dieser Gelegenheit sei auf Uzūn Hasans enge Beziehungen zum Sufi-Orden der Șafawiyya hingewiesen. Seine Unterstützung war für den Aufstieg der Safawiden von grosser Bedeutung. ${ }^{141}$

\footnotetext{
140 Mazzaoui, Origins 11.

141 Siehe zu der folgenden Darstellung auch ausführlicher Kapitel 2.4 (bei Anm. 194-218).
} 
Die Aq Quyunlu (Weisse Schafe) waren ebenso wie die Schwarzen Schafe vor ihnen darum bemüht, ihre Macht nach Osten auszudehnen. Ihre Bestrebungen führten in Kürze zu ernsthaften Auseinandersetzungen mit den Timuriden. Der Timuriden-Herrscher Abū Saīid, der bereits eine Niederlage gegen Ǧahān-Šāh aus der Dynastie der Qara Quyunlu hatte einstecken müssen, sah sich jetzt auch durch Uzūn Hasan bedroht. Abū Sa'ìd erlitt 873/1468-1469 eine schwere Niederlage gegen Uzūn Hasan und verlor dabei sein Leben. ${ }^{142}$ Nach diesem Erfolg kontrollierte Uzūn Hasan ein Gebiet, das sich von Khorasan und dem Persischen Golf im Osten bis nach Anatolien im Westen erstreckte. ${ }^{143}$

Uzūn Ḥasans bedeutende Stellung an der Ostgrenze ihres Reichs beunruhigte wiederum die Osmanen, die erst kurz zuvor Konstantinopel erobert hatten (1453). Das christliche Europa beobachtete das rasche Vordringen der Osmanen mit Argwohn. Gerade die Republik Venedig, aber auch Westeuropa im allgemeinen, suchten nach Möglichkeiten, die Osmanen zurückzuschlagen. Venetianische Gesandte im Nahen Osten machten auf die Möglichkeit aufmerksam, dass der Westen mit Uzūn Hasan gemeinsame Sache machen und den Osmanen auf diese Art Einhalt gebieten könnte. ${ }^{144}$

Uzūn Ḥasan zeigte sich gegenüber diesbezüglichen Kontaktaufnahmen aufgeschlossen. Venedig sandte darauf Waffen, insbesondere auch Feuerwaffen, nach Zypern, von wo man sie bei einer günstigen Gelegenheit an Uzūn Ḥasan weiterschicken wollte. Es scheint allerdings nie so weit gekommen zu sein. Dafür verantwortlich war auch, dass sich die Verbündeten aufgrund der schwierigen Kommunikation nicht klar untereinander absprechen konnten. Als es schliesslich zur Schlacht zwischen Mehmed II. und Uzūn Hasan kam, gewannen die Osmanen die Auseinandersetzung. Ihr Erfolg beruhte nicht zuletzt auf ihrer technologischen Überlegenheit, verfüg-

142 Mazzaoui, Origins 11.

143 Vgl. dazu die Karte bei Hinz, Aufstieg, Karte 4.

144 Mazzaoui, Origins 11 (mit Anm. 1). ten sie doch über Feuerwaffen und eine schlagkräftige, mit Kanonen ausgerüstete Artillerie. Die Schlacht hatte $877-878 / 1473$ bei Tercan in der Nähe von Erzincan stattgefunden. ${ }^{145}$ Das Jahr 1473 stellte auch den Höhepunkt der Macht der Aq Quyunlu dar. Uzūn Hasan starb wenige Jahre danach (882/1477-1478). Die Aq Quyunlu büssten ihre wichtige Stellung in der Region bald darauf ein. Venedig seinerseits hatte sich zu einem Friedensvertrag mit den Osmanen unter Bāyazīd II. durchringen können.

Das letzte Viertel des 15. Jh. war erneut durch Unruhen geprägt, die in dieser Gegend - wie auch zuvor immer wieder - auf den Tod eines mächtigen Herrschers folgten. Dies waren ideale Voraussetzungen dafür, dass die Safawiden die Macht in der Gegend endgültig übernehmen konnten. Die weiteren Ausführungen beleuchten ihren Aufstieg zu einer der drei mächtigsten Dynastien in der islamischen Welt im 16. und 17. Jh.

\subsection{Der Aufstieg der Safawiden in Ardabil: Vom sunnitischen Derwischorden zum schiitischen Gottesstaat}

Die Etablierung der Dynastie der Safawiden in Iran stellt einen Eckpunkt in den historischen Entwicklungen in der Region dar. Der eigentlichen Machtübernahme durch Šāh Ismācīl in Tabriz im Jahr 15 o1 war ein langer Prozess vorausgegangen, der sich über nahezu die gesamte Zeit zwischen ca. 1300 und 1500 erstreckte. Im Lauf dieser Entwicklungen war aus der anfänglich sunnitisch orientierten Sufi-Bewegung unter Šayh Șafī ud-Dīn (gest. 735/1334) ein schiitisch ausgerichtetes Staatsgebilde entstanden. Jedenfalls wurde Iran unter den Safawiden nach neun Jahrhunderten Fremdherrschaft durch die Araber, Seldschuken, Mongolen, Tataren und Turkmenen zum ersten Mal wieder zu einem eigenständigen Staat. ${ }^{146}$

145 Vgl. Hinz, op. cit. 67; siehe auch unten nach Anm. 206.

146 Vgl. dazu Hinz, op. cit. 7 . 
An diesen Entwicklungen im späten 14. und v.a. 15. Jh. sind auch unterschiedliche Kräfte heterodoxer Ausrichtung beteiligt. Die Qizilbāš spielten eine wichtige Rolle beim Aufstieg der Safawiden. Im Lauf dieses Transformationsprozesses vertraten die Șafawiyya-Šayhs zunehmend Positionen, die sich mit den Auffassungen eines traditionalistisch orientierten Islams kaum noch in Einklang bringen liessen. Diese Standpunkte kommen auch in Šāh Ismācils Gedichten (Dīwān) zum Ausdruck. In seinen Werken lassen sich Belege dafür feststellen, dass sich Šāh Ismā̄īl als Inkarnation Gottes auf Erden verstand. Gewiss ist zumindest, dass er von seinen Anhängern unter den Qizilbāš dafür gehalten und entsprechend verehrt wurde.

Derartige Auffassungen lassen sich selbstredend nicht mit den Positionen der Zwölferschia in Vereinbarung bringen. Sie sind aber auch aus andern Gruppierungen aus jener Zeit bekannt. Derartige Gruppierungen werden gemeinhin unter

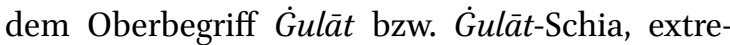
mistische Schia, zusammengefasst. Das zentrale Merkmal des Extremismus dieser Gruppierungen besteht darin, dass sie 'Alī b. Abī Ṭālib, den ersten Imam, als Gott verehren und dies auch in ihren Zeremonien feiern. Diese göttliche Verehrung kann sich auch auf mit 'Alī in Verbindung gebrachte Personen, z. B. Šāh Ismāc̄il, ausdehnen. ${ }^{147}$

Die weiteren Ausführungen zeichnen die Entwicklungen zwischen 1250 und 1500 nach, in deren Verlauf sich die Safawiden von einem kleinen Derwischorden zu einer der mächtigsten Dynastien im Nahen Osten entwickelten. Die folgende Darstellung stützt sich in erster Linie auf die Erkenntnisse von W. Hinz und M. Mazzaoui. ${ }^{148}$ Seit der Veröffentlichung der beiden angeführten Untersuchungen sind zwar neuere Studien erschienen. Sie vervollständigen unser Bild der entsprechenden

147 Vgl. zur Gulāt-Schia unten Kapitel 3.1.3 bei Anm. 115118; beachte die Untersuchungen von Moosa, Extremist Shiites; Karamustafa, God's unruly friends. Siehe auch hier unten, Abschnitt mit Anm. 224.

148 Vgl. dazu Hinz, Aufstieg, und Mazzaoui, Origins.
Entwicklungen zwar, aber deren Eckpunkte erfahren keine grundlegenden Veränderungen. ${ }^{149}$ Der anschliessenden Übersicht ist die Bemerkung vorauszuschicken, dass sich der Begriff Șafawiyya auf den Derwischorden selbst bezieht. Der Ausdruck Safawiden hingegen bezeichnet die unter diesem Namen bekannte Dynastie. ${ }^{150}$ W. Hinz unterscheidet in der Geschichte der Safawiden drei Phasen: ${ }^{151}$

1. 1301-1447: Die Șafawiyya ist als Glaubensgemeinschaft (Șūfì-Orden) in Ardabil organisiert. Die spirituellen und sozialen Motivationen der Handlungsträger stehen im Vordergrund. Als Gründer des Derwischordens gilt Šayh Ṣafī ud-Dīn (gest. 1334).

2. 1447-1494: In Ardabil entwickelt sich ein „Priesterstaat“. Die Vertreter des Ordens nehmen Beziehungen zu den weltlichen Machthabern in der Region auf und stellen für diese zunehmend eine Herausforderung dar. Die Safawiden konsolidierten ihre Macht, indem sie wiederholt Überfälle $(\dot{g} a z \bar{a}$, ğihād) gegen die christlichen Georgier im Kaukasus unternahmen. Sie liessen ihre Anhänger grosszügig an der Kriegsbeute teilhaben. Ihre Verschwägerung mit der mächtigen Dynastie der $\mathrm{Aq}$ Quyunlu festigte ihre Position zusätzlich.

3. 1500-1722: Mit der Machtübernahme ( ̌̆ulūs) durch Šāh Ismāc̄il im Jahr 15 o1 in Tabriz beginnt die Geschichte des von den Safawiden in

149 Bei diesen jüngeren Arbeiten handelt es sich u.a. um die Untersuchungen von J. Aubin, K. Babayan, E. Glassen, A.J. Newmann, H. Sohrweide (mit präzisen Angaben in der Bibliographie). W. Hinz arbeitet die Hauptaspekte allerdings besonders deutlich heraus. Seine Ausführungen lassen die Hintergründe der Verhältnisse in der Region zwischen Konya, Tabriz und Bagdad soweit fassbar werden, wie es für das Verständnis der Untersuchung der Dokumente in Rollenform erforderlich erscheint.

150 Der Übergang vom Sufi-Orden zur weltlichen Dynastie geschieht fliessend; die Abgrenzung zwischen Orden und Dynastie ist deshalb nicht immer klar. Spätestens mit Ismāc̄ils Machtübernahme ist dieser Prozess aber abgeschlossen.

151 Vgl. dazu Hinz, Aufstieg 8f. Siehe auch Browne, History of Persian literature IV, 32 f. Auch Mazzaoui, Origins u. a. 71, weist implizit auf diese Zusammenhänge hin. 
Iran eingerichteten Staates. In Iran entsteht jetzt ein grosses Reich, in dem der schiitische Glaube eine prägende Rolle spielt.

W. Hinz beleuchtet v.a. die Hintergründe jener Transformationsprozesse, in deren Verlauf aus einer primär spirituell orientierten Glaubensgemeinschaft eine politisch relevante Kraft entsteht. Sie fanden in erster Linie in der zweiten Hälfte des 15. Jh. statt, als die Leitung des Ordens in den Händen von Šayh Ğunayd (Ordensleitung: 1447-146o), Šayh Haydar (146o-1488) und Sulțān 'Alī (14881494) lag. ${ }^{152}$ Erst das Verständnis der Entwicklungen in dieser zweiten Phase gestattet es, die Leistungen des Reichsgründers Šāh Ismā̄īl (lebte 14871524) zu würdigen. Eine besondere Rolle spielen dabei die engen Beziehungen Ğunayds und Ḥaydars zu Uzūn Hasan, dem Vorsteher der Aq Quyunlu, der sich als Herrscher über Westiran und Mesopotamien hatte durchsetzen können. ${ }^{153}$

Phase I: Ṣafĩ ud-Dīn (der Glaubensreine; lebte 1252-1334) gilt als Begründer des Derwischordens der Șafawiyya, die ihren Namen von ihm ableitet. Er wurde in der Gegend von Ardabil geboren. Er, bzw. die späteren safawidischen Geschichtsschreiber, führte seine Abstammung über den siebten Imam Mūsā al-Kāẓim auf 'Alīb. Abī Ṭālib zurück. ${ }^{154}$ Von entscheidender Bedeutung für Șafĩ ud-Dīns Leben ist sein Zusammentreffen mit Šayh Zāhidi Gīlānī, der sein Lehrmeister wurde (1276). ${ }^{155}$ Șafī ud-Dīn war damals 25, Šayh Zāhid aber bereits 6o Jahre alt. Șafì ud-Dīn heiratete dessen Toch-

$15^{2}$ Hinz, op. cit. $22 \mathrm{f}$.

153 Die Hauptstadt des Reichs der Weissen Horde war Diyarbakr. Zur Ausdehnung dieses Reichs vgl. die Karten 1-4 am Ende von Hinz, Aufstieg.

154 Vgl. Hinz, op. cit. 125 (Anhang 1). A. Kasrawi zeigte auf, dass es sich bei dieser Abstammung um eine gefälschte silsila handelt, die allein dazu diente, die Machtansprüche der Safawiden zu legitimieren. Siehe dazu Kasrawī, Šayh Șafíwa tabār-aš, Tihrān 1342 (19631964), ders., Nižād wa tabār-i șafawiyya 36o-365; ders., Șafawiyya sayyid na-buda-and 489-497; ders., Bāz ham Șafawiyya 8o1-812, alle in Āyanda 2 (1306/1927-1928).

155 Zu Šayh Zāhid Gīlāni siehe Babinger und Savory, Ṣafī al-Dīn Ardabīlī, in $E I^{2}$. Beachte ausserdem Gronke, Derwische 246-263 (Kapitel: Scheich Șafī und sein Meister Scheich Zāhid). ter Fāṭima und übernahm nach dem Tod seines Lehrers die Leitung des Ordens. Ṣafī ud-Dīn muss in Gilan auch mit 'Umar Halwatī (gest. 8oo/13971398), dem Gründer und Namensgeber des später weitverzweigten Halwatiyya-Ordens Kontakt gehabt haben. ${ }^{156}$

Aus Briefen Rašīd ud-Dīns (hingerichtet 718/ 1318) geht hervor, dass Ṣafĩ ud-Dīn in Ardabil eine bedeutende Stellung innehatte. Rašìd ud-Dīn bietet dem Šayh an, seinem hāanaqāh alljährlich zum Geburtstag des Propheten Lebensmittel und weitere Erträgnisse $\mathrm{zu}$ stiften. ${ }^{157}$ Ein weiterer Hinweis darauf, dass Ṣafĩ ud-Dīn bei den Īlhāniden in hohem Ansehen stand, findet sich in Hunğ̄is (gest. 1521) Tārīh-i 'ālam-ārāà-i Aminnī. ${ }^{158}$ Demnach lud der Îlhānide Ölğäytü (reg. 1304-1316) zur Einweihung seiner Reichshauptstadt Sulțāniyya die Gelehrten und Frommen zu einem Festmahl ein. Als er die Abwesenheit Șafĩ ud-Dīns bemerkte, soll er extra nach ihm gesandt haben. Dieser liess sich aber mit Verweis auf sein hohes Alter - er war damals beinahe 70 - entschuldigen. ${ }^{159}$

Nach Ṣafì ud-Dīns Tod (1334) ging die Leitung des Ordens der Reihe nach an seinen Sohn Șadr ud-Dīn (1334-1392), seinen Enkel Huwāğa 'Alī (13921429) und schliesslich an seinen Urenkel Šayh Ibrāhīm (1429-1447) über. ${ }^{160}$ Der Ruf der DerwischŠayhs war im 14. Jh. bis an den Hof der Osmanen in Bursa gedrungen. Auch sie liessen dem

156 Vgl. Sohrweide, Șafaviden 99 und 196: „Er [Ṣafī adDīn] war Sunnit und ein Schüler des Mystikers Zāhid Gīlānī, in dessen unmittelbaren Umgebung auch 'Omar Halvatī, der angebliche Gründer des Halvatī-Ordens, auftrat Dieser muss Șafī ad-Dīn persönlich gekannt haben, schloss sich ihm aber, wie es scheint, nach dem Tod Zāhids nicht an.“ Vgl. dazu Hinz, Aufstieg 13, der auf Browne, History of Persian literature IV, 19 und 33 verweist.

${ }_{15} 8$ Zitiert bei Hinz, op. cit. 14. Zu Faḍlallāh Rūzbihān Huunğī vgl. Haarmann, Khundjī, in $E I^{2}$.

159 Zu Sultāniyya vgl. Blair, Sultaniyya, ,the Imperial'; Blair und Bloom, Art and architecture 5-8 und 14 (ebenso ihr Index s.v. „Sultaniyya“, 347); vgl. auch https://archnet .org/sites/1671 (Gunbad-i Ülǧaytü); http://sultaniyya .org (Internetquellen: Stand 24. August 2017). Siehe ausserdem: Minorsky, Bosworth, Blair, Șultāniyya, in $E I^{2}$.

Hinz, op. cit. 14. 
Orden Jahr für Jahr Geschenke und finanzielle Unterstützung zukommen. ${ }^{161}$ Nachdem Timur im Jahr 1402 Bāyazīd I. in Ankara eine vernichtende Niederlage zugefügt hatte, soll er auf dem Rückweg dem Ṣafawiyya-Šayh Huañğa 'Alī in Ardabil die Ehre erwiesen haben. Der Eroberer soll bei dieser Gelegenheit Ardabil mitsamt den dazugehörenden Dörfern und Ländereien als Stiftung (waqf) an den Șafawiyya-Orden übertragen haben. ${ }^{162}$

Die Angaben zur Organisation der frühen Șafawiyya sind spärlich. Sie werden erst zahlreicher, nachdem sich aus dem Derwischbund eine Glaubensgemeinschaft mit politischen Zielen entwickelt hatte. Dieser Orden stand unter der Leitung eines Vorstehers, muršid oder pïr genannt, der stets aus der Familie der Safawiden stammte. Beim Nachfolger handelte es sich jeweils um einen Sohn des vorangehenden Vorstehers. ${ }^{163}$ Vieles spricht dafür, dass der Orden straff organisiert war. Gemäss W. Hinz ist es kaum zu Auseinandersetzungen wegen der Nachfolge gekommen. Die Regelung wurde auch respektiert, wenn der Nachfolger noch im Kindesalter war. W. Hinz relativiert diese Darstellung nur unwesentlich, indem er auf Ğaffars Versuch verweist, die Ordensleitung an sich $\mathrm{zu}$ reissen. Seine Bemühungen scheiterten letztlich. Šayh Ğunayd (1447-146o) hatte sich wegen Ğa'fars Aufbegehren allerdings gezwungen gesehen, Ardabil für längere Zeit zu verlassen. ${ }^{164}$

161 Vgl. Hinz, op. cit. 14, mit Quellenverweisen in Anm. 2.

162 Hinz entnimmt diese Angaben den Darstellungen in Šayh Ḥusayn b. Šayh Abdāl Pīrzāda Zāhidī, Silsilat un-nasab-i Safawiyya 48, und Iskandar Munšī, Tārīh$i$ 'álam-ārāy-i 'Abbāsī 12 (vgl. die Verweise in Aufstieg 15, Anm. 1). Bei dieser Gelegenheit soll Timur auf Bitten Hwāğa 'Alīs auch seine aus Anatolien mitgebrachten Gefangenen freigelassen haben. H. Sohrweide allerdings bezeichnet diese Freilassung als Legende; die historischen Zeugnisse würden diese Sichtweise der Dinge nicht stützen. Vgl. Sohrweide, Safaviden 197, ausführlicher: 125-131 (3. Die Tīmūr-Legende); beachte ausserdem Horst, Tìmūr und Hōōä 'Alī.

163 Šāh Ismāōìl I. folgte jedoch nicht direkt auf seinen Vater Haydar, sondern auf seinen älteren Bruder Sulțān 'Alī; vgl. Hinz, Aufstieg 17 (mit Anm. 1).

164 Hinz, Aufstieg $23 \mathrm{f}$.
Im Fall der Șafawiyya setzte der Ordensvorsteher seinen Nachfolger in der Regel noch zu seinen Lebzeiten ein. Bei dieser Einsetzung wurde auch die Gabe der wilāyat weitergegeben. ${ }^{165}$ Beim Nachfolger handelte es sich nicht immer um den ältesten Sohn. Šayh Ibrāhīm z.B. war der dritte und Šayh Ğunayd der sechste Sohn. ${ }^{166}$ Der Nachfolger übernahm nicht nur das geistliche, sondern auch das weltliche Vermächtnis des Ordens. Durch ein geschicktes Vorgehen gelang es den ȘafawiyyaŠayhs im Lauf der Zeit, beträchtliche Ländereien zu erstehen und ihr Vermögen zu mehren. ${ }^{167}$

Mit der zunehmenden Grösse und Verbreitung des Derwischordens der Șafawiyya bildete sich eine komplexere Organisation aus. Der Kontakt zwischen Ordensoberhaupt (šayh, pirr) und den Anhängern, gerade jenen in entfernteren Gegenden, lief oft über Mittelsmänner, halîfa, Pl. hulafä genannt. Sie kümmerten sich auch um die Verbreitung der Ordenslehre. Šāh Ismācill setzte 1508 überdies einen Gross-Halīfen (halīfat ul-hulafä') ein, dem die gewöhnlichen halîfa unterstellt waren. Dieser halïfat ul-hulafä’ spielte eine wichtige Rolle bei der Leitung der Anhänger des Ordens in Anatolien und stand in hohem Ansehen. ${ }^{168}$

Unter den Anhängern des Ordens lässt sich zwischen Laienmitgliedern draussen auf dem Land und jenen Angehörigen unterscheiden, die im hāanaqāh in Ardabil selbst lebten. Gemäss den Angaben in den Tagebüchern Marino Sanutos lebten im Heiligtum in Ardabil jeweils etwa dreihundert Ordensangehörige. Sie hätten stets ein frommes Leben in Andacht geführt. Man habe sie deshalb nicht nur in Persien, sondern auch in Syrien, der gesamten Türkei und in der Barbarei verehrt. ${ }^{169}$ Auch safawidische Quellen bestätigen, dass die

\footnotetext{
165 Zur wilāyat vgl. Walker, Wilāya, 2. In Shicism, in $E I^{2}$.

166 Hinz, Aufstieg 17.

167 Vgl. dazu auch Gronke, Derwische 294-354 (Kapitel: Die wirtschaftliche Entwicklung des Ordens).

168 Hinz, Aufstieg $17 \mathrm{f}$.

169 Vgl. dazu Hinz, Aufstieg 18 (mit Anm. 4), wo Verweis auf einen Brief vom 6. November 1502 (Tagebücher Marino Sanutos IV, 500).
} 
Ordensangehörigen ein strenges Leben führten. ${ }^{170}$ Sie hätten den Tag mit einem langen Schweigen begonnen. Daran hätten sich Andachtsübungen angeschlossen, die auch am Abend abgehalten worden seien. Am Nachmittag seien Stellen aus dem Koran rezitiert worden. Die Angehörigen des Ordens hätten sich karg ernährt und oft gefastet. Überdies habe man sich während der letzten zehn Tage des Monats Ramaḍān und der ersten zehn Tage des Monats Dū l-Ḥiğğa zurückgezogen. Die als čilla bekannte vierzigtägige Periode des Rückzugs von jeglicher Gemeinschaft fand am Anfang des Winters statt. ${ }^{171}$

Mystisch orientierte Männerbünde - dazu gehört letztlich auch der Derwischorden der Șafawiyya - verfolgten zumindest implizit das Ziel, ihre auf dem Charisma ihrer Führerpersonen gründende spirituelle Autorität und ihren Einfluss in weltliche Macht umzusetzen. Der Derwischorden der Șafawiyya stellt unter den weiteren aus jener Zeit bekannten Bruderschaften einfach insofern eine Ausnahmeerscheinung dar, als es ihm gelungen war, ein staatliches Gebilde zu etablieren. Erwähnung verdient, dass sich nach der Gründung des safawidischen Staats durch Ismācill I. Kräfte bemerkbar machten, die die im Umfeld der Safawiyya im 15. Jh. deutlich erkennbaren heterodoxen Tendenzen zurückdrängten und zur Ausbildung eines traditionalistisch ausgerichteten Gottesstaats auf den Grundlagen der ZwölferSchia führten. Dieser Prozess war insbesondere mit einem Zurückdrängen und später bewussten Ausschalten des Einflusses der Qizilbāš auf das safawidische Herrscherhaus verbunden. ${ }^{172}$

Phase II: W. Hinz setzt die Anfänge des Übergangs der Șafawiyya von einem mystisch orien-

170 Vgl. dazu Hinz, Aufstieg 19 (mit Anm. 1), wo Verweis auf Šayh Ḥusayn b. Šayh Abdāl Pīrzāda Zāhidī, Silsilat unnasab-i Safawiyya 36-38.

171 Zur čilla vgl. Kapitel 3.4.2 (Abschnitt nach Anm. 462). Während dieser Periode fasteten die Mönche und führten körperliche Übungen durch, um einen Zustand der Entrückung zu erreichen.

172 Vgl. dazu Babayan, Mystics, monarchs, and messiahs u. a. $144-15$ o, 3o6-308, 351-366. tierten Orden zu einem staat-ähnlichen Gebilde in der Zeit von Šayh Ǧunayd (1447-146o) an. ${ }^{173}$ Er charakterisiert Ğunayd als „höchst seltsamen Mann“, der als Vorsteher einer glaubenswütigen Derwischgemeinde Anspruch auf weltliche Herrschaft erhoben habe. Zwar setzten die Beziehungen zwischen den Šayhs in Ardabil und den weltlichen Machthabern nicht erst jetzt ein. Gemäss W. Hinz bestand in den Anfängen des Ordens allerdings ein deutliches Gefälle zwischen der spirituell orientierten Bruderschaft der Șafawiyya und den Vertretern weltlicher Macht. Die weltlichen Herrscher hatten eindeutig die Oberhand. ${ }^{174}$

Als Šayh Ğunāyd 1447 die Leitung des Ordens übernahm, sah er sich mit heftigem Widerstand von Seiten seines Onkels Šayh Ğa'far konfrontiert. ${ }^{175}$ Dieser war der älteste Sohn Hwāğa 'Alīs und hatte bereits eine wichtige Rolle gespielt, als noch sein, also Ğa'fars, Bruder Šayh Ibrāhīm den Orden geleitet hatte. Ğunayd dürfte 1447 beim Tod seines Vaters ziemlich jung gewesen sein. Ğafar war deshalb wohl als sein Vormund eingesetzt worden. W. Hinz charakterisiert Ğunayd als „unruhigen Kopf“, der die seit Huwāğa 'Alī klar schiitisch geprägte Lehre des Ordens weiterentwickelte. Ğunayd förderte auch den Zustrom von Anhängern und baute dadurch seine Macht aus. Wegen des durch Ğa'far ausgeübten Drucks sah sich Ğunayd, wohl 1448, gezwungen, seine Heimatstadt zu verlassen. Ğa'far erlangte die Kontrolle über das Ardabiler Heiligtum.

Ǧunayd verstand es allerdings seinerseits, die zersplitterten machtpolitischen Verhältnisse in der Dreiecksregion zwischen Konya, Tabriz und Bagdad zu seinen Gunsten auszunutzen. ${ }^{176}$ Das in dieser Region um 1450 herrschende Staatenwirrwarr erleichterte es ihm, seine auf die Übernahme weltlicher Macht ausgerichteten Pläne umzusetzen. Ğunayd hielt sich zwischen 1449 und 1456 als

\footnotetext{
173 Hinz, Aufstieg 22, spricht von einem safawidischen "Priesterstaat". Hinz, Aufstieg 22-24. Hinz, Aufstieg $23 \mathrm{f}$. Vgl. Hinz, Aufstieg, Karte 1 (am Schluss seiner Studie).
} 
"Gast" an den unterschiedlichsten Höfen in Anatolien und Syrien auf. ${ }^{177}$

Nach seiner Ausweisung aus Ardabil suchte Ğunayd zuerst beim Osmanen Sulțān Murād II. (reg. 1421-1451, mit Unterbruch von 1444-1446) Zuflucht und wollte zusammen mit seinen Jüngern in dessen Reich sein frommes Leben fortsetzen. Murād II. schickte Ğunayds Gesandte allerdings mit abschlägigem Bescheid zurück. Ğunayds inzwischen klar erkennbare weltliche Machtansprüche liessen Murād II. keine andere Möglichkeit.

Dieser Misserfolg zwang Ğunayd dazu, ausserhalb des Osmanischen Reichs Zuflucht zu suchen. Er fand vorläufig Schutz bei den Qaramān-Oğlū (Qaramāniden) in Konya. ${ }^{178}$ Die dortige Bevölkerung - ebenso wie die Bewohner von Ḥamīd und Tekke - waren gegenüber der schiitischen Lehre der Șafawiyya durchaus offen. Viele Hinweise sprechen dafür, dass sich Ğunayd um 1450 in Konya aufhielt, präzis festlegen lässt sich dies jedoch nicht. Es ist allerdings bekannt, dass Ğunayd rasch mit Šayh 'Abd al-Lațîf, dem sunnitischen Vorsteher der ihn beherbergenden Zayniyya-Klause, in Streit geriet. Dieser warf ihm vor, ein kāfir zu sein. ${ }^{179}$ Ğunayds Auffassungen dürften schon damals deutlich von gemässigten schiitischen Standpunkten abgewichen haben. ${ }^{180}$

177 Bereits um 1470 hatten sich die machtpolitischen Konstellationen in dieser Gegend grundlegend verändert: Anatolien stand jetzt weitgehend unter der Kontrolle der Osmanen. Als zweite Macht waren vorläufig noch die Mamluken in der Region präsent. Das mamlukische Syrien und Ägypten gingen aber 1516 bzw. 1517 im Osmanischen Reich auf. Dritter Machtfaktor in der Region war sodann das mesopotamisch-persische Reich mit der Hauptstadt Tabriz unter Uzūn Hasan, dem Vorsteher der Aq Quyunlu.

178 Für einen Überblick über die Herrschaftsbereiche in Anatolien zu jener Zeit siehe: https://de.wikipedia.org/ wiki/Germiyan\#/media/File:Beylicats_d'Anatolie_vers _1330-de.svg. Siehe ausserdem Kreiser und Neumann, Kleine Geschichte der Türkei, 65-76 (mit Karte S. 66 f.). auch Sohrweide, Șafaviden 119 und 143-144, 196.

Hinz, Aufstieg $26 \mathrm{f}$.
Ğunayd sah sich vor dem Hintergrund dieser Auseinandersetzungen gezwungen seine Flucht zusammen mit seinen Anhängern in Richtung Syrien fortzusetzen. Syrien gehörte damals zum Reich der Mamluken unter der Herrschaft Čaqmaqs. Ğunayd konnte vom lokalen Machthaber Ibn Bilāl am Golf von Alexandretta eine verfallene Kreuzfahrerburg im Ğabal Arsūs pachten. ${ }^{181}$ Es gelingt ihm darauf, von hier aus neue Anhänger $\mathrm{zu}$ werben. ${ }^{182}$ Darunter befanden sich mutmasslich auch ehemalige Anhänger Badr ad-Dīns (76o-819/1359-1416). Dieser hatte 1416 von Rumelien aus einen gewaltigen Derwischaufstand angezettelt, den Mehmed I. (reg. 1413-1421) nur unter grössten Anstrengungen blutig hatte unterdrücken können. ${ }^{183}$

Ǧunayds Aktivitäten im Ğabal Arsūs erregen allerdings bald das Missfallen der Anhänger Mawlānā Aḥmad Bakrīs und weiterer Šayhs in Aleppo. Sie veranlassen jedenfalls den Sulțān in Kairo dazu, die Wegweisung Ğunayds anzuordnen. Es kam dabei auch zu Kampfhandlungen. Schliesslich erreichte Ğunayd nahezu ohne Anhänger die am Schwarzen Meer gelegene Gegend Canik. ${ }^{184}$ Ğunayds Ausweisung aus Syrien dürfte vor 1453 stattgefunden haben, da Sulțān Čaqmaq in jenem Jahr starb.

Canik mit der Hauptstadt Samsūn war zwar seit 1422 osmanisches Gebiet. Allerdings widersetzte sich der Statthalter Meḥmed Beg den ambitiösen Plänen Ğunayds nicht, der in Canik erneut um Anhänger warb. Ğunayd hegte auch die Absicht, das christliche Trapezunt zu erobern und auf dessen Trümmern ein eigenes Reich zu errich-

181 Es handelt sich dabei wahrscheinlich um die 1129 zerstörte Burg Sarepta (modern; as-Saret); vgl. Hinz, Aufstieg 27.

182 Diese Sufis stammen zumeist aus Syrien, Rūm (Anatolien) und Mesopotamien. Vgl. Hinz, Aufstieg $27 \mathrm{f}$. (mit Anm. 1, S. 28, wo Quellenverweise).

$183 \mathrm{Zu}$ Badr ad-Dīn vgl. Kissling, Das Menaqybnāme Scheich Bedr ed-Dīns; ders., Badr al-Dīn b. Kạḍī Samāwnā, in $E I^{2}$; Karatas, Badr al-Dīn b. Qāọī Samāwnā, in $E I^{3}$; Balivet, Vie du Cheikh Bedreddîn.

184 Vgl. Taeschner, Djānīk, in $E I^{2}$. 
ten. Es gelingt Ǧunayd allerdings nicht, das stark geschwächte Trapezunt einzunehmen. Er musste sich zurückziehen, als die Osmanen heranrückten. Dank Ğunayds Vorarbeiten fällt Trapezunt rasch in die Hände der Osmanen (1456). Nach dem Fall Byzanz' (1453) erobern die Osmanen damit auch das letzte Überbleibsel des Oströmischen Reichs.

Ğunayd zieht in seiner Not wieder in Richtung Süden, wo 1453 in Diyarbakr Uzūn Ḥasan, der Vorsteher des Turkmenenstamms der Aq Quyunlu, an die Macht gekommen war. ${ }^{185}$ Uzūn Hasan seinerseits war - ebenso wie Ğunayd - mit ĞahānŠāh von den Qara Quyunlu verfeindet. Die Aq Quyunlu hatten als Folge ihrer internen Machtkämpfe beträchtliche Gebiete an sie verloren. ${ }^{186}$ Uzūn Hasan war für seine gegenüber den Derwischen zuvorkommende Haltung bekannt. Ğunayd hoffte deshalb, bei ihm gastliche Aufnahme zu finden. ${ }^{187}$

Ğunayds Begegnung mit Uzūn Hasan sollte für den ganzen Nahen Osten tiefgreifende Konsequenzen haben. Die Ausdehnung von Uzūn Hasans Reich war zwischen 1455 und 146o deutlich kleiner, als dies zur Zeit seines Grossvaters Uțmān Beg der Fall gewesen war. Ğunayd reiste also nicht zum Herrscher jenes Grossreichs, das sich zwischen 1468 und 1478, also nur wenig später, von Anatolien bis nach Ostiran (Khorasan) erstrecken

185 Uzūn Ḥasan war es kurz vor Ğunayds Zug nach Süden gelungen, seinen Bruder Ğahāngīr aus Diyarbakr zu verdrängen und zum alleinigen Machthaber über die Aq Quyunlu aufzusteigen. Uzūn Hasan hatte auf eigene Faust auch eine Reihe von Kriegszügen gegen die kurdischen Machthaber im Osten unternommen. Zwar setzte sich der überlistete Ǧahāngīr anfänglich militärisch zur Wehr. Er musste sich allerdings ebenso wie Uways, der dritte Bruder, dem inzwischen unbesiegbaren Uzūn Hasan beugen.

Die Turkemenenstämme der Qara und Aq Quyunlu waren im Gefolge des Mongolensturms gegen Ende des 13. Jh. aus Turkestan nach Aserbaidschan eingewandert. Die Schwarze Horde (Qara Quyunlu) besiedelte dabei die Gegenden von Erzincan und Sivas und nördlich des Van-Sees. Die Weisse Horde liess sich im Gebiet um Diyarbakr nieder.

187 Hinz, Aufstieg 32. sollte. ${ }^{188}$ Um 1457 war Uzūn Ḥasan noch nicht der unbestrittene Vorsteher eines ganzen Nomadenstamms, sondern befehligte vielleicht fünftausend Krieger. Ğunayd konnte sich mit dieser Macht zwar nicht wirklich messen. Allerdings wurde auch er von ca. fünftausend Sufis begleitet. Er konnte Uzūn Hasan also auf Augenhöhe gegenübertreten. Ğunayd dürfte 1457 (?) an der Seite Uzūn Hasans in Diyarbakr (Amīd) eingezogen sein. ${ }^{189}$

Ğunayd hielt sich wohl während drei Jahren am Hof Uzūn Hasans auf (ca. 1456-1459). Die Beziehung zwischen den beiden wurde während dieser Zeit immer enger. Ğunayd heiratete Hadiğa Begūm, Uzūn Hasans Schwester (wohl 1459). ${ }^{190}$ Die Stadt Diyarbakr jedenfalls bot Ğunayd ausgezeichnete Voraussetzungen zur Verbreitung seiner Glaubenslehre. Die Bevölkerung setzte sich aus Muslimen, hauptsächlich Sunniten, Christen (Griechen und Armeniern) sowie Juden zusammen. Gemäss W. Hinz' Darstellungen schlossen sich in Diyarbakr Tausende blindlings ergebene Sufis dem Safawiyya-Orden an. ${ }^{191}$ Ğunayd konnte im Gebiet der Weissen Horde im Einverständnis mit Uzūn Ḥasan allenthalben Stellvertreter (halīfa) einsetzen, die für ihn weitere Anhänger gewannen.

Während Ǧunayds Aufenthalt in Diyarbakr spielten sich im Nahen Osten gewichtige politische Entwicklungen ab. Ein Abgesandter des trapezuntinischen Kaisers Kalo Ioannes wurde 1457 am Hof Uzūn Hasans vorstellig. Der Gross-Komnene erbat vom Vorsteher der Weissen Horde allerdings nicht die Auslieferung Ğunayds, der ihm wenig zuvor übel mitgespielt hatte. Vielmehr ersuchte er ihn um Unterstützung gegen die immer stärker gegen Osten vordringenden Osmanen. Uzūn Hasan war zu dieser Unterstützung bereit, verlangte aber Despina Hātūn (Kyra Katerina), Kalo Ioannes' Tochter, zur Gattin und die Provinz Kappadokien als Morgengabe. Angesichts der drückenden Bedrohung durch die Osmanen sah sich Kalo Ioannes

\footnotetext{
188 Vgl. Hinz, Aufstieg 36 und Karte 4.

189 Hinz, Aufstieg 37.

190 Hinz, Aufstieg 38.

191 Hinz, Aufstieg 38.
} 
gezwungen, diesen Forderungen zu entsprechen. Er stellte allerdings die Bedingung, dass Despina Hātūn ihren Glauben behalten dürfe. Sie gebar Uzūn Hasan drei Töchter und einen Sohn. Eine dieser Töchter gebar später ihrerseits einen Sohn namens Ismāīil. Es handelt sich um den nachmaligen Šāh Ismācîl, der 15 o1 das Safawiden-Reich gründete. ${ }^{192}$

Bereits 1458, die Heiratsfeierlichkeiten in Diyarbakr waren kaum zu Ende, entfaltete das soeben abgeschlossene Bündnis zwischen Trapezunt und Uzūn Hasan zum ersten Mal Wirkung. ${ }^{193}$ Despotina Hātūns Vater Kalo Ioannes war allerdings noch vor der Heirat verstorben. Jedenfalls waren nach dem Fall Konstantinopels (1453) in Europa erneut Gedanken an einen Kreuzzug gegen den osmanischen Feind aufgekommen. Konkret hatte Papst Calixt III. den Franziskaner Lodovico da Bologna nach Trapezunt und Georgien gesandt. Er sollte die dortigen Machthaber zu einem Feldzug gegen die Türken bewegen, dem sich auch der Westen anschliessen würde. Dies würde die Voraussetzungen zu einem Doppelangriff gegen die Osmanen schaffen. Auf dem Rückweg aus Georgien kam der Franziskaner am Hof Uzūn Hasans in Diyarbakr vorbei. Eine Gesandtschaft aus dem Osten, darunter Vertreter Uzūn Hasans, reiste in dieser Angelegenheit nach Rom und ins Burgund. Zu ihrer grossen Ernüchterung mussten Uzūn Hasans Gesandte allerdings feststellen, dass sich der Kreuzzugseifer auf westlicher Seite in engen Grenzen hielt.

In Bezug auf die Situation im Nahen Osten lässt sich jedenfalls feststellen, dass die einzige wirksame Stütze im christlich geprägten Dreibund zwischen Trapezunt, Georgien und Mesopotamien im Kampf gegen den Osmanen Mehmed II. Uzūn Hasan, der Vorsteher der Aq Quyunlu, war. ${ }^{194}$ Ğunayd erlebte diese Entwicklungen in Diyarbakr hautnah mit. Noch vor dem Abschluss des Bündnisses gegen Meḥmed II. hatte Uzūn Ḥasan im Jahr

192 Hinz, Aufstieg 41.

193 Hinz, Aufstieg $41 \mathrm{f}$.

194 Hinz, Aufstieg 43.
$145^{8}$ einen Kriegszug gegen Georgien unternommen und riesige Beute gemacht. ${ }^{195}$ Uzūn Hasan kehrte Ende $145^{8}$ nach Diyarbakr zurück, wo Šayh Ğunayd die Berichterstattungen über seinen Feldzug gierig aufnahm. Diese Berichte dürften in Ğunayd die Erinnerungen an seine eigenen Kriegszüge wachgerufen haben. Er selbst war überdies immer noch darauf bedacht, sich weltliche Macht zu sichern.

Jedenfalls verliess Ğunayd, wohl 1459, Diyarbakr in Begleitung einer bedeutenden Schar von SufiAnhängern und kehrte nach Ardabil zurück. Sein Ansehen war nach seiner Heirat mit Uzūn Hasans Tochter beträchtlich gestiegen. Sein Oheim Ğa'far und Ǧahān-Šāh, der Vorsteher der Schwarzen Horde, waren ihm allerdings nach wie vor übel gesinnt. Angesichts dieser offenen Feindschaft zog Ğunayd seine Anhänger zusammen und unternahm mit ihnen einen Glaubenskrieg ( ̌̆ihād bzw. $\left.\dot{g} a z \bar{a}^{3}\right)$ gegen die christlichen Tscherkessen. Seinem Beutezug war ebenso viel Erfolg beschieden wie jenem Uzūn Ḥasans gegen Georgien ein Jahr zuvor. Ğunayd bezog auf dem Rückweg in Karabach Winterlager. Sein Beutezug gegen Norden hatte allerdings Halīl, den Herrscher von Šìrwān, alarmiert, waren ihm die Tscherkessen doch tributpflichtig. In einem Schreiben ermutigte Šayh Ğafar darauf Halīl-Sulțān, gegen seinen Neffen Ğunayd militärisch vorzugehen. Dieser sei ein gemeiner Empörer und Aufrührer; er solle sofort aus dem Weg geschafft werden. Schliesslich kam es im Tal des Qara Șū zur Schlacht, in deren Verlauf Ğunayd von einem Pfeil tödlich verletzt wurde (4. März 146o). ${ }^{196}$

Nur einen Monat nach Ğunayds Tod brachte seine Gattin Hadī̌̆a Begūm - sie war in Diyarbakr zurückgeblieben - einen Knaben namens Ḥaydar (der Löwe) zur Welt. Dieser jüngste Spross des Safawidengeschlechts wuchs in Diyarbakr auf, bis die Aq Quyunlu den Machtkampf mit den Qara Quyunlu zu ihren Gunsten entschieden und die

\footnotetext{
195 Hinz, Aufstieg 45. Dieser Beutezug fand noch vor Abschluss des soeben erwähnten Dreibunds statt.

196 Hinz, Aufstieg $47 \mathrm{f}$.
} 
Hauptstadt ihres Reichs nach Tabriz verlegt hatten. $\mathrm{Zu}$ jener Zeit begab sich der inzwischen neunjährige Šayh Haydar nach Ardabil und übernahm die Nachfolge seines Vaters.

Mit Ğunayds Tod hatten die Machtansprüche der Safawiden einen herben Rückschlag erlitten. ${ }^{197}$ Uzūn Hasan seinerseits war Meḥmed II. schmählich unterlegen und musste 1461 einen Sonderfrieden mit den Osmanen schliessen, die ausserdem Trapezunt von Kaiser David erobert hatten. Die Georgier ihrerseits hatten überhaupt nicht in diese Auseinandersetzungen eingegriffen. Diese Entwicklungen waren für die Aq Quyunlu allerdings durchaus vorteilhaft. Uzūn Hasan war dadurch der Verpflichtungen gegenüber seinen Bündnispartnern entledigt und konnte sich letztlich mit den Osmanen leidlich arrangieren. Dies gestattete es ihm wiederum, sein Herrschaftsgebiet in Richtung Osten auszudehnen. Er tat dies in erster Linie in Kurdistan, Georgien, gegen die Mamluken und in Aserbaidschan.

Bei Uzūn Ḥasans Vorstössen nach Osten kam es zu Auseinandersetzungen mit den Qara Quyunlu. Als Ğahān-Šāh (Vorsteher der Qara Quyunlu) aus Bagdad zurückkehrte, wo er seine unbotmässigen Söhne in die Schranken gewiesen hatte, kam es $1467 \mathrm{zu}$ den entscheidenden Kämpfen zwischen Aq Quyunlu und Qara Quyunlu. Uzūn Hasan entschied sie zu seinen Gunsten. Ǧahān-Šāh starb am 11. November 1467 im Bezirk Chapakchur (türkisch: Çapakçur). ${ }^{198}$ Die Aq Quyunlu konnten ihre Macht danach Richtung Iran ausdehnen. ${ }^{199}$

Da Uzūn Hasan bereits 1470 einen Zusammenstoss mit den Osmanen voraussah, knüpfte er Kontakte zu Venedig. ${ }^{200}$ Er wollte auch direkte Verbindungen mit der venetianischen Flotte vor Zypern aufnehmen und versuchte, auf Kosten der Mamluken ans Mittelmeer vorzustossen. Da dieses Vorhaben misslang (1472-1473), bildete der Euphrat

\footnotetext{
197 Hinz, Aufstieg 5o.

198 Hinz, Aufstieg 55-57, der die Entwicklungen im Detail nachzeichnet.

199 Hinz, Aufstieg $54 \mathrm{f}$.

200 Vgl. dazu bereits oben bei Anm. 143-145.
}

auch weiterhin die Grenze zum Mamlukenreich. Nach diesen gescheiterten Expansionsbestrebungen kühlten sich Uzūn Hasans zuvor freundschaftlichen Beziehungen zu den Mamluken ab. Obwohl Uzūn Hasan 1473 eine schwere Niederlage gegen die Osmanen hatte einstecken müssen, ${ }^{201}$ fürchtete der mamlukische Sulțān Qāiit Bay weiterhin, dass der Vorsteher der Aq Quyunlu mit seinen Turkmenen die Grenzmarken seines Reichs heimsuchen könnte. Die Mamluken sahen sich dieser Gefahr erst mit Uzūn Hasans Tod (1478) entledigt.

Die in Bedrängnis geratenen Qara Quyunlu können sich nach der Niederlage gegen Uzūn Hasan zwar vorläufig in Tabriz an der Macht halten. Unter Ğahān-Šāh war die Stadt übrigens ein wichtiges Kulturzentrum. Er bzw. seine Frau Hātūn Ğān Begum errichtete hier u.a. die Blaue Moschee. ${ }^{202}$ Nach der Niederlage seines Vaters Ǧahān Šāh stellte Hasan 'Alī ein gewaltiges Heer zusammen, hatte aber bei Marand auch selbst das Nachsehen gegen die Aq Quyunlu. Hasan 'Alī hatte sich bereits zuvor an den Timuriden Abū Sa'̄ìd in Herat gewandt und ihn um Unterstützung gegen die Aq Quyunlu gebeten (Herbst 1468). ${ }^{203}$ Angesichts dieser Bedrohung verzichtete Uzūn Hasan vorerst auf die Einnahme von Tabriz.

Die winterlichen Verhältnisse und die schwierige Versorgungslage verunmöglichten es $\mathrm{Abū} \mathrm{Sa}{ }^{c} \overline{1} d$ aber, erfolgreich gegen Uzūn Hasan vorzugehen. Dieser hatte sich im milden Karabach ein komfortables Winterlager eingerichtet. Abū Sā̄ì zog in den Auseinandersetzungen jedenfalls den Kürzeren. Er wurde auf der Flucht eingeholt und vor Uzūn Hasan gebracht. Dieser wollte zwar sein Leben schonen. Allerdings hielt sich auch der Timuriden-Prinz Yādgār Muhammad im Lager der Aq Quyunlu auf. Dieser Urenkel Šāh-Ruhs verlangte Abū Sacids Kopf, war dieser doch für den Tod seiner Mutter Gawhar-Šād Begum verantwort-

\footnotetext{
201 Hinz, Aufstieg $62 \mathrm{f}$.

202 Vgl. Aube, Tabriz, X. Monuments, X.1 The Blue Mosque, in EIr. Der Bau der Blauen Moschee wurde 1465 beendet. Siehe auch Aube, La céramique.

203
} 
lich. ${ }^{204}$ Gewiss ist, dass Abū Saīd mit seinem Leben büsste und sein Kopf 1469 an den Mamlukensultan nach Kairo gesandt wurde. Uzūn Hasan konnte schliesslich auch Ḥasan 'Alī beseitigen, der nach Hamadān ausgewichen war. Mit diesem Sieg war der Widerstand der Qara Quyunlu gebrochen. Die Aq Quyunlu herrschten fortan weitgehend uneingeschränkt über Aserbaidschan und weite Teile Irans. ${ }^{205}$

Während dieser Zeit sah sich Uzūn Ḥasan auch mit den Herausforderungen durch die Osmanen konfrontiert, in die er nicht zuletzt verwickelt war, da ihn der christliche Westen in den Kampf gegen den gemeinsamen Feind eingebunden hatte. ${ }^{206}$ Während Uzūn Hasan einen ersten Zusammenstoss mit den türkischen Truppen zu seinen Gunsten hatte entscheiden können, fügte ihm die osmanische Artillerie in der Entscheidungsschlacht bei Tercan (in der Nähe von Erzincan) am 12. August 1473 eine schwere Niederlage zu. Damit endet das abendländisch-persische Bündnis in einem Fiasko.

Uzūn Hasan sah sich zu dieser Zeit überdies mit weiteren Schwierigkeiten konfrontiert. So widersetzten sich ihm seine eigenen Söhne Oğurlu Muhammad in Shiraz und Maqșūd in Bagdad (1474). Ausserdem leistete ihm sein Bruder Uways in Ruhā Widerstand (1475; eigentlich Ruhāa: Edessa). Überdies suchte die Pest sein Reich heim. Allerdings zeichnete sich Uzūn Ḥasans Staat im allgemeinen doch durch Festigkeit und Beständigkeit aus. $^{207}$

Uzūn Hasan hatte seine Hauptstadt bereits 1469 nach Tabriz verlegt. Dies hatte indirekt zu einer deutlichen Iranisierung der Aq Quyunlu geführt, wie sich dies zuvor bereits im Fall der Îlhāniden

\footnotetext{
204 Hinz, Aufstieg 6o.

205 Vgl. für die Ausdehnung von Uzūn Hasans Macht zu dieser Zeit Karte 4 in Hinz, Aufstieg.

206 Vgl. zu den Einzelheiten dieser Auseinandersetzungen Hinz, Aufstieg 62-67; auch oben bei Anm. 143-145. Die westlichen Mächte wollten Uzūn Hasans Reiterei v.a. mit der Lieferung von Feuerwaffen und Geschützen im Kampf gegen Mehmed II. unterstützen (1473). Allerdings erreichten diese Lieferungen Uzūn Hasan nicht.

hatte beobachten lassen. Unter Uzūn Ḥasans Sohn Ya'qūb (reg. 1478-149o) war das kulturelle Leben am Hof in Tabriz eindeutig persisch geprägt. Nach Uzūn Hasans Tod (1478) war es zwischen seinen Söhnen zu den in der Region üblichen Nachfolgekämpfen gekommen, aus denen Yáqūb als Sieger hervorgegangen war. Sein Bruder verlor bei einer Auseinandersetzung gegen Ya'qūb 1478 bei Marand das Leben. ${ }^{208}$

Als Uzūn Ḥasan die Qara Quyunlu unter ĞahānŠāh und die Timuriden unter Abū Sā̄id besiegt hatte, lagen die Geschicke des safawidischen „Priesterstaats“ in den Händen des noch jungen Šayh Haydar. ${ }^{209}$ Er war nach dessen Sieg über den Timuriden Abū Sa'̄ì zusammen mit Uzūn Hasan zum ersten Mal nach Ardabil gekommen. Uzūn Hasan setzte ihn dort als Nachfolger Ğunayds ein. Ğa'far, Ğunayds Onkel und Widersacher, dürfte über diese Entwicklungen nicht erbaut gewesen sein. Allerdings gelang es ihm, sich mit Uzūn Hasan zu arrangieren. Haydar wuchs darauf in Ardabil unter den scheelen Blicken seines Grossonkels Ğafar auf, genoss allerdings zugleich den Schutz des mächtigen Uzūn Hasan in Tabriz.

Nachdem die Verbreitung der Lehre der Șafawiyya nach Ğunayds gescheiterten Expansionsbemühungen ins Stocken geraten war (1460), erlebte der Orden jetzt einen neuen Aufschwung. Jedenfalls stieg die Zahl der Pilger an, die das Heiligtum in Ardabil aufsuchten. Die Anhänger der Șafawiyya stammten vornehmlich aus Rūm, und zwar v.a. aus dessen südlichen Teilen Qaramān, Tekke und Hamīd. Auch aus Syrien (Šām), Gilan und Talysch reisten zahlreiche Verehrer der Șafawiyya-Šayhs nach Ardabil. Das Ansehen der Šayhs stieg zusätzlich, als Haydar sich mit Marta, Uzūn Hasans ältester Tochter aus seiner Ehe mit Despina Hātūn, verheiratete. Aus dieser auch politisch wichtigen Verbindung gingen drei Söhne -

\footnotetext{
208 Hinz, Aufstieg $5^{8}$.

209 Hinz, Aufstieg 72-75; der Ausdruck „Priesterstaat“ stammt von W. Hinz.
} 
'Alī, Ismāîl und Ibrāhīm - hervor. Der 1487 geborene Ismāīl gründete 1501 den Safawidenstaat. ${ }^{210}$

Šayh Haydar hatte offensichtlich die Absicht, jene Ziele zu realisieren, die sein Vater Ğunayd nicht hatte erreichen können. Er hegte v.a. den Wunsch, am Šīrwān-Šāh den Tod seines Vaters zu rächen. Er begann deshalb, seine Anhänger zu bewaffnen, und beteiligte sich auch selbst an der Herstellung von Waffen. Er praktizierte ausserdem ritterliche Übungen wie Pfeilschiessen, Lanzenwerfen, Bogenspannen und Schwertfechten. ${ }^{211} \mathrm{Er}$ scheint dabei Derwischkutte und Sufimütze getragen zu haben. Haydar war ausserdem für seinen Mut und seine Tapferkeit bekannt. Diese Feststellungen legen den Schluss nahe, dass es Haydar in viel deutlicherem Umfang als seinem Vater Ğunayd gelang, aus der Ordensbruderschaft der Șafawiyya eine Kampfgemeinschaft zu formen, die auch politischen Einfluss ausüben konnte. ${ }^{212}$

Die unter Haydar eingeleitete straffere Organisation des Șafawiyya-Ordens war mit der Einführung einer Art Uniform verbunden. Die Zugehörigkeit zu einem bestimmten Derwischorden lässt sich gerade an der Kopfbedeckung ihrer Anhänger erkennen. ${ }^{213}$ Gemäss Th. Menzel ist der Derwischtracht, v.a. der Mütze, eine mystische Kraft und Bedeutung inhärent. ${ }^{214}$ Im Fall der Șafawiyya trugen die Angehörigen des Ordens einerseits die blaue Derwischkutte. ${ }^{215}$ Unter Haydar wurde überdies die traditionelle turkmenische țaqiyya durch den tāă-i haydarī ersetzt. Dieser tāă (eigentlich „Krone“) bestand aus einem roten Aufsatz mit zwölf Zwickeln (tark). Der Aufsatz ruhte auf einem Unterbau aus weissem Stoff. Die zwölf Zwickel und die rote Farbe spielen auf die Verbundenheit der Șafawiyya mit 'Alī und den elf weite-

\footnotetext{
210 Vgl. Hinz, Aufstieg 74, mit einer Zusammenstellung der Abstammung der Safawiden.

211 Hinz, Aufstieg 75.

212 Hinz, Aufstieg 76.

213 Vgl. zur Frage die Untersuchungen von Menzel, Beiträge zur Kenntnis des Derwisch-tāğ; Anetshofer, Derwischmützen; Frembgen, Kleidung und Ausrüstung.

214 Vgl. Menzel, Beiträge 178.

215 Hinz, Aufstieg 76.
}

ren schiitischen Imamen an. Ihre Namen wurden auf die zwölf Zwickel des tā̆g gestickt. Die rote Farbe hat den Anhängern der Șafawiyya auch den Namen gegeben; sie waren inskünftig als Qizilbā̌s, „die Rotköpfigen, die Rotkappen“, bekannt. ${ }^{216}$ Die Einführung dieser roten Kopfbedeckung hatte eine innere Festigung der Kampfgemeinschaft unter Haydar zur Folge. Nur die ernsthaften Anhänger der Șafawiyya trugen diesen Wechsel mit. Diese Kappe kam nach Haydars Tod (gest. 1488) zwar nahezu ausser Gebrauch. Sie gewann allerdings unter Šāh Ismācill als Kennzeichen der Anhänger der Safawiden erneut an Bedeutung. Die Venezianer sollen am Anfang des 16. Jh. roten Stoff in grossen Mengen über Aleppo an den „Sophi“ (Šāh Ismā̄îl) in Iran geliefert haben. ${ }^{217}$

Die Safawiden verdanken ihren Aufstieg massgeblich der Unterstützung durch diese Qizilbāš. Die Qizilbāš-Bewegung zeichnet sich durch ihre zugleich militärisch und religiös geprägte Organisationsform aus. Die Qizilbāš rekrutierten sich im wesentlichen unter den Turkmenenstämmen in Südost-Anatolien und Nordwest-Iran. ${ }^{218}$ Unter den Qizilbāš spielten angeblich auch die Nachkommen jener Kriegsgefangenen eine bedeutende Rolle, deren Freilassung Huwāğa 'Alī von Timur erwirkt hatte. ${ }^{219}$ Bereits Ğunayd (gest. 146o) war sich des militärischen Potentials bewusst, das den Qizilbāš inhärent war. Sie bildeten auch bei Ismāīils Machtübernahme und beim weiteren Aufstieg der Safawiden am Anfang des 16. Jh. eine wichtige Stütze der Streitkräfte. Die ȘafawiyyaŠayhs herrschten über die Qizilbāš einerseits als weltliche Vorsteher der jeweiligen Stammesverbünde. Sie vermittelten ihnen anderseits auch

\footnotetext{
216 Von türkisch qizil (rot) und $b \bar{a} s ̌$ (Kopf).

217 Damit ist Šāh Ismā̄̄l gemeint. Der Begriff „Sophi“ leitet sich vom Ausdruck șūfı her. Siehe zur Frage Hinz, Aufstieg 77 .

218 Vgl. Hinz, Aufstieg 78f.; siehe ausserdem Yildirim, Turkomans $3-5$. R. Yildirim hält fest, dass die Qizilbāš im 15. Jh. gemäss ihrer Stammeszugehörigkeit gegliedert waren. Es handelte sich bei ihnen zumeist um Turkmenen.

219 Vgl. Hinz, Aufstieg 15f., und oben Anm. 162.
} 
geistige Orientierung. Sie verloren ihren Einfluss aber im Lauf des 16. Jh. nach und nach und spielten unter Šāh 'Abbās I. (reg. 1587-1629) nur noch eine untergeordnete Rolle. ${ }^{220}$ Die Erfolge der Șafawiyya-Šayhs weckten übrigens bereits zuvor den Argwohn der weltlichen Machthaber. Sie schreckten allerdings oft davor zurück, ihren heiligmässigen Herausforderern mit offener Feindschaft zu begegnen.

Die religiösen Vorstellungen der Qizilbāš sind durch ein aus Kleinasien bekanntes folkloristisches Brauchtum geprägt, das für seine Häresien bekannt und gegenüber allerhand eklektischen Haltungen offen war. Unter den Qizilbāš lässt sich auch christliches Gedankengut feststellen. Eine wichtige Rolle spielten unter ihnen schiitische Vorstellungen, gerade auch die Mahdī-Erwartungen. Sie vertraten aber auch sozialistische und dissidente Positionen, wie sie aus dem Umfeld der Qalandariyya $^{221}$ und der Ǧalālī-Bewegung bekannt sind. Für die Kampfgemeinschaft, die sich unter Šayh Haydar herausgebildet hatte, war jedoch nicht primär die Zugehörigkeit zu einem Stamm relevant, sondern ihre innere Bindung gegenüber dem Ordensvorsteher, im konkreten Fall Šayh Haydar.

Die soeben angesprochenen Tendenzen erfahren zwar unter den Qizilbāš ihre deutlichste Ausprägung. Sie liessen sich in modifizierter Form zuvor aber bereits in der Sarbadār-Bewegung ${ }^{222}$ und der Muša ša ${ }^{223}$ feststellen. Unter den Qizilbāš selbst bildete sich ein religiös motiviertes Bedürfnis nach Erneuerung aus. Diese Sehnsucht äus-

220 Vgl. dazu Babayan, Mystics, monarchs, and messiahs 351-366. Die Qizilbāš verloren ihre Stellung im 17. Jh. an die $\dot{g} u l a \bar{m}$ aus Georgien und weitere Schichten der persischen Bevölkerung (Tādğı̌k), die jetzt zum Militärdienst herangezogen wurden.

Zur Qalandariyya vgl. Knysh, Islamic mysticism 272-274; Yazici, Kalandariyya, in $E I^{2}$.

222 Zur Sarbadār-Bewegung vgl. oben Anm. 37.

223 Zur Muša ša ${ }^{c}$ vgl. Amoretti, 12. Religion in the Timurid and Safavid periods, in $\mathrm{CHI}$ VI, 610-655; Mazzaoui, Origins 12; Luft, Musha'sha', in $E I^{2}$ : Die Dynastie der Muša šac war in der kleinen Stadt Huwayzā am Persischen Golf beheimatet. serte sich am deutlichsten in der Beziehung zwischen šayh und murìd, wie sie von den SufiBewegungen auch sonst bekannt ist. Der šayh ist grundsätzlich legitimiert, religiöse Autorität über seine murìds auszuüben. Es kommt unter diesen Voraussetzungen zu einem langsamen Übergang von einer auf Askese ausgerichteten Bewegung zu einer Ideologie, die in der Zwölferschia auf jenen Funktionen aufbaut, die die hagiographische Literatur dem Mahdī zuschreibt. Diese Entwicklung führt dazu, dass sich der šayh als Mahdī bezeichnet und sich somit als Manifestation (mazhar) Gottes auf Erden versteht.

Im Umfeld der Qizilbāš konnte sich in Anatolien ausserdem jene synkretistische Form des schiitischen Islams entwickeln, die als Alawitentum bezeichnet wird. Die Alawiten machen heute ca. 20 Prozent der Bevölkerung in der Türkei aus. Mit den Überzeugungen der Alawiten eng verwandt sind auch die in der Bektāšiyya vertretenen Auffassungen. Qizilbāš, Alawiten und Bektāšis vertreten heterodoxe Standpunkte und werden unter dem Oberbegriff $\dot{G} u l a \bar{t}$-Schia zusammengefasst. Hierhin gehören übrigens auch die Ahl-i haqq ${ }^{224}$ und die 'Alī-Ilāhīs. Die Abgrenzungen zwischen den einzelnen $\dot{G} u l a \bar{t}$-Bewegungen waren im 15. Jh. oft unklar. Derartige Gruppierungen bedienten sich zur Tarnung wiederholt unterschiedlicher Bezeichnungen und ordneten sich vordergründig in die Zwölfer-Schia ein. ${ }^{225}$

224 Ihre häretische Vorstellungen hinderten die Ahl-i Haqq aus Kurdistan nicht daran, Anschluss an die ZwölferSchia zu finden. Die Ahl-i Haqq waren in der Lage gewesen, die religiösen Vorstellungen der Qizilbāš zu kodifizieren, die in Kurdistan in Umlauf waren. Es sieht jedoch danach aus, dass die unter den Ahl-i Haqq bekannten Vorstellungen erst später und in moderner Zeit relevant geworden sind; vgl. Amoretti, 12. Religion in the Timurid and Safavid periods, in $\mathrm{CHI}$ VI, 610655, hier 632. Zu den Ahl-i Haqq siehe auch Moosa, Extremist Shiites 245-254, Kapitel 21: The Ahl-i Haqq. The role of Ali; Jalali-Moqaddam und Safvat, Ahl-i Haqq, in Encyclopaedia Islamica; Halm, Ahl-e Haqq, in EIr.

225 Vgl. auch oben vor Anm. 147 und unten Kapitel 3.1.3 bei Anm. $115^{-118 .}$ 
Im Jahr 1483 waren Šayh Haydars Kampfvorbereitungen und sonstigen Massnahmen derart weit gediehen, dass er nach dem Vorbild seines Vaters Ğunayd einen Beutezug $(\dot{g} a z \bar{a})$ gegen die christlichen Tscherkessen wagen konnte. ${ }^{226}$ Seine Anhänger konnten sich bei diesem Beutezug materiell bereichern. Haydars Erfolg liess die Zahl seiner Anhänger erneut ansteigen. Allerdings hatte der Šayh nie eigentliche Eroberungszüge geplant. Nach dem erfolgreichen tscherkessischen Abenteuer zog Haydar an der Spitze seiner Anhänger im Herbst 1483 wieder in Ardabil ein. Es bestehen Hinweise darauf, dass Haydar bereits zu diesem Zeitpunkt im Gebiet des südlichen Šĩrwān hoheitliche Rechte beanspruchte. Ḥaydar ermahnte seine Qizilbāš-Anhänger nach der Rückkehr, den Gewinn aus der Beute in erster Linie in ihre weitere Bewaffnung zu investieren. Er führte im Frühling 1487 einen weiteren Beutezug gegen die Tscherkessen an.

Haydars Erfolge und das Anschwellen seiner Anhängerschaft hatte inzwischen auch den König Ya'qūb von den Aq Quyunlu in Tabriz alarmiert. ${ }^{227}$ Er liess Haydar wissen, dass er weitere Beutezüge unterlassen und keinerlei Beziehungen mehr zu seinen halîfa in Kleinasien unterhalten solle. Ansonsten bestehe die Gefahr eines Aufstands. Ausserdem zog man in Betracht, den Šayh aus Ardabil zu verbannen. Schliesslich entschied sich Ya'qūb aber zu einem milderen Vorgehen. Er liess ihn nach Ardabil zurückkehren, nachdem er ihm den Treueid abgenommen hatte. Dort wurde wenig später sein Sohn Ismāīl geboren (17. Juli 1487), der als eigentlicher Begründer des Safawidenreichs gilt.

Im folgenden Jahr (1488) erhält Haydar sogar die Erlaubnis zu einem weiteren Raubzug gegen die Tscherkessen. ${ }^{28}$ Ya'qūb weist den Šìrwān-Šāh jedenfalls an, Haydars Truppen erneut den Durchzug nach Norden zu gestatten. Er profitierte von

226 Vgl. Hinz, Aufstieg 8of.; siehe überdies Yildirim, Turkomans $225^{-227 .}$

227 Hinz, Aufstieg 82.

228 Hinz, Aufstieg 83f. der günstigen Gelegenheit und fügte dem ŠirwānŠāh erhebliche Nachteile zu. Dies wiederum rief Ya'qūb auf den Plan, der mit Truppen gegen Ardabil vorstiess, danach mit Verstärkung die Kura überschritt und ins Reich des Šīrwān-Šāh vordrang. Am 9. Juli 1488 kam es an der Grenze zu Ṭabarserān zur Schlacht, in deren Verlauf Haydar umkam und die Safawiden eine Niederlage erlitten. ${ }^{229}$

Nach Haydars Tod befanden sich seine Frau Marta (auch ‘Ālamšāh Begum genannt) zusammen mit ihren drei Söhnen 'Alī, Ismāēil und Ibrāhīm in Ardabil, wo die Sufis 'Alī bereits zum Nachfolger Haydars bestimmt hatten. ${ }^{230}$ Sie alle werden allerdings noch im Herbst 1488 in die Provinz Fārs verschleppt und dort festgehalten. Während ihrer Gefangenschaft stirbt Ya'qūb 149 o unter nicht restlos geklärten Umständen im Alter von nur dreissig Jahren. Sein Tod markiert den Beginn des Zusammenbruchs der Herrschaft der Weissen Horde.

Die drei in Fārs festgehaltenen SafawidenPrinzen und ihre Mutter kommen im Lauf dieser Entwicklungen frei. ${ }^{231}$ Sie werden im Frühjahr 1493 von Rustam in Tabriz ehrenvoll empfangen. Zusammen mit den Anhängern des ȘafawiyyaŠayhs 'Alī kann es Rustam wagen, gegen seinen gefährlichsten Widersacher Bāysunqur vorzugehen und ihn zu schlagen. Da die Anhänger der Șafawiyya-Šayhs in diesen Auseinandersetzungen unter den Aq Quyunlu die entscheidende Rolle spielen, kann nicht erstaunen, dass die Safawiden wenig später unter Ismāīll selbst die Macht übernehmen.

Nach diesem Erfolg zog sich Rustam nach Ardabil zurück, das erneut zum Zentrum des religiösen und politischen Lebens der Șafawiyya wurde. Jedenfalls besuchten die Anhänger des Ordens die Stadt Ardabil in Scharen. Diese Entwicklung wiederum beunruhigte Rustam, der Šayh 'Alī eng überwachen liess. Es kommt auch zu kämpferischen Auseinandersetzungen zwischen Šayh 'Alī und dem Aq Quyunlu-Herrscher Rustam. Daraus

\footnotetext{
229 Hinz, Aufstieg 88f.

230 Hinz, Aufstieg 86 und gof.

231 Hinz, Aufstieg 94.
} 
geht 'Alī zwar als Sieger hervor. Er verliert allerdings sein Leben bei einem Unfall in Anschluss an die eigentlichen Kampfhandlungen. Er hatte zuvor jedoch noch seinen Bruder Ismāî̀l zu seinem Nachfolger bestimmt und ihm zu seinem Schutz sieben namentlich bekannte Anhänger zur Seite gestellt. ${ }^{232}$

Die Erlebnisse der beiden überlebenden Brüder nach 'Alīs Tod werden in einer als Anonymus Ross bekannten Quelle geschildert. ${ }^{233}$ Demnach liess Rustam durch seine Vertrauten den beiden Prinzen auch in Ardabil nachstellen. Sie wurden deshalb an unterschiedlichen Orten versteckt gehalten. Bei Folterungen konnte Marta ('Âlamšāh Begum) keine Auskunft über Ismāc̄ils Verbleib geben, da sie darüber nicht informiert war. Da Rustams Häscher weiterhin nach Ismā̄îl und seinem Bruder suchten, schaffte man sie letztlich aus der Stadt. Zusammen mit treu ergebenen Anhängern des Ordens, brachte man Ismāēill in die Gegend von Rašt. Schliesslich bot ihm der Kārgiyā Mīrzā 'Alī, der Herrscher von Lāhiǧān, im Osten Gilans Schutz an. ${ }^{234}$ Ismā̄îl erhielt dort seine Ausbildung und wuchs unter grosser Geheimhaltung auf. Rustam stellte Ismācil zwar auch im Exil in Lāhiǧān nach, konnte seiner allerdings nicht habhaft werden. Die Angelegenheit erledigte sich schliesslich, als Rustam in einer Auseinandersetzung mit seinem Vetter Gevde Ahmad und Aybeh Sulțān umkam (1497). Der Zerfall der Macht der Aq Quyunlu war danach unausweichlich. Diese Entwicklungen blieben auch Ismāîl nicht verborgen, der sich durch seine ausgesprochen frühe Reife auszeichnete. Ismāīl war kaum 13 Jahre alt, als er aus Lāhiğān auszog (hurūğ). Er war bereit, das Erbe seines Grossvaters anzutreten (Beginn von Phase III). ${ }^{235}$

\footnotetext{
232 Hinz, Aufstieg 96.

233 Hinz, Aufstieg 96 f. Zur Einordnung des Anonymus Ross siehe Yildirim, Turkomans 3o. Beachte auch Ross, The early years of Shah Ismail.

234 Hinz, Aufstieg 99.

235 Hinz, Aufstieg 10o. Zu Gevde Aḥmad vgl. Matuz, L' accession au pouvoir des Safavides; zu Gevde Ahmad: 26 (Anm. 18).
}

\subsection{Die Osmanen und Safawiden und ihre Konfrontationen im 16. Jh.}

Um 1500 zeichnet sich in der islamischen Welt eine Zäsur ab, die ähnlich markant ausfällt wie der Einfall der Mongolen im 13. Jh. Kurz vor 15 oo war der direkte Seeweg nach Indien entdeckt worden (1497-1498). Der Nahe Osten verlor damit seine Bedeutung als Scharnier zwischen dem Abendland und den weiter entfernt gelegenen Regionen im Osten (z. B. Indien, China). Diese veränderten geostrategischen Konstellationen trugen indirekt dazu bei, dass sich in der islamischen Welt nach 1500 drei mächtige Dynastien etablieren konnten:

1. Die Safawiden, deren Aufstieg soeben thematisiert wurde (1501-1722).

2. Die Osmanen, die ihre Machtansprüche in Anatolien bereits ab 1300 geltend gemacht hatten und sich am Anfang des 16. Jh. zu einer eigentlichen Grossmacht entwickelten. Sie setzten der Herrschaft der Mamluken ein Ende und wiesen die Safawiden in ihre Schranken.

3. Die Mogul-Dynastie, die sich nach 1500 auf dem Indischen Subkontinent etablierte $\left(15^{26}\right.$ 1858). ${ }^{236}$ Diese Entwicklungen in Indien betreffen uns hier aber nur am Rand. ${ }^{237}$

Zwischen den Safawiden und Osmanen kommt es im Lauf des 16. Jh. wiederholt zu heftigen Auseinandersetzungen. Sie kamen sich nicht nur wegen ihrer jeweiligen Machtansprüche entlang der gemeinsamen Grenze in Ostanatolien oder im Iraq in die Quere. Sie verfolgten vielmehr auch in Glaubensfragen unterschiedliche Agenden. Die Osmanen waren dem sunnitischen Islam verpflichtet. Die Safawiden hingegen hatten mit der Machtübernahme durch Šāh Ismāōil der Schia den Vorzug gegeben. Iran wurde zwar am Anfang des 16. Jh. nicht über Nacht zu einem durchwegs schiitischen Staatsgebilde. Die schiitische Lehre

\footnotetext{
236 Bosworth, New Islamic dynasties 331-334 (Nr. 175).

237 Wahrscheinlich sind verschiedene späte Belegstücke in Rollenform in Indien entstanden; vgl. dazu in den Beschreibungen Kapitel 7.1.
} 
kann sich hier jedoch im Lauf des 16. Jh. durchsetzen und stellt im 17. Jh. die staatstragende Ideologie dar.

Die Osmanen waren zwischen etwa 1450 und 1520 dramatisch schnell von einer eher bescheidenen, in Kleinasien angesiedelten Regionalmacht zum grössten Staatsgebilde in Vorderasien und Osteuropa aufgestiegen. ${ }^{238}$ Gerade im Westen der islamischen Welt kommt den Osmanen nach 1500 die Führungsrolle zu. Sie üben ihre militärische Macht vom Atlasgebirge in Nordafrika bis ans Kaspische Meer im Osten aus. Sie machen ihren Einfluss hier auch als Förderer einer reichen Kultur geltend.

Gemeinhin wird die Eroberung Konstantinopels unter Mehmed II. als entscheidender Moment im Aufstieg der Osmanen betrachtet (1453). Vieles spricht allerdings dafür, dass das zweite Jahrzehnt des 16. Jh. für diesen Aufstieg noch bedeutender war. Selim I. (reg. 1512-1520) ${ }^{239}$ fügte den Safawiden unter Šāh Ismā'īl ${ }^{240} 1514$ bei Čāldirān eine vernichtende Niederlage zu. ${ }^{241}$ Die Osmanen besiegten kurz darauf ausserdem die Mamluken. Nach der Schlacht von Marğ Dābiq (nördlich von Aleppo; 24. August 1516) fiel Syrien in ihre Hände. Und nach der Schlacht bei ar-Raydāniyya im Norden der Sinai-Halbinsel am 22.-23. Januar 1517 zogen die Osmanen auch in Ägypten ein. Sie zwangen ausserdem den Scherifen von Mekka, ihren Sultan als Kalifen, also als religiöses Oberhaupt der Muslime, anzuerkennen. Die Osmanen waren damit Hüter der heiligen Stätten des Islams und Beschützer des hăğğ geworden. Während die

238 Vgl. Kreiser und Neumann, Kleine Geschichte der Türkei 105-118; siehe auch Haywood, Der neue Atlas der Weltgeschichte $148 \mathrm{f}$.

239 Selim I. war der Vater Sulaymāns des Prächtigen (reg. 1520-1566).

240 Vgl. zu ihm Savory und Karamustafa, Esmācīl ı Ṣafawī, in EIr; Savory und Gandjeï, Ismācill I, in $E I^{2}$.

241 Die Schlacht selbst fand am 23. August 1514 statt; vgl. dazu Özgüdenli, Ottoman-Persian relations: I. Under Sultan Selim I and Shah Esmāil I, in EIr; McCaffrey, Čālderān, in EIr; jeweils mit leicht abweichenden Datumsangaben. Siehe ausserdem Walsh, Čāldirān, in $E I^{2}$.
Dynastie der Mamluken mit dieser zweiten Niederlage endete, konnten sich die Safawiden in Iran weiterhin an der Macht halten. Sie zogen sich aber etwas weiter nach Osten zurück.

Süleymān (reg. 1520-1566) gelang es, das Osmanische Reich in einer Reihe von Kriegen abzurunden. Er tat dies im Westen auf Kosten ÖsterreichUngarns und Venedigs und im Osten auf jene der Safawiden. Süleymān drang auch sonst weit in Richtung Europa vor. Rhodos ging $15^{22}$ an die Osmanen über, da die den dort ansässigen Johannitern zugesagte Hilfe nicht eintraf. In Europa hatte sich im Gefolge von Reformation und Gegenreformation der Kreuzzugseifer deutlich abgekühlt. Süleymān profitierte indirekt davon und besiegte die Ungarn in der Schlacht von Mohács (29. August 1526). Die Osmanen drangen danach weiter in Richtung Europa vor. Buda ergab sich am 8. September 1529. Die eigentliche Integration Ungarns ins Osmanische Reich erfolgte allerdings erst 1541. Am 27. September 1529 stand Süleymān vor den Toren Wiens. Seine anschliessende Belagerung der Stadt scheiterte eher am harschen Winterwetter und seinen langen Nachschublinien als am besonders effizienten Widerstand der Habsburger. Unter Süleymāns Herrschaft gelang es den Osmanen überdies, den wichtigen Beylik-Staat der in Elbistān (Albistān) beheimateten Dū l-Qadr in Südost-Anatolien zu liquidieren. Die Dū l-Qadr waren für ihre Aufmüpfigkeit bekannt. ${ }^{242}$

242 Vgl. Bosworth, New Islamic dynasties 238 (Nr. 129); Mordtmann und Ménage, Dhu 'l-Kadr, in $E I^{2}$. Bei den Dū l-Qadr (1337-1521) handelt es sich um eine weitere turkmenische Dynastie. Sie herrschten in der Gegend von Mar`aš und dem Hochland über der Ebene von Adana in Südostanatolien. Dieses Territorium hatte den Nachteil, zwischen den Gebieten der mächtigen Osmanen im Westen, den Mamluken im Süden und den Qara Quyunlu bzw. Aq Quyunlu im Osten eingeklemmt zu sein. Obwohl diese drei Mächte immer wieder versuchten, Elbistān, das Kernland der Dū l-Qadr, unter ihre Kontrolle zu bringen, gelang dies erst Sulțān Selīm, als er im frühen 16. Jh. gegen die Mamluken in Syrien (Fall 1516) und Ägypten (Fall 1517) in den Krieg zog. Am Anfang der Herrschaft Sulțān Süleymāns ging die Dynastie der Dū l-Qadr zu Ende. 
Die Osmanen übten ihre Macht im Norden und Nordwesten ihres Reiches ausserdem aus, indem sie eine Reihe von Vasallenstaaten installierten. So herrschte die Dynastie der Zápolya als Vasallen in Siebenbürgen (Transsilvanien). Die Osmanen etablierten weitere derartige Vasallenstaaten in der Moldau und der Walachei, auf der Krim und ausserdem im Kaukasus und in Ostanatolien. In Nordafrika banden sie die im Hinterland lebenden Stämme auf dieselbe Art in ihr Reich ein.

Im Osten verloren die Safawiden im Nachgang der Schlacht von Čāldirān (1514) Tabriz, damals ihre Hauptstadt, vorübergehend an die Osmanen. Sie verlegten ihr Zentrum gerade auch wegen der osmanischen Bedrohung weiter ostwärts, zuerst nach Qazwin und später nach Isfahan. ${ }^{243}$ Es ist bekannt, dass Selim I. in Anschluss an die Schlacht von Čăldirān ungehindert in Tabriz einmarschierte (7. September), dort aber nur eine Woche lang blieb (Abzug am 15. September). Er brachte 1000 Handwerker und Künstler aus Tabriz nach Istanbul zurück. ${ }^{244}$ Auch E. Atıl macht darauf aufmerksam, dass im Naqqā̌s-ḩāna in Istanbul im 16. Jh. zahlreiche Spezialisten aus Iran tätig waren. In Istanbul hergestellte Manuskripte lassen sich oft nicht von jenen aus Herat oder Tabriz unterscheiden. ${ }^{245}$

243 Tabriz blieb bis 1555 Hauptstadt der Safawiden (siehe Aube, Tabriz - Blue Mosque, in EIr). Šāh Țahmāsp verlegte die Hauptstadt 962/1555 nach Qazwin (siehe Lambton, Kazwīn, in $E I^{2}$ ). Unter Šāh 'Abbās wurde Isfahan Zentrum des Safawidenreichs (1005/1596-1597; vgl. Lambton, Ișfahān, in $\left.E I^{2}\right)$.

244 Minorsky und Bosworth, Tabrīz, in $E I^{2}$, halten fest, dass sich die Osmanen nach der Schlacht in Čāldirān in Tabriz der Schätze der Perser bemächtigten und tausend begabte Handwerker (skilled artisans) nach Istanbul brachten. Identische Informationen bei Özgüdenli, Ottoman-Persian relations: I. Under Sultan Selim I and Shah Esmāil I, in EIr, der auch auf ein Dokument mit den Namen der damals deportierten Spezialisten aufmerksam macht (İsmail Hakki Uzunçarşılı, Osmanlı sarayında Ehl-i Hıref (sanatkarlar) defterleri, in Belgeler 11 (1986), 23-76, hier zitiert gemäss Özgüdenli in EIr). Vgl. zu dieser Frage auch der kurze Hinweis bei Kreiser und Neumann, Kleine Geschichte der Türkei 111.

245 Atıl, Age of Sultan Süleyman 66a-b, z. B.: „The development of the local [Ottoman] style of painting [in Istanbul] was overshadowed by the influx of artisans from
Überhaupt galt Persien im 16. und 17. Jh. im Osmanischen Reich als Leitkultur. ${ }^{246}$

Diese Auseinandersetzungen zwischen Osmanen und Safawiden setzten sich danach über mehrere Jahrzehnte fort. Dabei standen sich nicht mehr Selīm I. und Šāh Ismā̄īl gegenüber. Vielmehr übten jetzt ihre beiden Söhne Süleymān (reg. 1520-1566) ${ }^{247}$ auf osmanischer Seite und Šāh Ṭahmāsp (reg. 1524-1576) ${ }^{248}$ auf safawidischer Seite die Macht aus. Süleymān griff wiederholt selbst in die Kämpfe ein. ${ }^{249}$

Auf Anraten des abtrünnigen Ulāma aus dem turkmenischen Stamm der Tekke besetzten Süleymāns Truppen unter dem Befehl des Gross-Wesirs Ibrāhīm Pāšā Tabriz am 13. Juli 941/1534. ${ }^{250}$ Die Osmanen übertrugen die Macht über Aserbaidschan in Anschluss daran Ulāma, der diese Stellung bereits unter Šāh Ṭahmāsp innegehabt hatte. Am 27. September 1534 erreichte Süleymān selbst Tabriz. Er unternahm einen Vorstoss bis nach Sulțāniyya und besetzte Bagdad. Auf dem Rückweg verbrachte er vierzehn Tage in Tabriz und kümmerte sich um Verwaltungsangelegenheiten. Die Kälte zwang die Türken allerdings zum Rückzug. Die Safawiden rückten darauf bis nach Van vor. Im Jahr 955/28. Juli 1548 besetzte Sulțān Süleymān Tabriz erneut, doch blieb er selbst nur fünf Tage in der Stadt. Nachschubprobleme und die schwierige

Herat and Tabriz, who arrived in the nakkaşhane in 1514 as a result of the eastern campaigns of Selim I and were immediately put to work." Mit Präzisierungen danach.

246 Atıl, op. cit. 66a-b, macht darauf aufmerksam, dass im Zusammenhang mit dem Aufstieg der Safawiden verschiedene abgesetzte Herrscher aus Iran bei den Osmanen Zuflucht suchten. Sie seien mit ihrem Gefolge und ihren Schätzen nach Istanbul gekommen. Darunter hätten sich auch wertvolle Manuskripte befunden. Erwähnt wird Alwand, der letzte Sulțān der Aq Quyunlu, und Badī‘ az-Zamān, der letzte TimuridenSultan, der nach Tabriz flüchtete, als die Usbeken 1507 Herat eroberten.

247 Vgl. Veinstein, Süleymān, in $E I^{2}$.

248 Vgl. Mitchell, Ṭahmāsp I, in EIr.

249 Diese Angaben gemäss Minorsky und Bosworth, Tabrīz, in $E I^{2}$.

250 Diese Angaben stützen sich auf Minorsky und Bosworth, Tabrīz, in $E I^{2}$. 
Trinkwassersituation vor Ort zwangen die Osmanen zum raschen Rückzug. ${ }^{251}$

Süleymān konnte einen wichtigen militärischen und politischen Erfolg verbuchen, als es ihm 1555 gelang, mit den Safawiden den Frieden von Amasya zu schliessen. ${ }^{252}$ Dieser Vertrag legte die Grenze zwischen dem Osmanischen Reich und den Safawiden entlang jener Linien fest, die bis heute mehr oder weniger Bestand haben. Das Gebiet der turksprachigen Provinzen wurde den Safawiden zugewiesen und war deshalb fortan schiitisch geprägt. Mesopotamien mit einem von alters her bedeutenden Anteil an Schiiten und den Schreinstätten der Imame wurde aber dem Osmanischen Reich zugeschlagen.

Die Osmanen und Safawiden führten ihre Auseinandersetzungen auch besonders intensiv, da zahlreiche Anhänger des Derwischordens der Șafawiyya und danach der jungen Dynastie der Safawiden aus Ostanatolien stammten. Wie erinnerlich waren die Safawiden unter Šāh Ismāīil durch die tatkräftige Unterstützung der Qizilbāš an die Macht gekommen. Diese Qizilbāš brachten gerade auch Ismāīil selbst göttliche Verehrung entgegen und waren in ihrem Glaubenseifer und Fanatismus bereit, sich mit entblösster Brust für ihren Šayh ins Schlachtgetümmel zu stürzen. Die Qizilbāš rekrutierten sich hauptsächlich aus den Turkmenenstämmen und lebten genauso in Persien wie in Aserbaidschan, Ost- und Zentralanatolien.

Zahlreiche Qizilbāš hatten sich Šāh Ismā̄̄l direkt angeschlossen. Andere waren in Ostanatolien geblieben, das im Lauf des 16. Jh. zunehmend unter osmanische Kontrolle geriet. Sie suchten aber das Heiligtum in Ardabil im Rahmen von

251 Eine spezielle Episode in diesen Auseinandersetzungen, nämlich die Revolte des Alqās Mīrzā, könnte für die Kontextualisierung von св 542, Fondation M. Bodmer, Cologny-Genève, eine Rolle spielen. Die Einzelheiten werden bei der Beschreibung von СВ 542 im Rahmen eines Exkurses vorgestellt (vgl. Kapitel 5.2, bei Anm. 18o-202).

252 Vgl. Kreiser und Neumann, Kleine Geschichte der Türkei 115. Zusätzliche Hinweise zum Frieden von Amasya bei Köhbach, Amasya, Peace of, in EIr.
Pilgerfahrten auf und verehrten dort ihren Šayh. Sie wurden in Ardabil auch in der Lehre der Șafawiyya unterwiesen. Ausserdem reisten zahlreiche halîfas Šāh Ismācīls durch Ostanatolien und sorgten dafür, dass die dortigen Anhänger eng mit den Vorstehern des Ordens in Ardabil verbunden blieben. Diese halïfas kümmerten sich auch um die weitere Verbreitung der safawidischen und damit schiitisch ausgerichteten Lehre.

Die Osmanen verfolgten diese Aktivitäten mit Argwohn. Die Safawiden sorgten auch für Unruhe, indem sie jene in Ostanatolien so oder so vorhandenen Spannungen anheizten, die ihren Hintergrund in den im Osmanischen Reich in Gang gekommenen sozio-politischen Veränderungen hatten. Das Osmanische Reich entwickelte sich zunehmend zu einem straff organisierten Staat mit einer urbanen Elite. Diese Transformationsprozesse gingen mit der Entmachtung der türkischen Stämme einher. ${ }^{253}$ Bāyazīd II. (reg. 14811512) schien eine offene Konfrontation mit den Safawiden noch vermieden zu haben. Diese $\mathrm{Zu}$ rückhaltung erwies sich aber spätestens von jenem Zeitpunkt an als verfehlt, da die Qizilbāš mit offenem Widerstand auf die staatliche Unterdrückung durch die Osmanen reagierten. Die Safawiden nutzten diese Spannungen ihrerseits aus, indem sie die Aufstände Šāhkulus (bzw. Šāhqulı̌s) in der Gegend von Antalya (1511) und Šayh Celāls (1519) unterstützten. ${ }^{254}$

Mit der Machtübernahme durch Selim I. (reg. 1512-1520) änderte sich die tolerante Haltung der Osmanen gegenüber den Turkmenen im Osten ihres Reichs grundlegend. Selim I. ging bereits am Anfang seiner Herrschaft gegen die aus sunnitischer Perspektive häretischen Anhänger der Safawiden auf osmanischem Territorium vor und verfolgte sie unerbittlich. Verschiedene Quellen hal-

\footnotetext{
253 Vgl. zu diesem Konflikt Yildirim, Turkomans.

254 Ausführlicher zum Aufstand Šāhqulǐs siehe Sohrweide, Safaviden 145-164 (6. Der Aufstand Šāhqulǐs, 1511-1512). $\mathrm{Zu}$ den weiteren Aufständen in Anatolien im 16. Jh. siehe ebenda, 164-186 (7. Weitere Aufstände in Zentralund Südanatolien in der ersten Hälfte des 16. Jh., unter anderem a. Der Ǧelālī-Aufstand, 1519-1520).
} 
ten fest, dass diese Verfolgungen unter den Qizilbāš 40'ooo Todesopfer forderten. Im einzelnen lässt sich dies allerdings nicht beweisen. Es ist aber gewiss, dass sich die Qizilbāš wegen dieser Verfolgungen durch die Osmanen im 16. Jh. zunehmend in entlegenere Gebiete in Anatolien zurückzogen.

Für die Auseinandersetzungen mit den Dokumenten in Rollenform relevant ist, dass es im Rahmen der Verfolgungen der Qizilbāš im Osmanischen Reich wiederholt zu Deportationen von Anhängern Šāh Ismāīlls bzw. der Șafawiyya aus dem Umfeld der Qizilbāš nach Rumelien kam (der in Europa gelegene Teil des Osmanischen Reichs, v.a. auf dem Balkan). H. Sohrweide hält fest, dass die Qizilbāš im Osmanischen Reich im 16. Jh. - gerade unter Selim I. (reg. 15121520), aber auch später - heftig verfolgt wurden. Ihre halîfas, also die Sendboten der Safawiden, seien zumeist hingerichtet worden. Da man aber davor zurückschreckte, ein allgemeines Blutbad anzurichten, habe man die breiten Massen ins Exil verbannt. Die Verbannten seien oft nach Zypern geschickt worden. ${ }^{255}$ Auch die Peleponnes ist als Ziel dieser Deportationen bekannt. ${ }^{256}$ Wieder andere Angehörige der Qizilbāš wurden nach Ungarn verschleppt. ${ }^{257}$ Auch C.H. Imber unter-

255 Sohrweide, Safaviden 127 und 141f., macht darauf aufmerksam, dass die Machtübernahme durch Šāh Ismācîl (1501), das auf osmanischer Seite bereits feststellbare Unbehagen über die Qizilbāš-Bewegung in Anatolien verstärkt habe. Man habe deshalb alle Einwohner mit Sympathien für die Qizilbāš im Gesicht gezeichnet und zwangsweise in die europäische Türkei, v.a. nach Modoni und Koroni auf Morea (Peleponnes) in Griechenland, umgesiedelt.

$256 \mathrm{Zu}$ Zypern als Bestimmungsort für die Verbannten: Sohrweide, Șafaviden 193. Imber, Persecution 257, hält fest: „[In 1577 the Ottoman] government was determined to be rid of them [the kızılbaş] decreeing that they should be executed, but those whose crimes could not be 'proven according to the sharī $a$ ', should suffer exile to Cyprus." Siehe auch 259; 268: Exil in Hisinkeyf.

Sohrweide, op. cit. 192, zitiert aus einem Befehl an den Beglerbeg von Rūm vom August 1565. Demnach solle man jene Personen hinrichten, die mit Votivgaben auf dem Weg nach Persien abgefangen worden seien. Ihre Familien und Verwandten aber seien nach Ungarn zu streicht die Bedeutung von Verbannungen nach Zypern und nach Ungarn im Rahmen der QizilbāšVerfolgungen. ${ }^{258}$

Diese Verbannungen erklären auch, dass sich die unter den Qizilbāš verbreiteten religiösen Auffassungen später in Bulgarien, Thrakien oder Rumänien nachweisen lassen, wie I. Mélikoff aufzeigte. ${ }^{259}$ Die genauen Umstände dieser Deportationen sind allerdings bis heute schlecht erforscht. Es ist jedoch unbestritten, dass es zu derartigen Zwangsumsiedlungen gekommen ist. Dies findet indirekt ein Echo auf gewissen im 16. und 17. Jh. im Osmanischen Reich angefertigten Belegstücken in Rollenform. Darauf lassen sich Elemente feststellen, die sich nur vor dem Hintergrund von Auffassungen erklären lassen, die in heterodox orientierten Gruppierungen wie jener der Qizilbāš gepflegt wurden.

\subsection{Zur Position der Schia in Iran im 16. Jh.}

Šāh Ismāc̄il vereinigte in seiner Person die Qualitäten eines geistigen Vorstehers, eines militärischen Befehlshabers und eines Reformers, der auch den wirtschaftlichen Bedürfnissen seiner Anhänger Aufmerksamkeit schenkte. ${ }^{260}$ Er setzte die grundlegenden Vorstellungen der Qizilbāš und anderer häretisch orientierter Gruppierungen aus jener Zeit in die Tat um, wie sich anhand von Sanutos Diarii aufzeigen lässt. Die Qizilbāš bringen ihrem dede, ihrem Vorsteher, ganz besondere Verehrung entgegen. Die Person des dede ist ihnen heilig. Auch alles, was der dede berührt hat, wird heilig. Der Staub des Weges, auf dem er oder sein Ross gekommen ist, hat heiligen Charakter. Ebenso der Staub auf seinem Grab.

verbannen. Vgl. zu Verbannungen von Qizilbāš nach Ungarn auch Imber, Persecution 254.

258 Imber, Persecution 272.

259 Vgl. Mélikoff, Hadji Bektach: Un mythe et ses avatars 53 106, 141, 148f., 209.

26o Die Ausführungen in diesem Abschnitt (2.6) stützen sich auf Amoretti, 12. Religion in the Timurid and Safavid Periods, in $C H I$ VI, 634-643. 
Šāh Ismāc̄il war grundsätzlich ein Sufi. Er nahm allerdings Funktionen wahr, die deutlich über die traditionelle Rolle eines Sufi-Šayhs hinausgingen. Er verstand sich als Vermittler zwischen den Menschen und Gott, wobei er eine grössere Nähe zu Gott empfand als zu den Menschen, mit denen er direkten Umgang hatte. Insofern war er die lang ersehnte Führer- und Erlösergestalt. Seine beeindruckenden militärischen Erfolge galten als Beweis für seine übermenschlichen Fähigkeiten. Wie andere messianische Gestalten aus seiner Zeit verfolgte auch Šāh Ismā̄̄il das Ziel, einen Staat aufzubauen, in dem er seine religiöse Ideologie realisieren konnte. Nachdem er an die Macht gekommen war, ging allerdings auch Šāh Ismā̄̄il politische Kompromisse ein und stellte seine religiösen Überzeugungen teilweise hintan.

Ismāîl vertrat in mehrfacher Hinsicht häretische Positionen. Eridentifizierte sich selbst mit 'Alī oder Allāh. Ausserdem setzte er sich über šarīarechtliche Bestimmungen hinweg. Es ist bekannt, dass er Wein in grossen Mengen genoss. Dies trifft gerade auf die Zeit nach seiner Niederlage in Čăldirān zu. Er schenkte einerseits individuell geprägten religiösen Erfahrungen grosse Aufmerksamkeit. Anderseits versuchte er, diese individuellen Erlebnisse zugunsten des Gemeinwohls allgemein zugänglich zu machen. B.S. Amoretti versteht Ismā̄ill als typischen islamischen condottiere, als wahren Kalifen. Er verkörperte auf vollkommene Art jene Ideale, die im Lauf der islamischen Geschichte 'Alī b. Abī Ṭālib zugeschrieben worden waren.

Westliche Quellen aus dem 16. Jh. erkennen in Ismāīil einen neuen Propheten, der sich in der Rolle eines Mahdī sah und eine reformerische Agenda verfolgte. Seine Anhänger zeichneten sich durch ihren Fanatismus aus und brachten Ismā̄̄l militärisch-religiöse Verehrung entgegen. Diese westlichen Quellen beschreiben Ismācīl ausserdem als Freund der Christen. Sie unterscheiden ihn deutlich von den Osmanen, die mit dem christlichen Europa seit längerem in feindliche Auseinandersetzungen verwickelt waren.
Der Übergang Irans von der Sunna zur Schia fand nicht von einem Tag auf den andern statt. Er war vielmehr das Resultat eines längeren Prozesses im Lauf des 16. und teilweise des 17. Jh. Als sich Šāh Ismāc̄il 1501 in Tabriz zum Šāh krönte, war der Ort, wie die meisten andern städtischen Zentren Irans, sunnitisch geprägt. Die neuen Machthaber dürften auf der religiösen Ebene auch keine drastischen Massnahmen eingeleitet haben. Tabriz dürfte sich vielmehr nach und nach vom Šāfi'ismus zu einer strikteren Form des Ğafarismus, also zu schiitischen Positionen, entwickelt haben. Auch als Selim I. nach seinem Sieg in Čāldirān 1514 in Tabriz einmarschierte, muss ihm die Stadt noch einen klar sunnitischen Eindruck gemacht haben. Jedenfalls traf Selim I. keinerlei Massnahmen, um die Position der Sunniten zu stützen. Da er unmittelbar zuvor angeblich 40'0oo Qizilbāš aus Anatolien hatte umbringen lassen, ist dies doch ein deutlicher Hinweis, dass Tabriz im Jahr 1514 noch weitgehend sunnitisch war. Die Entwicklungen in Tabriz während der nächsten zwanzig Jahre sind historisch nicht hinreichend dokumentiert.

Als Sultān Süleymān allerdings 1534 in Tabriz einzog, scheint sich die Situation grundlegend verändert zu haben. Die Stadt war inzwischen schiitisch geworden. Aus venetianischen Quellen geht hervor, dass zahlreiche Janitscharen von den Osmanen zu den Safawiden übergelaufen waren. Auch lehnten sich die breiten Massen in der Stadt gegen die Osmanen auf und lobpriesen den Safawiden Šāh Ṭahmāsp als Befreier. Dieses Verhalten der Bevölkerung unterstreicht, dass die Stadt inzwischen eindeutig schiitisch ausgerichtet war.

Šāh Ṭahmāsp stand am Anfang seiner Herrschaft klar unter dem Einfluss der Qizilbāš. Es lässt sich allerdings feststellen, dass die Qizilbāš ihre angesehene Stellung gerade unter ihm zunehmend einbüssten. Als die Qizilbāš noch geachtet und verehrt wurden, wurden den Sufis bedeutende Zugeständnisse gemacht. Ein Bissen ihrer Nahrung verlieh Fürsprache (šafāa $a$ ) bei Gott. Die Qizilbāš werden mit der Zeit jedoch nur noch für niedrige 
Dienste eingesetzt. ${ }^{261}$ Ihr Abstieg erklärt sich mit dem Druck von Seiten jener Theologen, die in Iran den Positionen einer traditionalistisch orientierten Zwölfer-Schia zum Durchbruch verhelfen wollten. Diese Religionsgelehrten kritisierten die häretischen Auffassungen der Qizilbāš und waren darauf bedacht, sie zurückzudrängen. ${ }^{262}$ Ismācīl selbst verliert im Lauf dieser Entwicklungen jene Vorrechte, die ihm die Qizilbāš zugeschrieben hatten. Unter dem Einfluss der Religionsgelehrten kommen diese Vorrechte wieder ausschliesslich den schiitischen Imamen zu.

Die Safawiden hatten an der Verehrung der zwölf Imame insofern noch Anteil, als sie jetzt als Nachkommen der Ahl al-bayt betrachtet wurden. Sie galten als sayyids und gingen über die Linie Husayns auf den Propheten zurück. Die ersten Kontakte zwischen Šāh Ṭahmāsp und den schiitischen Religionsgelehrten scheinen in den 153oerJahren in Uskūya in der Nähe von Tabriz stattgefunden zu haben, wie sich Iskandar Munšīs Berichten entnehmen lässt. ${ }^{263}$ Allerdings strömten auch weiterhin zahlreiche Qizilbāš aus Anatolien nach Iran. Es lässt sich belegen, dass allein in Qazwin zehntausend neue Zuwanderer lebten, als Tahmāsp starb (1576). Offensichtlich hatte Ismāōils Niederlage doch nicht dazu geführt, dass sich die Qizilbāš in Scharen von den Safawiden abgewandt hätten. ${ }^{264}$

Es scheint allerdings, dass Tahmāsps Bemühungen, in Iran das schiitische Bekenntnis durchzusetzen, nicht allseits auf Gegenliebe gestossen waren. Jedenfalls warf man ihm eine allzu kle-

261 Vgl. dazu Babayan, Mystics, monarchs, and messiahs 36o-365, 375-387; siehe auch ihr Index s.v. „Qizilbash, waning of", 568 .

262 Unter den anatolischen Qizilbāš liessen sich Sühnezeremonien beobachten, wie sie auch aus der Bektāšiyya bekannt sind. Bei diesen Zeremonien werden die Sufis mit einem Stock geschlagen. Vgl. dazu Morton, The Chūb-i tarīq and Qizilbāsh ritual in Safavid Persia. Siehe auch Babayan, Mystics, monarchs, and messiahs 232-233.

263 Amoretti, 12. Religion in the Timurid and Safavid Periods, in $\mathrm{CHI}$ VI, 642 .

264 Vgl. Quellenverweis bei Amoretti, op. cit., 642 (Anm. 3). rikale und v.a. frömmlerische Haltung vor. Auch hatte sein Nachfolger Ismācil II. (reg. 1576-1577) ernsthafte Anstrengungen unternommen, in Iran wieder sunnitische Auffassungen einzuführen. Die Schia hatte sich allerdings gerade in den Städten rasch durchsetzen können. Dort hatten die alteingesessenen Eliten längstens verstanden, dass es zur Wahrung ihrer eigenen Interessen klüger war, die Auffassungen der jeweiligen weltlichen Machthaber möglichst rasch zu übernehmen. Auf dem Land hingegen gewann die Schia nur mit Verzögerung an Bedeutung.

Ismāîl II. versuchte, eine Rückkehr zum Sunnismus und die Durchsetzung šarĩ $a$-rechtlicher Bestimmungen auch als Lösung der anstehenden wirtschaftlichen Probleme darzustellen. Seine Anstrengungen zielten darauf ab, die Machtstellung der schiitischen 'ulama $\bar{a}$ ' zu untergraben und ein neues Gleichgewicht zwischen der iranischen Aristokratie und den Qizilbāš herzustellen. Aufgrund der Rivalitäten zwischen der Aristokratie und den Qizilbāš waren beide Kreise bereit, Ismā̄̄īls Position zu stützen. Ismācils II. Haltung dürfte dabei v.a. antiklerikal motiviert gewesen sein. Nur wenig später schien Muhammad Hudābanda (reg. 1578-1587) die Schia in Iran wieder gestärkt zu haben. Und unter 'Abbās I. war Iran unübersehbar zu einem primär schiitischen Staat geworden. ${ }^{265}$

\subsection{Die Entwicklungen im Osmanischen Reich im 17. Jh. bis zum Entsatz von Wien (1683)}

Die Ausführungen in diesem Kapitel sind zwar in erster Linie historisch orientiert. Dennoch ist an dieser Stelle auch auf ausgewählte Aspekte der religiösen Entwicklungen hinzuweisen. Im frühmodernen Osmanischen Reich lässt sich die klare Tendenz feststellen, den Islam neu zu fassen und staatlich zu reglementieren. Im Gegensatz zum schiitischen Iran war der Islam im Osmanischen Reich sunnitisch ausgerichtet. Zugleich ist allerdings zu

265 Amoretti, op. cit. 643 . 
erwähnen, dass im Osmanischen Reich allenthalben unterschiedliche Derwischorden aktiv waren, die zwar nicht grundsätzlich schiitisch waren, sich von der Schia aber weniger stark abgrenzten als die traditionalistische Sunna. ${ }^{266}$

Die meisten Städter, aber auch zahlreiche Bewohner auf dem Land, fühlten sich einem der verschiedenen Orden verbunden und waren in der einen oder andern Form im Rahmen einer Initiation in eine solche Gemeinschaft aufgenommen worden. Der Derwischkonvent $(t e k k e$, vgl. persisch: hāanaqāh) spielte eine bedeutende Rolle auch für jene Angehörigen eines Ordens, die nicht selbst dort lebten. Konvente wichtiger Scheichs konnten bedeutende Dimensionen annehmen und das Stadtbild prägen.

In den gesellschaftlichen Debatten war heftig umstritten, inwiefern die einzelnen Orden noch als sunnitisch-rechtgläubig angesehen werden konnten. So wurde das Abhalten von Sama $\bar{a}^{c}$ Veranstaltungen ${ }^{267}$, wie sie auch in der Halwatiyya gepflegt wurden, ungern gesehen. Ebenso schwer hatten es pantheistische Spekulationen, wie sie bereits von Ibn 'Arabī (gest. 1240) angestellt worden sind, sich später aber auch in der gerade in Bosnien aktiven Malāmiyya beobachten liessen. Derartige Praktiken wiesen oft heterodoxe Elemente auf und wurden nur geduldet, wenn sie nicht gerade in aller Öffentlichkeit stattfanden. ${ }^{268}$ Die bereits erwähnten Qizilbāš und die aus ihnen hervorgegangenen Alawiten überlebten im Osmanischen Reich v.a. in ländlichen Regionen. Dieselben Feststellungen gelten in Bezug auf die Drusen oder Jesiden, die sich in Berggegenden zurückgezogen hatten und dort ihre religiösen Auffassungen praktizierten. ${ }^{269}$

Nach dem Ende der blutigen Qizilbāš-Verfolgungen im Rahmen der Auseinandersetzungen mit den Safawiden lassen sich im Osmanischen Reich aber auch Bestrebungen feststellen, jene

266 Vgl. Kreiser und Neumann, Kleine Geschichte der Türkei 147-149.

267 Zur Praxis des sama $\bar{a}^{c}$ vgl. unten Kapitel 3.4.2.

268 Vgl. Kreiser und Neumann, op. cit. $148 \mathrm{f}$.

269 Loc. cit. $148 \mathrm{f}$.
Auffassungen institutionell zu integrieren, die mit einem traditionalistisch orientierten Islam nur noch schwer in Vereinbarung zu bringen waren. Als Auffangbecken für diese heterodoxen Strömungen diente wiederholt der Derwischorden der Bektāšiyya. ${ }^{270}$ In diesem Orden fanden u. a. die verfolgten Anhänger der Ḥurūfiyya Schutz und Aufnahme. ${ }^{271}$ Die Bektāšiyya ist im vorliegenden Kontext ausserdem von Bedeutung, da sie enge Beziehungen zu den Janitscharen, den osmanischen Elitetruppen, unterhielt. Die Janitscharen betrachteten Ḥāğğği Bektāš als ihren Schutzpatron. Auf diese Zusammenhänge ist im nächsten Kapitel ausführlicher zurückzukommen. ${ }^{272}$

Vorerst stehen aber die grossen Linien der historischen Entwicklungen im Vordergrund, insofern sie für die Auseinandersetzungen mit den hier untersuchten Dokumenten in Rollenform relevant sind: ${ }^{273}$ Trotz verschiedener Rückschläge (z. B. Niederlage in der Seeschlacht von Lepanto gegen die Heilige Liga, 1571) stellte das Osmanische Reich im 17. Jh. weiterhin eine wichtige Grossmacht dar. ${ }^{274}$ Es war fest etabliert und erwies sich als krisenresistent.

$\mathrm{Zu}$ den Krisen und Herausforderungen, mit denen sich das Osmanische Reich konfrontiert sah,

270 Zur Bektāšiyya vgl. Kapitel 3.1.3

271 Zur Hurūfiyya vgl. auch Kapitel 3.1.3 bei Anm. 132-135. Begründer der Ḥurūfiyya ist Faḍlallāh Astarābādī (gest. 796/1394). Er entwickelte eine antinomistische Lehre, die das Missfallen Timurs erregte und ihn das Leben kostete. Seine Lehre weist den Buchstaben (hurūf) des persisch-arabischen Alphabets eine bedeutende Rolle zu. Astarābādī stellte auch den Versuch an, diese Buchstaben mit dem menschlichen Körper in Beziehung zu setzen. Zur Ḥurūfiyya vgl. Algar, Horufism, in EIr; ders., Astarābādī, Fażlallāh, in EIr; Bashir, Fazlallah Astarabadi; Mir-Kasimov, Words of power.

Vgl. dazu unten Kapitel 3.1.3, bei Anm. 124-13o.

Die folgende Darstellung stützt sich auf Kreiser und Neumann, op. cit. 187-241, hauptsächlich 187-191.

274 Die christlichen Mittelmeermächte hatten sich zur Heiligen Liga zusammengeschlossen, um gegen die Osmanen vorzugehen. In diesem Bündnis spielten Spanien und die Republik Venedig eine bedeutende Rolle. Die Heilige Liga errang 1571 am Eingang zum Golf von Patras den eher überraschenden, aber wichtigen Sieg gegen die Flotte der Osmanen. 
zählten u.a. die sogenannten Celālī-Aufstände. Sie sorgten gerade im ländlichen Anatolien ab dem Ende des 16. und bis in die Mitte des 17. Jh. wiederholt für Unsicherheit. Sie hatten ihre Ursache im grundlegenden Konflikt zwischen Untertanen (reāyā) und den steuerbefreiten Angehörigen der Eliten (askerī). Zur Verschärfung dieses Gegensatzes trug bei, dass das Osmanische Heer inzwischen deutlich weniger Kriegsbeute machte. Auch wirkte sich die durch die Entdeckung des direkten Seewegs nach Indien und Amerika veränderte Ausgangslage negativ auf den Handel im Osmanischen Reich aus. Dies führte zu einem Rückgang der entsprechenden Einnahmen. Die früher wichtigen Verbindungen durch das Mittelmeer hatten für Europa an Bedeutung verloren. Ausserdem gelangte aus Südamerika viel Silber in die Alte Welt. Dies führte nicht nur im christlichen Europa, sondern auch im Osmanischen Reich zu einer deutlichen Entwertung der jeweiligen Silberwährungen. Dies machte sich im Osmanischen Reich ab dem Ende des 16. Jh. mit leichter Verzögerung gegenüber dem christlichen Westen bemerkbar. $^{275}$

Das Osmanische Reich führte im 17. Jh. weiterhin zahlreiche Kriege gegen seine verschiedenen Kontrahenten. Diese Auseinandersetzungen dauerten jetzt länger als zuvor und waren deutlich kostspieliger. Die grundlegenden fiskalischen Probleme des Osmanischen Reichs verschärften sich in der zweiten Hälfte des 17 . Jh. Die finanzielle Belastung durch den Unterhalt eines stehenden Heeres hatte dramatische Dimensionen angenommen. ${ }^{276}$ Die Janitscharen, sie stellten lange die türkischen Elitetruppen, waren aufgrund ihrer grossen Macht in der Lage, ihre Ansprüche auch gewaltsam durchzusetzen. Sie erwarteten bei Thronwechseln vom neuen Machthaber hohe Zuschüsse zu ihrem Sold. Dies führte 1622, 1623 und 1640 zu ernsthaften Währungskrisen, musste die Verwaltung doch binnen kurzer Zeit beträchtliche Geldsummen zur Verfügung stellen. Es war jeden-

275 Vgl. Kreiser und Neumann, op. cit. 194.

276 Vgl. loc. cit. 199. falls mit hohen politischen Risiken verbunden, ausgerechnet die am besten ausgerüsteten Teile der osmanischen Streitkräfte nicht angemessen zu besolden. Trotz ihrer grossen Macht sahen sich die Janitscharen aber zunehmend gezwungen, einem zusätzlichen Broterwerb nachzugehen. Sie gingen dabei oft enge Verbindungen mit den in Zünften organisierten Handwerkern in den Städten ein. ${ }^{277}$

Die Zeit des grössten Einflusses der Janitscharen auf die osmanische Politik endet mit der Ermordung von Kösem Māhpeyker Sulțān im Jahr 1651. Diese Frau war die Mutter der drei Sultane Murād IV. (reg. 1623-1640), Ibrāhīm (reg. 1640-1648) bzw. Grossmutter Mehmeds IV. (reg. 1648-1687). Allerdings stellten die Janitscharen im Osmanischen Reich auch danach einen bedeutenden Machtfaktor dar und entwickelten sich zunehmend zu einer Landplage. Erst Sulțān Maḥmūd II. (reg. 18o8-1839) gelang es 1826, das JanitscharenKorps aufzulösen. Er ging dabei mit äusserster Brutalität vor. ${ }^{278}$

Am Anfang des 17. Jh. hatten sich die beiden Mächte Habsburg-Österreich und die Osmanen weitgehend miteinander arrangiert. Sie hatten jedenfalls 1606 den Frieden von Zsitvatorok geschlossen und sich gegenseitig als gleichwertige Mächte anerkannt. Dieser Friede endete, als die Osmanen 1663 das etwa $100 \mathrm{~km}$ östlich von Wien gelegene Nové Zamky einnahmen. ${ }^{279}$ Die österreichische Armee unter Montecuccoli konnte den Osmanen allerdings wenig später bei Szentgotthárd eine Niederlage zufügen. Den osmanischen Diplomaten gelang es bei den anschliessenden Verhandlungen aber dennoch, Nové Zamky zu halten.

Die Beziehungen zwischen Habsburg-Österreich und dem Osmanischen Reich nahmen eine dramatische Wende, als die Osmanen unter Qara Muștafā 1683 nach 1529 zum zweiten Mal vor

277 Yi, Guild dynamics. Zu den Beziehungen zwischen den Janitscharen und den Zünften siehe auch Kafadar, Yeniçeri-Esnaf relations u. a. $101 \mathrm{f}$.

278 Vgl. dazu Kapitel 3.1.3 nach Anm. 129.

279 Vgl. Kreiser und Neumann, op. cit. 212. 
Wien aufkreuzten und die Stadt belagerten. ${ }^{280}$ Der Angriff der Osmanen auf Wien war primär durch ihre Machtansprüche in Ungarn motiviert. Das osmanische Heer belagerte die Stadt zwischen dem 13. Juli und 11. September während nahezu zweier Monaten. Es ist auch sehr wahrscheinlich, dass Wien in die Hände der Osmanen gefallen wäre, wäre nicht ein bedeutendes Entsatzheer der Stadt zu Hilfe geeilt. Es bestand neben habsburgischen Streitkräften aus Kontingenten, die von den deutschen Fürsten unter der Führung des polnischen Königs Jan III. Sobieski zur Verfügung gestellt worden waren. Diese Streitkräfte fügten den Osmanen in der Schlacht am Kahlenberg am 12. September 1683 eine vernichtende Niederlage bei.

Diese Niederlage hatte für die unterlegenen Osmanen schwerwiegende politische und militärische Konsequenzen und veränderte die Beziehungen mit dem christlichen Europa grundlegend. Meḥmed IV. machte Qara Mușțafā aus der Familie der Köprülü für die Niederlage verantwortlich und liess ihn schliesslich hinrichten. Er konnte so auch den Einfluss der inzwischen allzu mächtigen Familie der Köprülü zurückbinden. In Istanbul selbst kam es im Nachgang zu dieser Niederlage zu ernsthaften politischen Krisen und Machtkämpfen. Die Janitscharen wehrten sich dagegen, dass ihre Macht weiter beschnitten wurde. Die Niederlage vor Wien war aber nicht nur ein militärisches und menschliches Desaster. Sie hatte vielmehr auch schwerwiegende finanzielle Konsequenzen. Kriegsführung war ohnehin teuer. Der Verlust einer ganzen Armee war unter diesen Umständen kaum zu verkraften.

Auch verloren die Osmanen im Nachgang zur Schlacht um Wien weitere Territorien an ihre Widersacher. Diese hatten sich zur Heiligen Allianz zusammengeschlossen, der neben Habsburg, Polen und Venedig auch verschiedene deutsche Fürstentümer angehörten. Die Osmanen verloren 1686 Budapest an die Habsbruger und mussten in

280 Vgl. loc. cit. 188 und $212 \mathrm{f}$. den Jahren danach weitere Niederlagen in Mohács (1687), Slankamen (1691) und Senta (1697) einstecken. Diese Auseinandersetzungen endeten somit mit einer schweren Niederlage der Osmanen, was Mehmed IV. letztlich den Thron kostete. Ausserdem verlor das Osmanische Reich Ungarn, die Peleponnes, Serbien und später auch die Krim. Dieser Konflikt endete mit dem Frieden von Karlowitz (1699). Die Osmanen waren danach zwar nicht in militärische Bedeutungslosigkeit abgesunken. Es hatte sich allerdings gezeigt, dass die Zeit der militärischen Vormachtstellung der Osmanen im Landkrieg vorüber war. Habsburg, Polen und Russland hatten bewiesen, dass sie in der Lage waren, die Osmanen in die Schranken zu weisen. Die Osmanen galten jedoch weiterhin als militärische Grossmacht, mit der nicht zu spassen war.

Da das Osmanische Reich keinen Zugang zu den transozeanischen Handelswegen hatte, wurde es zunehmend von den weiteren Entwicklungen in der damaligen Welt abgeschnitten. Von Bedeutung ist überdies, dass sich der Buchdruck im Osmanischen Reich im Gegensatz zu Europa zu jener Zeit noch nicht hatte durchsetzen können. Der Austausch und Kontakt mit der Aussenwelt hatte unter diesen Voraussetzungen geringeres Gewicht als die inner-osmanischen Dynamiken. Das Osmanische Reich sah sich im Lauf des 17. Jh. jedenfalls mit unterschiedlichen Krisen konfrontiert. ${ }^{281}$ Diese bildeten ideale Voraussetzungen, die das Auftreten von religiösen Bewegungen unterschiedlicher Ausrichtung begünstigten. Derwischorden spielten dabei weiterhin eine wichtige Rolle. Es machten sich aber auch Gruppierungen bemerkbar, die eindeutig heterodoxe Auffassungen vertraten. Dazu zählten die Malāmiyya, die Hurūfiyya oder atheistisch orientierte Strömungen.

Die Kādīzādeliler waren über diese Entwicklungen nicht erbaut und hatten sich um die Mitte des 17. Jh. als Bewegung konstituiert, die zumindest den schlimmsten Auswüchsen Einhalt zu bie-

281 Vgl. loc. cit. $233^{-237}$. 
ten versuchte. Diese Bewegung leitet ihren Namen von Kādīzāde Meḥmed Efendī (gest. 1635) ab, der als Prediger an der Fātiḥ- und der Hagia SophiaMoschee wirkte. In dieses Umfeld gehören auch weitere frühere Prediger wie Üstüvānī Mehmed (gest. 1661) oder Birgevī Meḥmed Efendī (gest. 1573). Sie beriefen sich auf die Lehren Ibn Taymiyyas (gest. 1328), der mystische Praktiken, Wallfahrten zu den Grabstätten heiligmässiger Männer oder das Beten an Gedächtnistagen (z.B. Geburtstag des Propheten) als unerlaubte Neuerungen (bid'a) untersagt hatte. Die Kādīzādililer sprachen sich für eine Wiederherstellung jener Glaubenspraxis aus, die zu Lebzeiten des Propheten Gültigkeit besessen hatte. Sie vertraten rigorose Standpunkte und traten u.a. für ein Verbot von Kaffee und Tee ein. Sie verurteilten überdies all jene Gruppierungen, die sich in ihren Augen nicht an das religiöse Gesetz hielten. Gelegentlich kam es unter ihrer Führung auch zur Stürmung von Derwischkonventen. Davon war auch die an und für sich gemässigte und staatstragende Bruderschaft der Halwatiyya betroffen, pflegten die Angehörigen dieses Ordens bei ihren Zusammenkünften doch auch Rituale mit tanzartigen Elementen.

Allerdings sahen sich die Kādīzādililer wiederholt mit Widerstand aus der breiten Bevölkerung konfrontiert. Die Stimmung im Volk kippte jeweils, wenn die Kādīzādililer für sich höhere Legitimität einforderten als sie dem Staat selbst zukam. Die Grenzen des religiös Erlaubten mussten bei diesen Auseinandersetzungen immer neu ausgehandelt werden. Die Kādizādililer unternahmen zwar mehrfach den Anlauf, die rituellen Tänze $\left(s a m \bar{a}^{c}\right)$ der Mawlawiyya- oder der HalwatiyyaAngehörigen zu unterbinden und den Weingenuss zu verbieten. Es zeigte sich jedoch, dass sowohl die Praxis des $s a m \bar{a}^{c}$ als auch der Weinhandel auf die Dauer überlebten.

Innerhalb des tolerierten Rahmens bewegte sich mit Gewissheit auch der Derwischorden der Ğalwatiyya (Celvetiyye), der im Lauf des 17. Jh. und am Anfang des 18. Jh. an Bedeutung gewann. Der Gründer dieses Ordens, 'Azīz Mạ̣mūd Hü̈dāyī (1541-1628), oder Ismāīil Ḥakkı Brūsevī (1653-1725) vertrat zwar offen pantheistische Auffassungen, die eindeutig heterodox waren. Die wichtigen Celvetiyye-Šayhs hatten allerdings ein enges Netzwerk von Unterstützern aufgebaut und konnten ihre Stellung in der Gesellschaft behaupten. Sie konnten dies auch tun, da sie die breiten Massen ihrer Anhänger zu einer strikten Einhaltung der šarī $a$ anhielten. Nur Mitglieder mit höheren Initiationsgraden hatten Zugang zum Kern der Ordenslehre, die sich mit der allumfassenden Existenz Gottes befasst. ${ }^{282}$

Allgemein lässt sich jedoch aufzeigen, dass es heterodoxe Auffassungen im Osmanischen Reich zunehmend schwer hatten. Dies kommt gerade auch darin zum Ausdruck, dass die einst bedeutende Stellung der Bektāšiyya im Gefolge der Auflösung des Janitscharen-Korps (1826) beschnitten wurde. Ihre Konvente und weiteren Besitzungen gingen an mit den islamischen Dogmen kompatiblere Derwischorden, v.a. die Naqšbandiyya und die Halwatiyya, über. ${ }^{283} 1926$ wurden die Orden in der Türkei sogar gänzlich aufgehoben. Dieses Verbot ist zumindest de iure auch noch heute in Kraft.

\subsection{Iran nach dem Ende der Dynastie der Safawiden (1722)}

Die folgenden Ausführungen werfen nochmals einen Blick auf Iran und machen auf die dortigen Entwicklungen nach dem Ende der Dynastie der Safawiden aufmerksam: ${ }^{284}$

Die Safawiden waren in der weiteren hier interessierenden Region aufgrund ihres Bekenntnisses zur Schia weitgehend isoliert. Alle andern in der Gegend massgeblichen Mächte waren der Sunna verpflichtet. Neben den bereits erwähnten Osmanen und Mogul-Indien ist an dieser Stelle auf die ebenso sunnitischen Usbeken in Zentralasien auf-

\footnotetext{
282 Vgl. loc. cit. $236 \mathrm{f}$.

283 Vgl. z. B. Birge, The Bektashi order 78; Öztürk, The eye of the heart 82.

284 Die weiteren Ausführungen stützen sich auf die sehr knappe Übersicht bei Gronke, Geschichte Irans 68-9o.
} 
merksam zu machen. Die Safawiden führten auch gegen sie mehrfach kriegerische Auseinandersetzungen.

Unter Šāh 'Abbās I. (reg. 1587-1629) erreichte der Staat der Safawiden seine grösste Ausdehnung. ${ }^{285}$ Es gelang 'Abbās I., die meisten unter seinen Vorgängern infolge innerer Auseinandersetzungen verlorenen Gebiete zurückzuerobern. Er drängte die Usbeken in Khorasan zurück und integrierte diese Region in sein Reich (1598-1599). Im Westen verbuchte er Erfolge gegen die Osmanen und nahm ihnen Aserbaidschan (1603-1604) und bedeutende Teile im Iraq mit Bagdad und weiteren Gebieten in Südost-Anatolien ab (1623-1624). Den Mogul-Kaisern wiederum entriss er Kandahar in West-Afghanistan (1622). Nach 'Abbās' Tod allerdings fielen grosse Teile im Westen wieder an die Osmanen zurück. ${ }^{286}$ Bei all diesen Auseinandersetzungen spielten zwar die Gegensätze zwischen Sunna und Schia eine wichtige Rolle. Allerdings verfolgten die involvierten Mächte stets auch ganz handfeste politische und territoriale Ziele.

Auf 'Abbās I. folgten - abgesehen von seinem Namensvetter 'Abbās II. (reg. 1642-1666) - unfähige Herrscher. Der Machtverlust der Safawiden war am Ende des 17. Jh. unübersehbar. Das Reich kämpfte mit wirtschaftlichen Schwierigkeiten und sah sich mit religiös motivierten Unruhen konfrontiert. Diese innere Schwäche der Safawiden ermöglichte es dem afghanischen Stamm der Ġalzay, in Iran einzufallen. ${ }^{287}$ Sie nahmen 1722 auch Isfahan ein und zwangen den letzen Safawiden-Herrscher (Sulțān Ḥusayn, reg. 1694-1722) zum Rücktritt. In Isfahan war es auch zu bedeutenden Brandschatzungen gekommen, bei denen u.a. die aller-

285 Loc. cit. $68 \mathrm{f}$.

286 Der Friede von Qașr-i Šīīn (Zuhāb) legte den Grenzverlauf zwischen den Reichen der Osmanen und Safawiden fest, wie er abgesehen von seinem nördlichen Teil bis heute auch für die jeweiligen Nachfolgestaaten Bestand hat. Mit diesem Vertrag verloren die Safawiden die Kontrolle über Iraq und die dort gelegenen Heiligen Stätten der Schia ('Atabāt-Städte).

287 Vgl. dazu Frye, Ghalzay, in $E I^{2}$. meisten Archivbestände des Safawidenreichs vernichtet wurden.

Nādir Šāh (geb. 1688; reg. 1736-1747) aus dem Turkmenen-Stamm der Afšāren konnte die Invasion der Afghanen in Iran stoppen. ${ }^{288}$ Die Afšāren lebten als Nomaden in Nord-Khorasan und gehörten zu den Qizilbāš. Nādir kann als militärischer Abenteurer betrachtet werden, der eigentlich während seines ganzen Lebens in Kampfhandlungen verstrickt war. Er war zuerst militärischer Befehlshaber im Dienst von Kronprätendenten aus der untergehenden Dynastie der Safawiden. Er liess sich aber 1736 in der Mugāan-Steppe (NW-Iran) selbst zum Šāh krönen und verlegte die Hauptstadt des Reichs darauf von Isfahan nach Mashhad, wo sein Stamm beheimatet war. Er unternahm auch zahllose Eroberungszüge nach Afghanistan und entführte den Pfauenthron und den KohinoorDiamanten (Lichtberg; kūh-i nūr) aus Indien nach Iran (1739). Gegenüber den Osmanen beharrte er auf der Einhaltung des im Vertrag von Qașr-i Šīīn (Zuhāb) festgelegten Grenzverlaufs. Seine unablässigen Kriegszüge waren allerdings mit horrenden Kosten verbunden, was Nādir Šāh den Hass weiter Teile der Bevölkerung eintrug. Nādir Šāh brachte mit seiner Religionspolitik ausserdem die Geistlichkeit gegen sich auf. Er versuchte nämlich, die Zwölferschia als gleichwertige fünfte Rechtsschule neben den vier andern sunnitischen madhab zu etablieren. Zahlreiche Mitglieder des Klerus verliessen darauf das Land und liessen sich in den heiligen Stätten der Schia im Iraq nieder. Angehörige aus den Stämmen der Afšāren und Qāḡāren ermordeten Nādir Šāh im Sommer 1747.

Nord- und Nordost-Iran glitten nach der Ermordung Nādir Šāhs ins Chaos ab, machten sich doch zahlreiche Militärführer Macht und Ländereien streitig. Südiran blieb von diesen Wirren weitgehend verschont. Hier konnte sich die Dynastie der Zand etablieren, unter der Shiraz und die Provinz Fārs eine Zeit von Frieden und Wohlstand erlebten. Diese Dynastie war aus einem im mittleren Zagros beheimateten Nomadenstamm hervorge-

288 Gronke, op. cit. $82 \mathrm{f}$. 
gangen. Ihr bedeutendster Vertreter war Muhammad Karīm Beg. Er übte seine Macht zunächst als Vertreter (wakīl) des Safawiden-Prinzen Ismācīl I I I. aus (regierte nominell von $175^{\circ}-1753$ ). ${ }^{289}$ Karīm Huān hielt Ismāî̀l allerdings eigentlich in ehrenvoller Gefangenschaft und setzte nach dessen Tod (1773) keinen weiteren Schattenkönig ein. Damit erloschen jegliche Hoffnungen auf eine Neuetablierung der Dynastie der Safawiden. Karīm Huān selbst liess sich in Shiraz nieder, wo er am Anfang der 176oer-Jahre seine Hauptstadt einrichtete.

Die Dynastie der Zand war zwar nur von 17511794 an der Macht. Gerade unter Karīm Huān Zand (reg. 1751-1779) selbst herrschte im Reich aber Ruhe. Es kam zu einem wirtschaftlichen Aufschwung. Karīm Huān liess sich nicht auf zwar prestigeträchtige, aber ruinöse Kriegszüge ein. Er versuchte vielmehr, sein durch die vorangehenden Wirren arg in Mitleidenschaft gezogenes Land zu stabilisieren. Er berücksichtigte dabei die schwierige wirtschaftliche Lage seiner Untertanen und erhob nur moderate Steuern. Jedenfalls erlebte Shiraz eine Zeit der Blüte und spielte auch eine wichtige Rolle als Handelsstadt. Karīm Huān errichtete in Shiraz überdies mehrere Bauten, die das Stadtbild bis heute prägen.

Nach Nādir Hāns Tod (1779) konnte sich keiner seiner vier Söhne durchsetzen. Sie sahen sich vielmehr mit den divergierenden Interessen ihrer erweiterten Verwandtschaft konfrontiert. Die meisten männlichen Angehörigen aus dieser Dynastie waren bis 1789 eines natürlichen Tods gestorben, in Kampfhandlungen umgekommen oder hingerichtet worden. Die Dynastie der Zand konnte sich daher nicht länger an der Macht halten. In kurzer Zeit ging das Land an die türkische Dynastie der Qāḡāren über, die danach von 1779-1925 über Iran herrschte. ${ }^{290}$

Unter den Qāğāren sah sich Iran mit grossen Herausforderungen konfrontiert, sprang die Rückständigkeit des Landes als Folge des intensivierten

289 Vgl. Perry, Esmācīl II Șafawī, in EIr.

290 Vgl. dazu Bosworth, New Islamic dynasties 285.
Austauschs mit westlichen Staaten doch auf den ersten Blick ins Auge. Da diese Entwicklungen für die vorliegende Arbeit nur noch bedingt von Interesse sind, werden sie hier nicht eingehender erörtert. ${ }^{291}$ 